University of Louisville

ThinkIR: The University of Louisville's Institutional Repository

\title{
The effect of trust in leader on job satisfaction and intent to leave present job in the context of the nursing profession.
}

\author{
William David Gibson \\ University of Louisville
}

Follow this and additional works at: https://ir.library.louisville.edu/etd

\section{Recommended Citation}

Gibson, William David, "The effect of trust in leader on job satisfaction and intent to leave present job in the context of the nursing profession." (2011). Electronic Theses and Dissertations. Paper 495.

https://doi.org/10.18297/etd/495

This Doctoral Dissertation is brought to you for free and open access by ThinkIR: The University of Louisville's Institutional Repository. It has been accepted for inclusion in Electronic Theses and Dissertations by an authorized administrator of ThinkIR: The University of Louisville's Institutional Repository. This title appears here courtesy of the author, who has retained all other copyrights. For more information, please contact thinkir@louisville.edu. 
THE EFFECT OF TRUST IN LEADER ON JOB SATISFACTION AND INTENT TO LEAVE PRESENT JOB IN THE CONTEXT OF THE NURSING PROFESSION

By

William David Gibson

B.A., University of Louisville, 1993

M.A., Western Kentucky University, 1998

\author{
A Dissertation \\ Submitted to the Faculty of the \\ Graduate School of the University of Louisville \\ In Partial Fulfillment of the Requirements \\ For the Degree of \\ Doctor of Philosophy \\ College of Education and Human Development \\ University of Louisville \\ Louisville, $\mathrm{KY}$
}

May 2011 

THE EFFECT OF TRUST IN LEADER ON JOB SATISFACTION AND INTENT TO LEAVE PRESENT JOB IN THE CONTEXT OF THE NURSING PROFESSION

$$
\text { By }
$$

William David Gibson

B.A., University of Louisville, 1993

M.A., Western Kentucky University, 1998

A Dissertation Approved on

March 23, 2011

By the following Dissertation Committee:

Joseph Petrosko

Dissertation Director

Rod Githens

Pat Leitsch

Thomas Reio 


\section{DEDICATION}

This dissertation is dedicated to my wife Amy for all the support and encouragement she gave to make this achievement possible. I would also like to dedicate this to my son, Augustus, who gave me the most important reason for finishing this endeavor. And I would finally like to dedicate this to my mother, sister, and late father who helped to establish the foundation by which I was able to complete this work. 


\section{ACKNOWLEDGEMENTS}

I would like to thank my dissertation committee, Dr. Joseph Petrosko, Dr. Thomas Reio, Dr. Patricia Leitsch, and Dr. Rod Githens. I had no experience with any of the committee before the dissertation process, but each individual was willing to guide me through it. I am most appreciative, especially Dr. Reio that began the process of being my dissertation chair and to my current dissertation chair, Dr. Petrosko who guided me to finish.

I would also like to thank Dr. Timothy Hatcher, Dr. Mike Boyle, and Dr. Randy Capps for their guidance throughout my graduate school experience. Thanks to Ellen Wathan, Linda Cason, Melody Littrell, Kathy Neuner, Veronica Croner, and Bonnie Braden for their help in the data collection process. 


\begin{abstract}
THE EFFECT OF TRUST IN LEADER ON JOB SATISFACTION AND INTENT TO LEAVE PRESENT JOB IN THE CONTEXT OF THE NURSING PROFESSION

\author{
William David Gibson
}

March 23, 2011

Three research questions made up the focus of the study. First, after controlling for demographic variables of age, gender, and tenure in organization, to what extent does trust in leader (nurse manager) relate to job satisfaction? Second, after controlling for demographic variables of age, gender, and tenure in organization, to what extent does trust in leader (nurse manager) and job satisfaction relate to intent to leave present job? Finally, are the effects of trust in leader (nurse manager) on intent to leave present job all direct effects, or are some or all of the effects indirect through the variable of job satisfaction?

For research question 1, results indicated, for the most part, that there was a significant positive association between trust in leader and job satisfaction controlling for demographic variables. The results suggest that the perception of trust in one's immediate leader does influence job satisfaction and vice versa. The results for the second research question suggest that after controlling for the demographic variables of age, gender, and years in organization, trust in leader and job satisfaction both influence intent to leave present job. 
The final research question addressed whether job satisfaction mediated the influence of trust in leader on intent to leave present job, or if the influence of trust in leader was a direct effect. Analysis demonstrated, for the most part, that trust in leader had a direct effect on intent to leave present job, but also an indirect effect through the mediation of job satisfaction. When controlling for job satisfaction, trust in leader had a significant direct effect on intent to leave present job. When controlling for trust in leader, job satisfaction had a significant direct effect on intent to leave present job. When controlling for each other, trust in leader came out as a stronger predictor variable than job satisfaction on intent to leave present job. When controlling for the three demographic variables, the relationships between the three key variables were similar as well.

The most interesting and significant finding of this research concerned the findings related to the third research question. Those findings suggested that trust in leader may influence intent to leave present job more than job satisfaction. While there was a mediating effect on trust in nurse manager and intent to leave present job via job satisfaction, there was an even stronger direct effect of trust in nurse manager on intent to leave present job while controlling for job satisfaction.

This research reinforces findings from previous research that job satisfaction influences intent to leave present job. However, this research introduces trust in leader as an important variable to study with regard to intent to leave and turnover literature. The implications for Human Resource Development could be profound. Hiring, training, performance evaluation and leadership development should include trust in leader as an important measure and outcome for its practice. 


\section{TABLE OF CONTENTS}

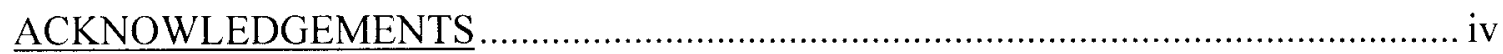

ABSTRACT

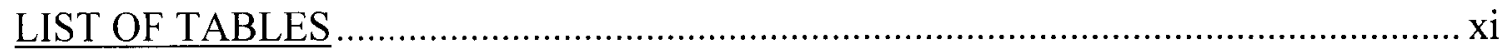

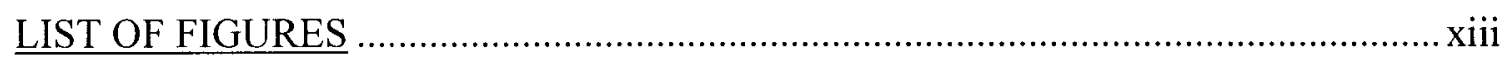

INTRODUCTION

Historical Review of Job Satisfaction and Intent to Leave Research ............................ 2

Measuring Job Satisfaction with the Job in General Scale (JIG) ................................... 3

Demographic Variables Used in the Turnover Research .............................................. 4

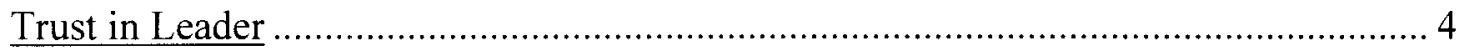

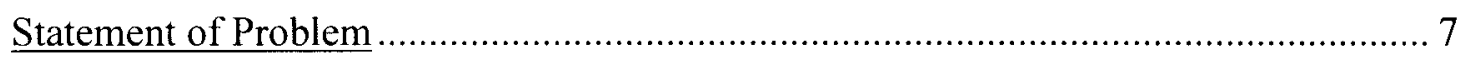

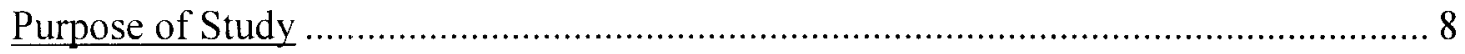

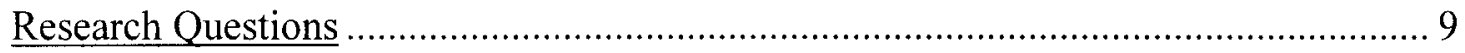

How Analyses Address the Purpose of the Study ………....................................... 9

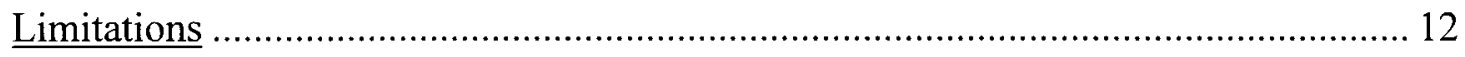

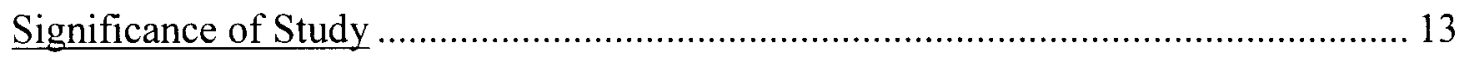

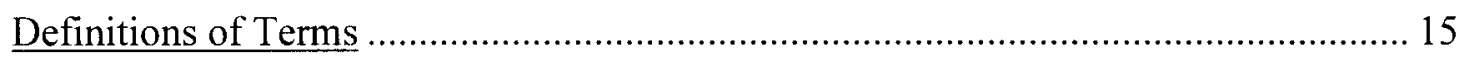

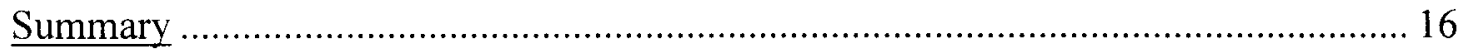

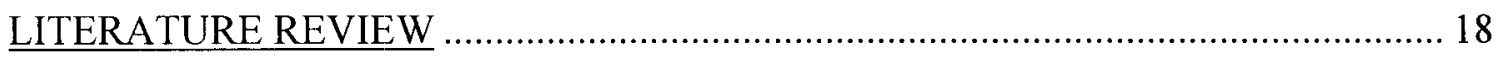

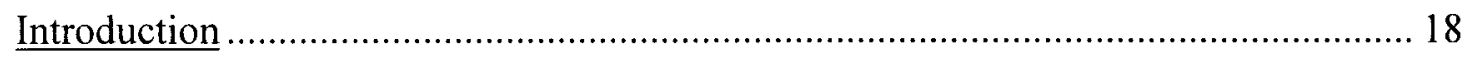

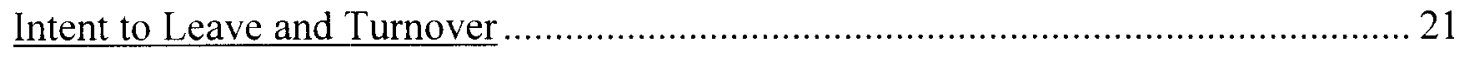




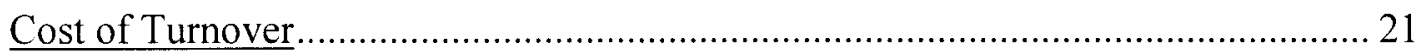

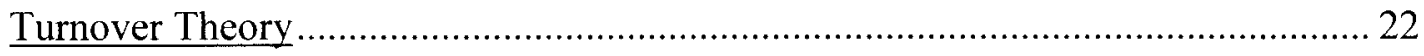

Research on Intent to Leave ………………....................................................... 25

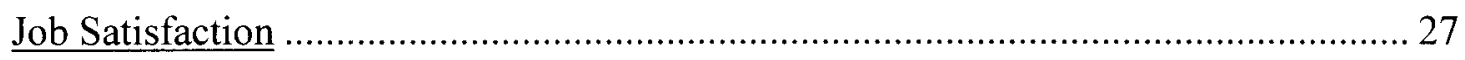

Job Satisfaction Theory ……………………………….................................... 27

Micro and Macro Levels of Job Satisfaction .......................................................... 29

Demographic Variables in Job Satisfaction Research .............................................. 31

Intent to Leave and Job Satisfaction Combined ............................................................. 31

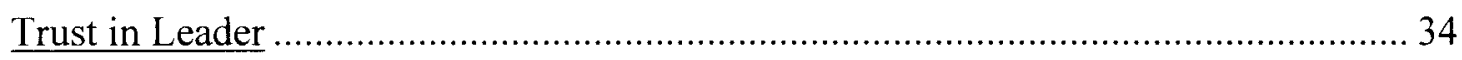

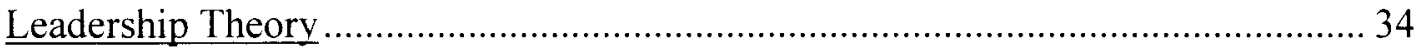

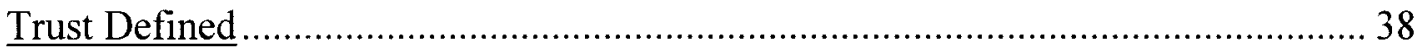

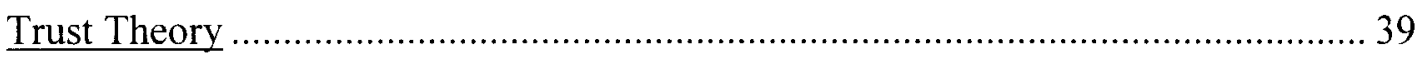

Antecedents of Trust in Leader/Organization .......................................................... 42

Trust in Leader/Organization as Criterion or Mediating Variable ............................. 47

Theory and Research Based on Mayer, Davis, and Schoorman Model (1995)......... 52

Trust in Leader/Organization, Job Satisfaction, Intent to Leave/Turnover.................... 54

Trust in Leader/Organization, Job Satisfaction, Intent to Leave/Turnover in Context of

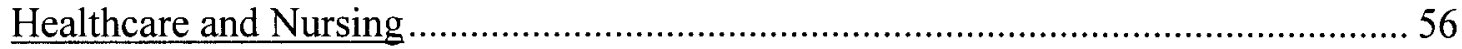

Intent to Leave/Turnover and

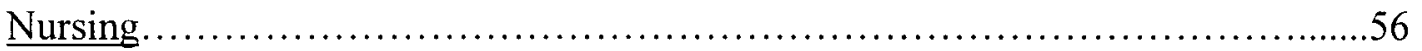

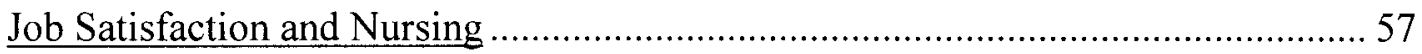

Job Satisfaction and Intent to Leave/Turnover Combined in Nursing ...................... 58

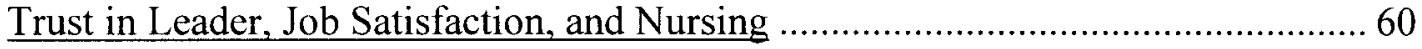

Trust in Leader, Job Satisfaction, Intent to Leave and Nursing ................................6 60

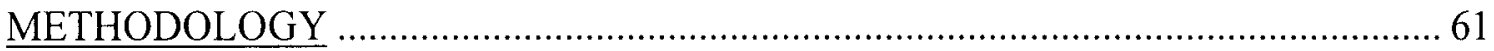

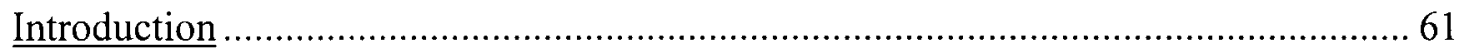

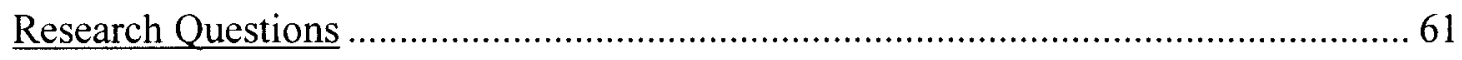

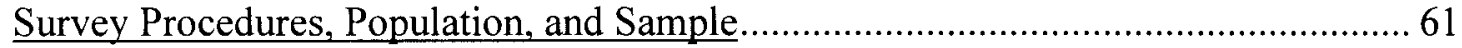

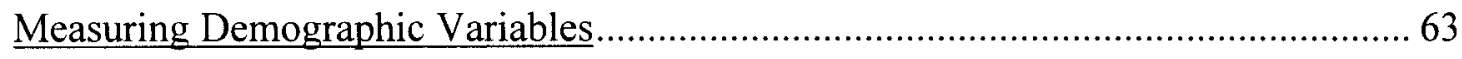

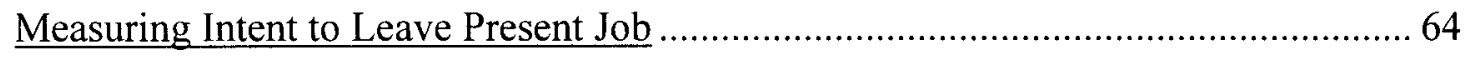




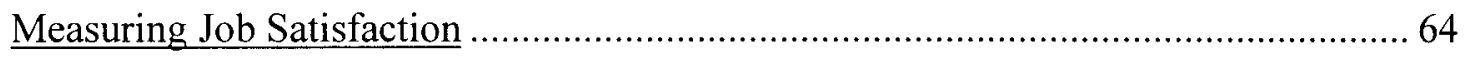

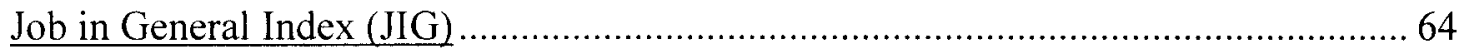

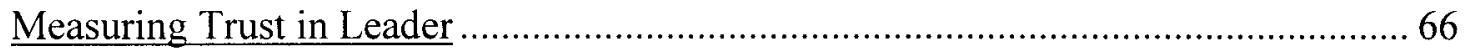

Procedure

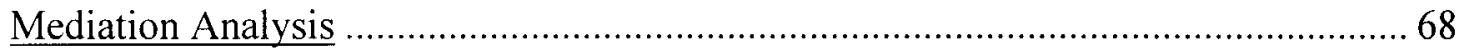

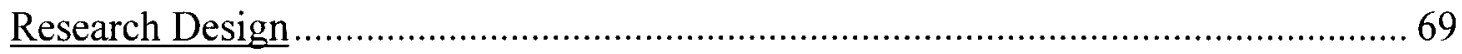

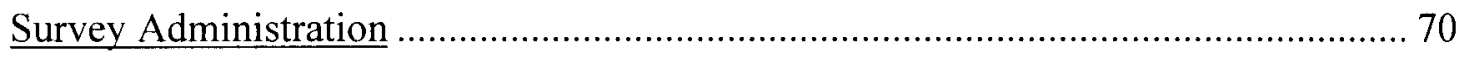

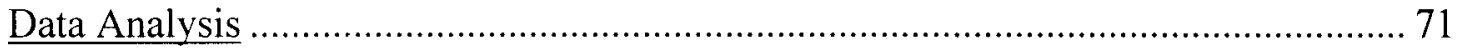

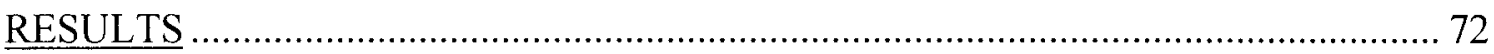

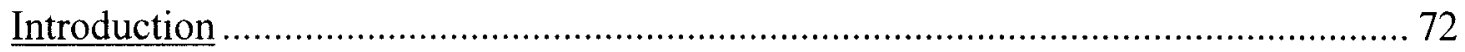

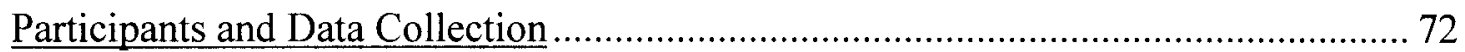

Descriptive Statistics on Demographic Variables and Scale Variables ....................... 73

Statistical Comparisons of Hospital 1 and 2 ........................................................ 79

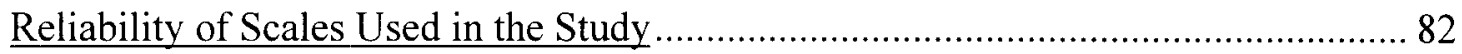

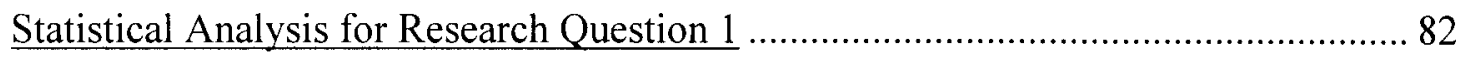

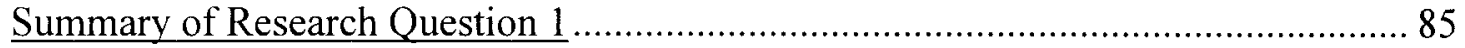

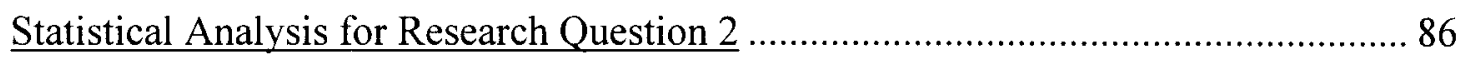

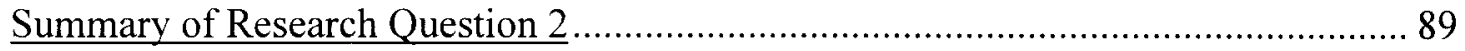

Statistical Analysis for Research Question 3 ……….............................................. 92

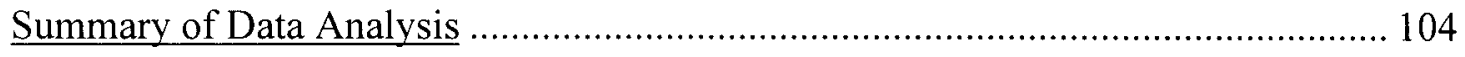

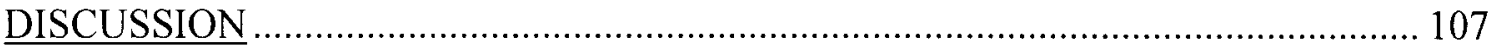

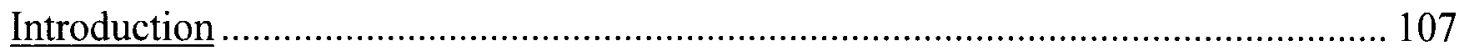

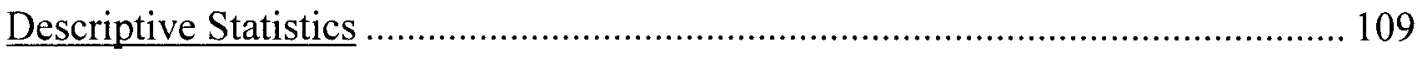

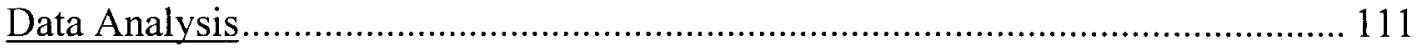

How the Study Relates to Past Research.................................................................. 116

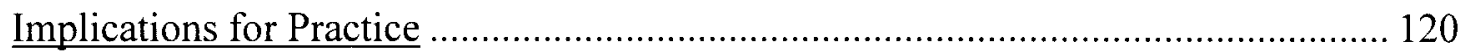

Limitations and Future Research........................................................................ 121

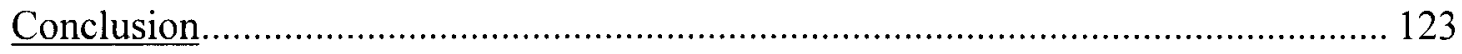

REFERENCES 


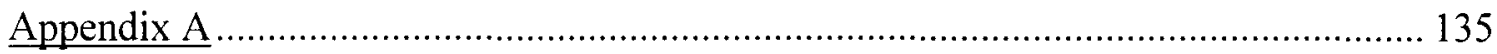

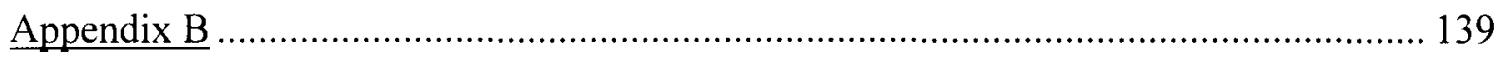

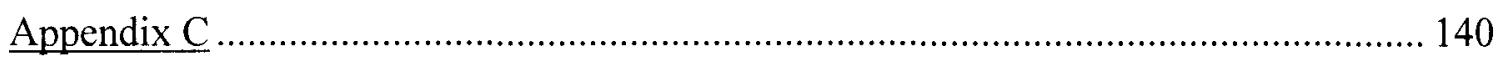

Appendix D

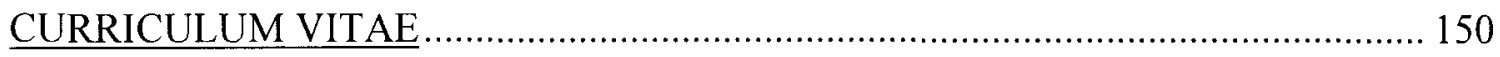




\section{LIST OF TABLES}

TABLE

PAGE

1. Original Research Questions, Modified Research Questions, and Analyses for Modified Research Questions.

2. Summary of Key Concepts from Literature Review.

3. Variables Used in this Study for Meditational Analysis. .68

4. Source of Regression Coefficients for Mediation Analysis.

5. Numbers and Percentages of Nurses for Age, Decade Degree was Earned, and

Gender.

6. Numbers and Percentages of Nurses for Ethnic Group and Educational Level

(Degree)

7. Numbers and Percentages of Nurses for Years Employed in Current Organization and Years Employed in Current

Position.

8. Numbers and Percentages of Nurses for Years of Experience with Current Nurse

Manager.

9. Descriptive Statistics for Trust in Manager, Job Satisfaction, and Intent to Leave

Present Job by

Hospital.

10. Comparisons of Hospitals on Four Time-Related Variables Using Independent ttests 
11. Comparisons of Hospitals on Three Demographic Variables Using Chi-Square Tests

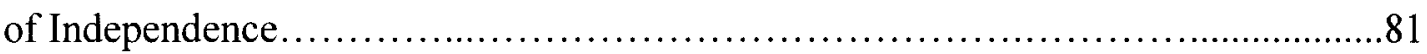

12. Cronbach's Alpha Internal Consistency Reliability Coefficients for Scales Used in the Study. .82

13. Regression Coefficients for Demographic Variables and Trust in Nurse Manager Predicting Job Satisfaction: All Cases $(n=297)$

14. Regression Coefficients for Demographic Variables and Trust in Nurse Manager Predicting Job Satisfaction: Hospital $1(\mathrm{n}=210)$ and Hospital $2(\mathrm{n}=87) \ldots \ldots \ldots \ldots . .86$

15. Regression Coefficients for Demographic Variables, Trust in Nurse Manager, and Job Satisfaction Predicting Intent to Leave Present Job : All Cases $(n=289) \ldots \ldots \ldots . . .88$

16. Regression Coefficients for Demographic Variables, Trust in Nurse Manager, and Job Satisfaction Predicting Intent to Leave Present Job: Hospital $1(n=210)$ and Hospital $2(n=87)$

17. Regression Summaries for Mediation Analysis: All Cases $(n=302) \ldots \ldots \ldots \ldots \ldots \ldots . .93$

18. Regression Coefficients (Beta) Used to Test Mediation: All Cases $(n=302) \ldots \ldots . .94$

19. Regression Summaries for Mediation Analysis: Hospital $1(n=213) \ldots \ldots \ldots \ldots \ldots 96$

20. Regression Coefficients (Beta) Used to Test Mediation: Hospital $1(n=213) \ldots \ldots . .97$

21. Regression Summaries for Mediation Analysis: Hospital $2(n=89) \ldots \ldots \ldots \ldots \ldots \ldots . . .99$

22. Regression Coefficients (Beta) Used to Test Mediation: Hospital $2(n=89) \ldots \ldots \ldots . .100$

23. Summary of Major Findings for Each Research Question........................106 


\section{LIST OF FIGURES}

FIGURE

PAGE

1.Conceptual Model of Trust in Leader's Effect on Job Satisfaction and Intent to Leave

Present Job Independent of Demographic Variables....................................9

2. Mediation Model for Intent to Leave Predicted by Trust in Nurse Manager and Job

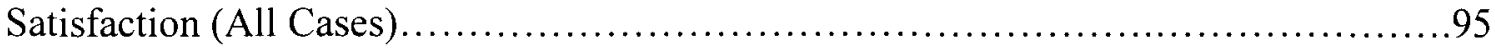

4. Mediation Model for Intent to Leave Predicted by Trust in Nurse Manager and Job

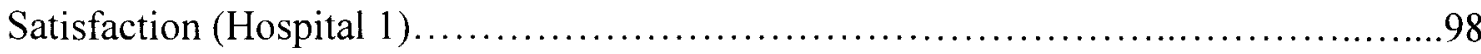

5. Mediation Model for Intent to Leave Predicted by Trust in Nurse Manager and Job

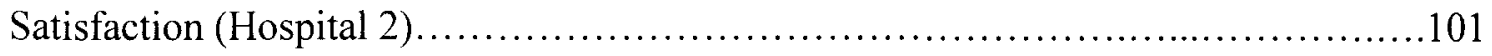

6. Mediation Model for Intent to Leave Predicted by Trust in Nurse Manager and Job Satisfaction: All Cases with Age, Gender, and Years in Current Organization Controlled for Each Regression............................................................. 


\section{CHAPTER I}

\section{INTRODUCTION}

Employee turnover is a major concern for researchers, human resource development (HRD) professionals, and organizational leaders alike. Employee turnover accounts for a significant loss of revenue both directly and indirectly. According to Amig and Amig (2001), the average cost of employee turnover is 25 percent of an employee's annual salary, and high turnover rates adversely affect organizations through additional training costs, lower productivity, loss of organizational memory, deterioration of company image, and poor morale.

One industry where the adverse effects of employee turnover are most pronounced is healthcare, and it is specifically the case with the nursing profession. Waldman and Sanjear (2004) described healthcare as an industry in which skilled professionals were in short supply, and retaining this workforce would be critical to sound clinical and financial outcomes. In fact Waldman and Sanjear found that between 1997 and 2001 average annual nurse turnover across one healthcare network was 17 percent. That percentage increased to 59 percent for newly hired nurses. Waldman, Kelly, Sanjear, and Smith (2004) found that annual turnover costs represented 3.4 - 5.8 percent of the annual operating budget of a medical center under study, and the largest cost was due to the loss and necessary replacement of nurses. 
Healthcare organizations are struggling to find a solution to this problem.

According to the Bureau of Labor Statistics (2006), hospitals offer signing bonuses, family friendly work schedules, and subsidized training to offset the shortage, and still the projected number nursing vacancies by 2020 will be 400,000 . The shortage comes from a variety of sources. Large numbers of veteran nurses will retire in the next decade. The number of new nurses graduating is not keeping up with demand, because there are not enough seats available in the universities and community colleges across the country. There are not enough graduate level instructors available to teach the next generation of nurses (Bureau of Labor Statistics, 2006). But even in the face of these challenges, nurses, veteran and novice, are leaving the hospitals they work for and leaving the profession all together. In fact between 1996 and 2000 nearly 175,000 nurses left the profession with even more ready to leave (HRSA, 2002). The reasons for this are even more plentiful.

The literature indicated that employees leave organizations for a variety of reason. However, two of the most cited reasons were job satisfaction (Mobley, 1977; Breukelen, Van Der List, \& Steensma, 2004) and intent to leave present job (Mobley, 1977).

Researchers focused in the healthcare industry have found job satisfaction and intent to leave present job as a causal link to employee turnover as well (Price \& Mueller, 1981). Historical Review of Job Satisfaction and Intent to Leave Research

Job satisfaction and intent to leave present job are two of the most frequently nominated antecedents of voluntary turnover (Tett \& Meyer, 1993). Both variables play an important role in the model of voluntary turnover outlined by Mobley, Griffeth, Hand, and Meglino (1979). In essence Mobley et al. posits that the process of turnover begins 
with the effects of individual characteristics (education and demographics), and work environment (status and tenure) have on an individual's affective responses to the job (job satisfaction and organizational commitment). In turn, these affective responses initiate withdrawal cognitions (intent to leave present job and intent to search). Ultimately intent to leave present job leads to actual voluntary turnover behavior. Mobley et al's. model received a great deal of empirical support over the years to reinforce this notion (Cotton \& Tuttle, 1986; Tett \& Meyer, 1993).

The role of job satisfaction and its role in turnover behavior have been thoroughly researched, and generally demonstrated a moderate negative relationship with turnover (Mobley, 1982; Hom \& Griffith, 1991; Tett \& Meyer, 1993; George \& Jones, 1996; Cunningham \& Saga, 2004). Intent to leave present job tends to demonstrate turnover behavior (Mobley, 1977; Steers \& Mowday, 1981; Carsten \& Spector, 1987; Hom \& Griffith, 1995). Since two of the most prevalent antecedents of actual turnover behavior are job satisfaction and intent to leave present job, it made sense to conduct research that examined other variables and their effects on the antecedents of turnover behavior to acquire a richer understanding. Measuring Job Satisfaction with the Job in General Scale (JIG)

When investigating employee job satisfaction, researchers have explored various relationships at both the individual and global levels of satisfaction. The individual level refers to the individual characteristics of the job such as satisfaction with work, pay, or opportunities for promotion. The global level of job satisfaction refers to how one feels about the job overall Results have been contradictory when reviewing correlations between individual job characteristics and overall job satisfaction. 
In 1989 Ironson, Smith, Brannick, Gibson, and Paul developed the Job in General scale to be utilized in conjunction with the Job Descriptive Index (Smith, Kendall, \& Hulin, 1969). According to the creators of the JIG, a number of differences between individual facets of job satisfaction and global job satisfaction contributed to the need for an additional measurement tool. For instance, factors exist that impact satisfaction with the job that are not covered by the Job Descriptive Index (e.g., employee benefits or the availability of training). Additionally, time plays an important role, whether long-term job considerations or short-term daily activities (Balzer, Kihm, Smith, Irwin, Bachiochi, Robie, Sinar, \& Parra, 1997). Consequently, the Job in General scale measures the macro-satisfaction with the job. This scale demonstrated both construct and convergent validity and consistently correlates with other global measures of satisfaction. Demographic Variables Used in Turnover Research

Age, gender, and years in organization have always been individual characteristic variables used to examine turnover. These demographic variables are consistently found in the turnover literature demonstrating a negative effect on turnover behavior (Mobley et al, 1979; Mobley, 1982; Cotton \& Tuttle, 1986). Age, gender, and tenure in organization have been acknowledged to affect job satisfaction as well (Mobley et al., 1979, Williams $\&$ Hazer, 1986). That is the younger the individual and the shorter the tenure inside an organization the more intent to leave and less the level of job satisfaction. Gender has been generally mixed. With that in mind age, gender, and years in organization were included in this study of job satisfaction and intent to leave present job. Trust in Leader 
A great place to work is one where employees trust the people they work for, have pride in what they do, and enjoy the people the work with (Levering, 1993).

Organizations that pay attention to developing trusting relationships tend to be more successful. The 100 best companies to work for, according to Forbes, had an annualized return of 62 percent higher than the stock index (Levering, 1996). Levering also found these companies had better quality products, greater ability to attract and retain highly qualified employees, were more innovative, exhibited higher levels of cooperation among coworkers and management, had lower healthcare costs, possessed less resistance to change, and had lower turnover. "When an organization must change, trust between management and employees will be the currency that pays for the change" (Levering, 1996, p .35).

Scholars have backed up these types of claims through research on trust in leader. Trust in leader is an important construct in a variety of business situations. Several instances of research demonstrate trust's significant effect on organizational commitment and support of leader (Muchinsky, 1977; Brockner, Siegal, Daly, Tyler, \& Martin, 1997; Dirks \& Ferrin, 2002). Trust has also been demonstrated to significantly affect power and influence (Frost \& Moussavi, 1992), increased productivity ( Spreitzer \& Mishra, 1999), increased employee morale (Spreitzer \& Mishra, 1999), more innovation (Spreitzer \& Mishra, 1999), team performance (Dirks, 2000), organizational performance (Jung \& Avolio, 2000), empowerment (Gomez \& Rosen, 2001), justice (Ayree, Budwhar, \& Chen, 2002), organizational citizenship behaviors (Ayree, Budwhar, \& Chen, 2002), and dysfunctional employee behavior (Choi, Dixon, \& Jing, 2005) 
Trust in leader has also shown to be positively related to the intent to leave (Dirks \& Ferrin, 2002) and job satisfaction (Butler, Cantrell \& Flick, 1999; Dirks \& Ferrin, 2002). Davis, Schoorman, Mayer, and Tan (2000) also found a relationship between trust in leader and the level of employee turnover in a restaurant chain. Finally, Spence-Laschinger, Finegan, and Shamian (2001) found that organizational trust mediated the effect of nurse empowerment on nurse job satisfaction and nurse intent to leave.

Before going on, there are significant differences between this research and that of Spence-Laschinger et al. (2001). The difference between this study and the study conducted by Spence-Laschinger is two-fold. First, Spence-Laschinger studied organizational trust and employed the operational definition of trust as the belief that an employer will be straightforward and follow- through on commitments (Gilbert \& Tang, 1998). This study examined trust in leader, and specifically the nurse manager. The operational definition of trust employed in this study comes from the work of Mayer, Davis, and Schoorman (1995), which defines trust as the willingness to be vulnerable to another party when that party cannot be controlled or monitored.

The second difference between this study and that of Spence-Laschinger et al. rests in the fact that Spence-Laschinger uses organizational trust as a mediating variable of empowerment on job satisfaction and intent to leave. This study assessed whether trust in leader had a direct effect on job satisfaction as well as intent to leave present job independent of each other. This research also tested for a mediating effect of job satisfaction on trust in leader and intent to leave present job. 
Mayer et al. (1995) provided the foundation for the examination of trust in this study. Mayer et al. outlined what has become one of the foremost scholarly works on trust in organizations and leaders of those organizations. According the Mayer et al., extending trust to another individual involves (1) the willingness to accept risk that is meaningful to the individual extending trust to the other, and (2) awareness that risk exists in the trust being extended. Thus the researchers define trust as "the willingness of a party to be vulnerable to the actions of another party based upon the expectation that the other will perform a particular action important to the trustor, irrespective of the ability to monitor or control that other party" (p. 712).

Mayer et al. go on to outline what leaders must do in order to develop and maintain trust from followers. Development and maintenance of trust requires that a leader demonstrate high levels of proficiency in the constructs of ability, benevolence, and integrity. Mayer et al. also outlined another construct referred to as propensity to trust. According to the researchers, propensity to trust is the generalized expectation of the trustworthiness of another. The level of propensity to trust is different for everyone, but is a stable within-party factor that will influence the likelihood that a person will trust. While this represents the overall theory outlined by Meyer et al., this study only captured trust in leader overall and its relationship with job satisfaction and intent to leave present job.

\section{Statement of the Problem}

There was a great deal of research on employee turnover as well as trust in leader. Two of the most prevalent antecedents to voluntary employee turnover are job satisfaction indirectly and intent to leave job directly (Mobley, 1979; Mowday, Koberg, 
\& McArthur, 1984; Breukelen, Van Der List, \&Steensma, 2004). Mayer, Davis, and Schoorman's model of trust in leader (1995) is fast becoming one of the more established models of trust. However no one has examined the effect of trust in leader as explained by Meyer et al. on job satisfaction and intent to leave present job. This study filled that gap in the research.

This research was also pertinent for two other reasons. First, voluntary employee turnover presents one of the key business outcomes that HRD professionals can truly influence. Depending on the results of the study and subsequent others like it, HRD may have a new emphasis point in the fight against turnover. From this learning, HRD professionals can help business leaders at all levels develop skills necessary to build and maintain trust in their subordinates. In return for that trust, job satisfaction may increase and intent to leave (and turnover) may decrease. Ultimately, HRD professionals focused on creating interventions around increasing trustworthiness in various levels of management throughout respective organizations could see a potential decrease in turnover.

The final problem that this research addressed is the nursing shortage. Understanding why nurses leave the organizations they work for is just one of the issues facing healthcare leaders today, but it is an important one. Anything that might help the leadership in hospitals, nursing homes, and doctor's offices understand the causes of nurse turnover may assist leadership better concentrate efforts and find solutions. Purpose of the Study

The primary purpose of this study was to investigate the relationship of trust in leader on job satisfaction as well as intent to leave present job. This study accomplished 
this by exploring how trust in leader relates to job satisfaction and intent to leave present $j o b$ in the context of the nursing profession. Specifically, nurses represented the respondents of the study. Those nurses' nurse manager represented the leader to be tested in reference to trust in leader. Trust in leader may also be referred to as trust in nurse manager, since respondents answered the survey with the language of "nurse manger" as opposed to "leader." Figure 1 demonstrates the model employed in this study. The model demonstrated below depicts a hypothesized relationship of trust in leader on job satisfaction as well as intent to leave present job independent of the demographic variables of age, gender, and years in organization.

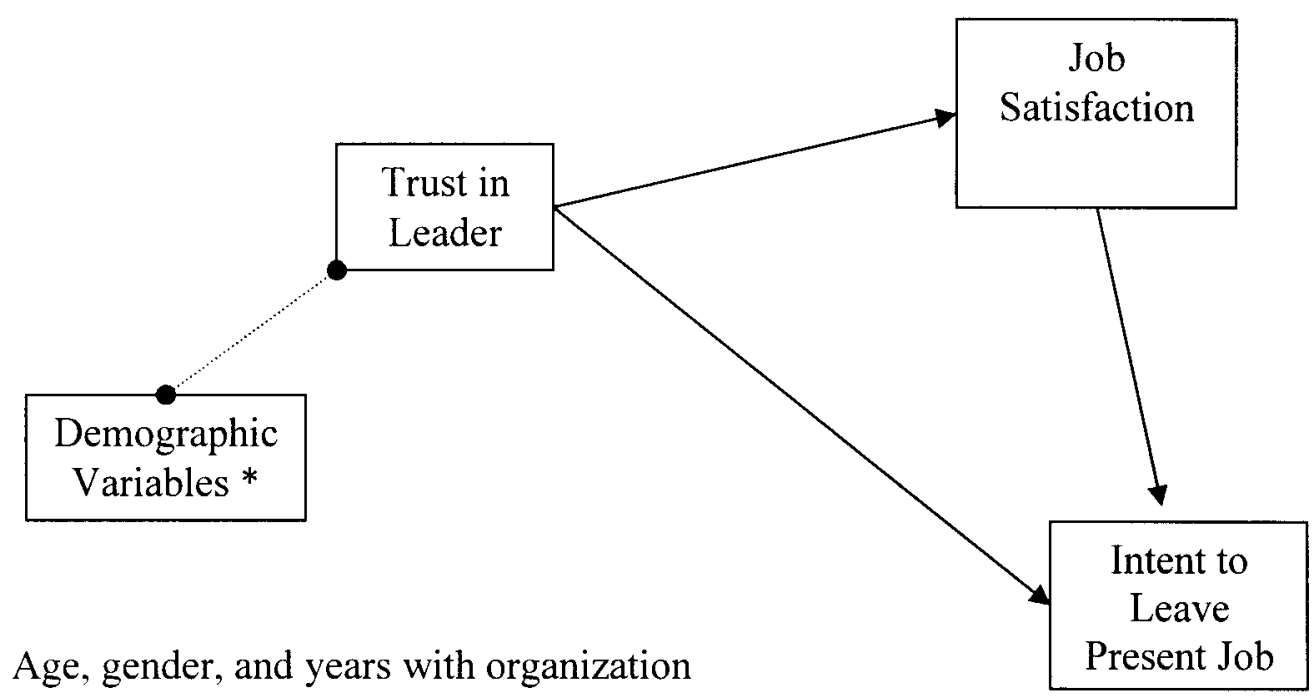

Figure 1: Conceptual Model of Trust in Leader's Effect on Job Satisfaction and Intent to Leave Present Job Independent of the Demographic Variables.

Research Questions

As mentioned previously, the purpose of this study was to examine the relationship of trust in leader on job satisfaction and intent to leave present job among nurses. Conducting the research in a time of a national nursing shortage provided an 
opportunity to make a significant industry impact. The research questions that were formulated to examine these relationships at the time of proposal changed prior to analysis.

How Analyses Address the Purpose of the Study

The analyses to be reported addressed modified research questions that were formulated for the study. It was decided that modified research questions were needed to better address the general purpose of the dissertation, which was to gain an understanding of how trust in leader, job satisfaction, and intent to leave the job were related to one another. Table 1 provides a comparison of the original research questions, the modified research questions, and the analyses performed to address the new questions. The analyses that were performed involved no loss of information, since they provide data on all possible relationships among the three key variables of the study. 
Table 1

Original Research Questions, Modified Research Questions,

and Analyses for Modified Research Questions

\begin{tabular}{|c|c|c|}
\hline $\begin{array}{c}\text { Original Research } \\
\text { Question }\end{array}$ & $\begin{array}{l}\text { Modified Research } \\
\text { Question }\end{array}$ & $\begin{array}{l}\text { Analysis for Modified } \\
\text { Research Question }\end{array}$ \\
\hline $\begin{array}{l}\text { 1. To what extent does } \\
\text { trust in leader relate to } \\
\text { job satisfaction and } \\
\text { intent to leave present } \\
\text { job? }\end{array}$ & $\begin{array}{l}\text { 1. After controlling for the } \\
\text { demographic variables } \\
\text { of age, gender, and } \\
\text { years in the } \\
\text { organization, to what } \\
\text { extent does trust in } \\
\text { leader relate to job } \\
\text { satisfaction? }\end{array}$ & $\begin{array}{l}\text { Hierarchical regression } \\
\text { predicting job } \\
\text { satisfaction. } \\
\text { Step 1: } 3 \text { demographic } \\
\text { variables. } \\
\text { Step 2: trust in leader }\end{array}$ \\
\hline $\begin{array}{l}\text { 2. After controlling for the } \\
\text { demographic variables } \\
\text { of age, gender, and } \\
\text { years in the } \\
\text { organization, to what } \\
\text { extent does trust in } \\
\text { leader relate to job } \\
\text { satisfaction and intent } \\
\text { to leave present job? }\end{array}$ & $\begin{array}{l}\text { 2. After controlling for the } \\
\text { demographic variables } \\
\text { of age, gender, and } \\
\text { years in the } \\
\text { organization, to what } \\
\text { extent does trust in } \\
\text { leader and job } \\
\text { satisfaction relate to } \\
\text { intent to leave present } \\
\text { job? }\end{array}$ & $\begin{array}{l}\text { Hierarchical regression } \\
\text { predicting intent to leave } \\
\text { present job. } \\
\text { Step 1: } 3 \text { demographic } \\
\text { variables. } \\
\text { Step 2: trust in leader } \\
\text { Step 3. job satisfaction }\end{array}$ \\
\hline $\begin{array}{l}\text { 3. Are the effects of trust } \\
\text { in leader on intent to } \\
\text { leave present job all } \\
\text { direct effects, or are } \\
\text { some or all of the } \\
\text { effects indirect, through } \\
\text { the variable job } \\
\text { satisfaction? }\end{array}$ & $\begin{array}{l}\text { 3. Are the effects of trust } \\
\text { in leader on intent to } \\
\text { leave present job all } \\
\text { direct effects, or are } \\
\text { some or all of the } \\
\text { effects indirect, through } \\
\text { the variable job } \\
\text { satisfaction? }\end{array}$ & $\begin{array}{l}\text { Two regression } \\
\text { analyses. } \\
\text { Regression } 1 \\
\text { Trust in leader } \\
\text { predicting job } \\
\text { satisfaction. } \\
\text { Regression } 2 \\
\text { Variables predicting } \\
\text { intent to leave present } \\
\text { job. } \\
\text { Step 1: trust in leader } \\
\text { Step 2. job satisfaction }\end{array}$ \\
\hline
\end{tabular}




\section{Limitations}

One limitation of the current study concerns ignoring the variables that affect trust in leader according to Mayer et al. (1995): propensity to trust and the antecedent to trust: ability, benevolence, and integrity. Mayer et al. theorized that one's propensity to trust in another affected the level of trust in the other. Future research should include propensity to trust. Specifically research could test whether one's propensity to trust his/her leader, team members or others in general affects intent to leave present job and job satisfaction.

Also each antecedent to trust in leader may have or may not have a more pronounced effect on job satisfaction or intent to leave present job. There could also be an interaction effect between the three antecedents to trust that strengthen the overall relationship of each on job satisfaction and intent to leave present job. Future research should include the antecedents to trust in leader as outlined by Mayer et al. (1995) when studying job satisfaction and intent to leave present job.

The lack of attention on the senior team of leadership is a concern for this study as well. Respondents (nurses) were asked to assess the nurse manager whom he/she immediately reports to. This would be a fuller study if senior leadership were researched in conjunction with immediate leadership, giving both a measurement of trust in leader and in organization. Thus trust in overall management may have some effect on job satisfaction and intent to leave present job that this study failed to address.

This study does not address actual voluntary employee turnover among the nursing population. Employee turnover data is often closely guarded by organizations, but a study employing actual turnover data in relation to trust in leader in the context of the nursing shortage would be very beneficial. There was only one example of research 
addressing trust in leader and actual voluntary employee turnover (Davis, Schoorman, Mayer, \& Tan, 2000). That research was conducted in the restaurant industry and the time span was extended later in the study to get at a significant result. Future research that replicates the spirit of Davis et al.'s study, especially in high turnover industries, would be vital to the field of HRD.

Finally, this study did not employ the individual facets of job satisfaction as outlined by Smith, Kendell, and Hulin (1969) that the JIG is actually an extension. While some research seems to include both instruments in the measure of job satisfaction, the research deemed that it was important to ascertain a global job satisfaction score to determine if a direct effect existed as a result of trust in leader. The decision to employ a global job satisfaction score also made it easier to determine if a mediating effect existed between trust in leader and job satisfaction on intent to leave present job. Incorporating the Job Descriptive Index could help us to better determine which facets of job satisfaction that may or may not be affected by trust in leader, which would give the research a deeper understanding of trust in leader's effects.

Significance of Study

The significance of a study that tests the effect of trust in leader on job satisfaction and intent to leave present job in the context of the nursing profession could have profound effects. First if this research indicated that trust in leader had a positive effect on job satisfaction and intent to leave present job, it could have great practical application. This study could lend evidence to the need to hire, promote and develop people with the potential to build and maintain trust with their staffs. With regards to the hiring, human resource professionals could build assessment tools and set up 
interviewing procedures to seek out this potential. Hospital administration could make the level of trust a team has in its leader a part of the performance appraisal system, and actually begin to hold leaders accountable for the development and maintenance of trust. Training, coaching, and mentoring activities could include material on how to build trust and maintain it among subordinate groups.

This study could also be of great importance in the research community. This study was an extension of the work first published by Mayer et al. (1995), and that has subsequently been tested in a variety of venues and tested against a variety of performance variables (Mayer \& Davis, 1999; Davis et al., 2000; Tan \& Tan, 2000; Serva, Fuller, \& Mayer, 2005). However this research went beyond what has already been accomplished, because little empirical evidence existed that demonstrates that trust in leader affects job satisfaction and intent to leave present job in the context of the nursing profession. Thus, this research filled a gap in the literature that has been touched upon by others (Spence-Laschinger, Finegan, \& Shamian, 2001), but in a different way. Spence-Laschinger et al. examined organizational trust as mediating variable along with job satisfaction on intent to leave. This research focused on trust in immediate leader (nurse manager), and test its direct effect on job satisfaction as well as on intent to leave present job.

This study was also significant because of its societal implications. The nursing shortage presents one of the United States more pressing issues. Trust is considered a foundational component of good management and leadership (Bass, 1985; Bennis \& Nanus, 1985; Covey, 1990; Kouzes \& Posner, 2003). Through the understanding trust as well as the development of nurse managers who know how to develop and maintain trust 
among their staffs, this study could help to alleviate the nursing shortage through better management of healthcare organizations' retention strategies.

Finally this study examined the effect of trust in leader, specifically the nurse manager, job satisfaction and intent to leave present job in a hospital setting. Although studies are similar, no study has examined the variable of trust in leader with that leader being the nurse manager. Empirical research allowing researchers and organizational leaders to understand the effect a nurse manager has on his/her nurses could potentially lead to a better understanding the effect of the nurse manager has on various organizational outcomes. In this study the organizational outcomes were job satisfaction and intent to leave present job.

Definition of Terms

Intent to Leave Present Job: Employee's cognition that he/she desires to leave an organization.

Job Satisfaction: The level that one feels positive or negative about his/her current job. Nurse: A person trained to take care of sick and/or disabled patients. Nurses in hospital settings will be the primary focus of this study.

Nurse Manager: A person assigned to plan, monitor and ensure implementation of patient care delivery, fiscal management and unit operations. This individual is normally in charge of an entire unit inside a hospital.

Trust: The willingness to be vulnerable to another party when that party cannot be controlled or monitored.

Trustee: The individual who is trusted.

Trustor: The individual who is trusting the other. 
Summary

This study examined the relationship of trust in leader with job satisfaction as well as intent to leave present job in the context of the nursing position. Obviously the nursing shortage provides a great venue for this study, because of its potential societal impact and the verification that problems of voluntary employee turnover exist. This study sought to illustrate the relationship of trust in leader on job satisfaction as well as intent to leave present job independent of age, gender, and year in the organization.

Finally this study also sought to determine if trust in leader has a direct effect on intent to leave present job, or did job satisfaction actually mediate the relationship between trust in leader and intent to leave present job?

Although trust is often considered a key indicator of successful leadership outcomes, many merely mention its importance or assume its presence and move on (Mayer et al., 1995). If trust is a key indicator of success then research should measure its effect on certain key outcomes that business leaders relate with. Just recently has this taken place with research examining it effect on increased productivity, innovation, and enhanced employee morale (Spreitzer \& Mishra, 1999), profits and sales (Davis, Schoorman, Mayer, \& Tan, 2000), employee empowerment (Gomez \& Rosen, 2001; Spence-Laschinger et al., 2001), in-role performance (Mayer \& Gavin, 2005), job satisfaction (Butler, Cantrell \& Flick, 1999; Spence-Laschinger et al., 2001; Dirks \& Ferrin, 2002), intent to turnover (Spence-Laschinger et al., 2001; Dirks \& Ferrin, 2002), and employee turnover (Mayer et al., 2000). As future research becomes more prevalent with regard to trust, the field of Human Resource Development will have the opportunity 
to employ its findings into different forms of leadership development that can help organizational leaders develop and maintain trust among their staff. 


\section{CHAPTER II}

\section{LITERATURE REVIEW}

\section{Introduction}

Chapter II reviews the literature concerning research and theory related to voluntary turnover, intent to leave present job, job satisfaction, and trust in leader and organization in the context of the nursing profession. The salient literature reviewed first examines the intent to leave and turnover literature. This section of the review is broken up into sections dedicated to the cost of turnover, turnover theory, and a summation of the research conducted on intent to leave specifically. The next major section of the review is dedicated to job satisfaction. This section was broken into subsections dedicated to job satisfaction theory, differentiation of micro and macro levels of job satisfaction, and a discussion of the demographic variables related to job satisfaction. The literature review next summarized the research that demonstrates intent to turnover and job satisfaction as two of the most important antecedent to actual employee turnover. The next section of the review begins the discussion concerning the independent variable under study: trust in leader. This section is broken into several subsections that include: leadership theory, trust theory, antecedents of trust, trust as a criterion or mediating variable, and a section dedicated to the theory and research employing the model outlined by Mayer, Davis, and Schoorman (1995). Mayer, et al's model will be the foundation of this research. The next major section of the review will focus on research that includes trust in relation to job satisfaction and/or intent to turnover or turnover. The final section 
of the review will focus on trust, job satisfaction, and intent to turnover/turnover in healthcare and nursing. Table 2 summarizes the key concepts from the literature. 
Table 2

Summary of Key Concepts from Literature Review

\begin{tabular}{|c|c|}
\hline Subsection & Key Concepts \\
\hline Intent to Leave and Turnover & $\begin{array}{l}\text { - Cost of turnover } \\
\text { - Turnover theory } \\
\text { - Research on intent to turnover }\end{array}$ \\
\hline Job Satisfaction & $\begin{array}{l}\text { - Job satisfaction theory } \\
\text { - Micro- and macro-job satisfaction } \\
\text { - Demographic variables in job } \\
\text { satisfaction research }\end{array}$ \\
\hline $\begin{array}{l}\text { Intent to Leave and Job Satisfaction } \\
\text { Combined }\end{array}$ & \\
\hline Trust in Leader & $\begin{array}{l}\text { - } \text { Leadership theory } \\
\text { - Trust theory } \\
\text { - Trust defined } \\
\text { - Antecedents of trust in } \\
\text { leader/organization } \\
\text { - Trust in leader/organization as } \\
\text { criterion or mediating variable } \\
\text { - Theory and research based on } \\
\text { Mayer et al. model (1995) }\end{array}$ \\
\hline $\begin{array}{l}\text { Trust in Leader/Organization, Job } \\
\text { Satisfaction, and Intent to Leave/Turnover }\end{array}$ & \\
\hline $\begin{array}{l}\text { Trust in Leader/Organization, Job } \\
\text { Satisfaction, and Intent to Leave/Turnover } \\
\text { in Context of Nursing and Healthcare }\end{array}$ & $\begin{array}{l}\text { - Intent to leave/turnover } \\
\text { - Job satisfaction } \\
\text { - Job satisfaction and intent to } \\
\text { leave/turnover combined } \\
\text { - Trust and job satisfaction } \\
\text { - Trust, job satisfaction, and intent to } \\
\text { leave }\end{array}$ \\
\hline
\end{tabular}


Intent to Leave and Turnover

The first dependent variable of this research is intent to leave present job. Intent to leave has been argued and shown empirically to be the most important determinant of actual employee turnover (Mobley, 1978; Mobley, 1982; Hom \& Griffeth, 1991). This research employs intent to leave present job as one of the dependent variables under study, but any study of intent to leave would be remiss if the discussion did not also encompass discussion about the cost of turnover as well as turnover theory. With that in mind, the next two sections of the review will focus on the cost of turnover and then theory related to turnover.

\section{Cost of Turnover}

Voluntary employee turnover constitutes a real business issues that affects the financial well-being of any organization, especially healthcare. Amig and Amig (2001) argue the average cost of employee turnover is 25 percent of an employee's annual salary, and high turnover rates adversely affect organizations through additional training costs, lower productivity, loss of organizational memory, deterioration of company image, and poor morale. Sagie, Rirati, and Tziner (2002) assessed the turnover costs of a $\$ 17$ million technology business with an average employee annual salary of $\$ 33,475$. At the time of the study, 35 of 329 employees left the organization. Results indicated that a direct and indirect turnover cost to the organization was a 16.5 percent loss of $\$ 17$ million before tax dollars for fiscal year 1997.

Turnover costs for nurses and in the healthcare industry are problematic as well. According to Waldman and Sanjear (2004) between 1997-2001, average annual turnover of nurses was 17 percent. That percentage increased to 59 percent of newly hired nurses. 
Waldman and Sanjear went on to demonstrate that average retention of nurses newly hired in 1995 over a four year period was 39 percent in year one, 30 percent in year two, $25 \%$ in year three, and $22 \%$ in year four. According to Peter (1994), the direct cost to replace one nurse ranges from $\$ 1300$ to $\$ 8000$. Waldman, Kelly, Sanjear, and Smith (2004) found that annual turnover costs represented 3.4-5.8 percent of the annual operating budget of a medical center under study, and the largest cost was due to the loss and necessary replacement of nurses.

\section{Turnover Theory}

Considerable research over the past few decades has been devoted to developing theoretical models linking predictors of voluntary employee turnover (March \& Simon, 1958; Mobley, 1977; Mowday, Porter, \& Steers, 1981; Mobley, 1982; Hom \& Griffeth, 1991). These models identify many common predictors of voluntary employee turnover: Organizational commitment, job embeddedness, perceived job alternatives, intrinsic motivation, promotional opportunities, employee ownership, pay, burnout, job satisfaction, and intent to leave. A number of demographic variables were included as well: tenure with organization, age, education, gender, and marital status.

In order to classify predictors of voluntary employee turnover, researchers have placed the variables into three categories: Personal variables, external variables, and work variables (Mobley, 1982; Cotton \& Tuttle, 1986). Personal variables include: tenure, sex, gender, education. External variables refer to variables outside the organization and unrelated to the individual, such as the overall health of the economy. March and Simon (1958) suggested that the health of the economy was almost always the number one predictor of voluntary employee turnover. To this day, health of the economy is a part of 
most theory concerning turnover (Mowday, et al., 1981, Mobley, 1982, Hom \& Griffeth, 1991; Tett \& Meyer, 1993).

Work variables are predictors of employee turnover that describe dimensions of the relationship between employee and organization. Two of the most studied work variables are intent to leave and job satisfaction (Mobley, 1977; Hom \& Griffeth, 1991). Hom and Griffeth's (1991) meta-analysis of predictors of turnover found that intent to leave and job satisfaction have a consistent and significant relationship with turnover. Since intent to turnover and job satisfaction constitute the dependent variables in the current study, much more will be written on them later in the review.

While March and Simon (1958) began the dialogue about employee turnover, Mobley (1977) highlighted variables that linked job attitudes with actual turnover behavior. Mobley suggested that job attitudes were most directly related to withdrawal cognition (intent to leave), which was most directly related to the decision to leave. Job attitudes were only indirectly related to actual turnover behavior.

Mobley, Horner, and Hollingsworth (1978) tested Mobley's notions about turnover among a sample of hospital employees. The researchers found general support for the model, with the most significant finding being that the best predictor of actual turnover behavior was turnover intent. In this research job satisfaction, thoughts of quitting, intention to search, and probability of finding an acceptable alternative were unrelated to actual turnover.

Mobley (1979) more comprehensively attempted to identify the broad range of factors that could initiate the desire to leave an organization. Mobley argued that the causal linkage that influences the initiation of the turnover process was as follows: First 
one has a lack of job satisfaction which leads to thoughts about leaving. When one thinks about leaving, it can lead to the intention to search. The probability of finding an acceptable alternative leads to the intent to leave. Thus intent to leave leads to actual turnover behavior. Mowday, Koberg, and McArthur (1984) also investigated the validity of Mobley's model of intermediate linkages in the turnover process (1979). Findings were generally consistent with the model. Other researchers have tested models with personal, external, and work variables in mind.

Spencer and Steers (1980) examined the effect of personal factors and work experiences on employee turnover. Personal factors included age, tenure in organization, tenure in position, sex, and educational attainment. Work experiences included the extent to which one's peers have positive or negative attitudes towards the employer, met expectations, job challenge, personal feelings that the employee is making a contribution, and organizational dependability. Findings suggested that personal characteristics were not significantly related to employee turnover, however work experiences were significant.

Breukelen, Van Der List, and Steensma (2004) conducted a longitudinal study that examined factors explaining why they individuals may leave an organization. The researchers found that intent to leave was the best predictor of actual turnover behavior Job satisfaction and tenure with organization combined for a significant portion of the variance in intent to turnover.

Elangovan (2001) found a strong causal linkage between high stress and low job satisfaction. The researcher also found a strong reciprocal relationship between high organizational commitment and high job satisfaction. The common variables in the 
turnover literature are organizational commitment, job satisfaction, and intent to leave. Stress is getting more attention in the literature. This research will only concentrate on two of the variables in the turnover process: job satisfaction and intent to leave present job. The next portion of the review will focus on research that looks at variables that reduce intent to leave, which is has been shown to be the most accurate predictor of employee turnover.

Research on Intent to Leave

While job satisfaction is considered one of the most important factors in intent to leave, several other factors have been empirically examined in relationship to the variable. Several studies examine intent to leave independent of job satisfaction, however. Eisenberger, Stinglhamber, Vandenbugeh, Sucharski, and Rhodes (2002) found that perceived organizational support mediated a negative relationship between perceived supervisor support and employee turnover.

Another variable gets a great deal of attention with intent to leave is stress or emotional exhaustion. Geurts, Schaufeli, and DeJonge (1998) examined the effect of burnout on intent to leave among mental health employees. Results showed that the more engaged in negative communication with colleagues about management, the more the feeling of inequity in the management/employee relationship, which led a high score for intent to leave. Emotional exhaustion explained the level of negative communication about management. Cropanzano, Rupp, and Byrbem (2003) conducted a study of hospital employees and found that emotional exhaustion accounted for intent to leave 
beyond the effects of age, gender and ethnicity. Roolli and Savicki (2006) found that higher levels of strain on the job predicted turnover above and beyond any contribution of procedural justice.

The ability for employees to articulate dissatisfaction factors into the intent to leave process. Spencer (1986) investigated the relationship between the extent to which employees have opportunities to voice dissatisfaction and the effect on voluntary employee turnover among hospital employees. Findings suggested that high numbers of mechanisms for employee voice were associated with high retention rates. The researchers reported that high numbers of employee voice explained 20 percent of the variance in voluntary turnover. Employee voice included grievance procedures, suggestion systems, employee/management meetings, counseling services, and survey feedback.

Justice has been demonstrated to affect intent to leave as well. Jones and Skarlicki (2003) examined the interactive effects of distributive, interactive, and procedural justice on intent to leave. The researchers found that higher levels of distributive justice resulted in lesser likelihood of turnover. Interestingly, higher procedural justice seemed to indicate higher levels of turnover. Findings also indicated that the two-way interaction of distributive and interactional justice was significantly related to turnover above and beyond the model.

Harris and Cameron (2005) examined psychological well-being and intent to leave. Findings indicated that intent to leave was negatively associated with self esteem and self efficacy. In other words those employees that reported higher levels of self 
esteem and self efficacy (one who feels that they have power over own destiny) also reported lower levels of intent to leave.

Leadership has been shown to have a significant impact on intent to leave. For example Vandenberg and Nelson (1999) found that high intent to leave did not automatically result in actual turnover behavior. The researchers found that individuals possessed different motives for articulating intent to leave, and that motives accounted to some extent for the correlation between intent to leave and actual turnover behavior. Most interesting was the finding that when controlling for motives related to supervisor or leader, there was strengthening of the relationship between intent to leave and actual turnover behavior. This suggests that positive feelings towards the leader could suppress the relationship between intent and actual turnover behavior, whereas negative feelings towards the supervisor strengthened that relationship.

Bauer, Erdogen, Linden, and Wayne (2006) examined extraversion/introversion as a moderator of relationships between the quality of leader-member exchange, performance and intent to leave in new executives. Researchers found that quality of leader-member exchange had no relationship on performance or intent to leave for those high in extraversion. Researchers did find a relationship between leader-member exchange quality and intent to leave overall and for introverts specifically.

Finally, other variables lead to intent to turnover as well, including training, organizational climate, work to decrease the level of intent to leave. Benson (2006) conducted an examination of an organization that increased employee development activities immediately after a series of layoffs. The researcher found that on-the-job training significantly affected organizational commitment and intent to leave. Griffith 
(2006) found that positive organizational climate led to lower levels of employee turnover among employees of public school systems.

Job Satisfaction

Job satisfaction constitutes the second dependent variable in this research. Most research dedicated to turnover examines job satisfaction as an independent variable of intent to leave. In the case of this research, the researcher wishes to determine the effect of trust in leader on intent to leave independent of job satisfaction, while also studying the effect of trust in leader on job satisfaction specifically, as well as in conjunction with each other. With this in mind, a discussion of job satisfaction independent of the turnover research is necessary.

Job Satisfaction Theory

Job satisfaction has been argued as one of the precursors to voluntary employee turnover (Mobley et al., 1977; Hom and Griffeth, 1995). Much has been significantly researched (Hoppock, 1935, Maslow, 1954, Vroom, 1964, Herzberg, 1966, Locke, 1976) dating back to the preliminary Hawthorne studies of the 1920's. Hoppock (1935) published the first intensive study on job satisfaction which included the results and interpretations that emphasized the multiplicity of facts that affect job satisfaction; such as, fatigue, monotony, working conditions, and supervision.

Locke (1976) indicated that "job satisfaction results from the perception that one's job fulfills or allows the fulfillment of one's important job values, providing and to the degree that those values are congruent with one's needs" (p. 1307). Recognizing certain conditions for job satisfaction, Locke formulated the following:

1. "mentally challenging work with which the individual can cope successfully; 
2. personal interest in work itself;

3. work that is not too terribly tiring;

4. rewards for performance which are just, informative and in line with the individual's personal aspirations;

5. working conditions which are compatible with the individuals physical needs and which facilitate the accomplishment of his work goals;

6. high self-esteem on the part of the employee; and

7. agents in the work place who help the employee attain job values; such as, interesting work, pay and, promotions, whose basic values are similar to his own, and who minimizes role conflict and ambiguity" (p. 1328).

Maslow's Hierarchy of Needs (1954) is often cited in the job satisfaction literature. Maslow's hierarchy identifies five categories of needs. Physiological needs include food, water, and air. Safety needs refer to needs that ensure that the individual remains out of harm's way. Needs of belonging refer to love and being part of a group. Esteem needs include mastery, achievement, and recognition. Finally, self-actualization is the act of becoming everything one is capable of becoming.

Herzberg (1966) developed Motivation-Hygience Theory, which functions around two factors relating to job satisfaction and job dissatisfaction: Motivators (intrinsic in nature) and hygiene (extrinsic in nature). Motivators include achievement, recognition, work itself, responsibility, and advancement. Hygiene factors include supervision, salary, interpersonal relations with peers, subordinates, and superiors, as well as working conditions. Herzberg argued that increased levels of intrinsic or motivator factors would 
lead to increased job satisfaction. However, the decrease of extrinsic or hygiene factors would lead to greater job dissatisfaction.

Vroom (1964) is also mentioned frequently in the job satisfaction literature. Vroom used job satisfaction and job attitudes interchangeably and asserted it refers to affective orientations on the part of the individual towards work roles they presently occupy. In other words, positive attitudes result in greater job satisfaction and negative attitudes lead to greater job dissatisfaction.

Micro and Macro Levels of Job Satisfaction

Measuring levels of satisfaction presents researchers with a quandary of whether job satisfaction is a global measure in and of itself (macro), or a series of satisfaction measures (i.e. satisfaction with pay or supervision) leading to a measure of job satisfaction. The micro level refers to the individual characteristics of the job such as work itself, pay, or promotion opportunity. The macro level of job satisfaction refers to how one feels about the job overall (Balzer et al. 2000; Kiziah, 2003). Results have been contradictory when reviewing correlations between individual job characteristics and overall job satisfaction. Ferratt (1981) demonstrated that one could not simply sum up the ratings of individual aspects of the job and obtain the overall job satisfaction. The study found that individual job facets account for approximately fifty percent of an employee's overall job satisfaction suggesting that factors other than job specific traits impact satisfaction.

It is not uncommon for researchers to be interested in both individual job components and overall job satisfaction. While several validated instruments exist that one might choose for measuring satisfaction, a common measurement instrument for 
measuring job satisfaction is the Job Descriptive Index (e.g., Balzer et al. 2000; Ferratt, 1981; Judge, Thoreson, Bono \& Patton, 2001; Skibba, 2002). This instrument measures individual job components, or the micro levels of job satisfaction; including work on the present job, pay, opportunities for promotion, supervision, and people on your present job. The Job Descriptive Index (originally developed in 1969) has demonstrated convergent validity and internal reliability.

In 1989 Ironson, Smith, Brannick, Gibson, and Paul developed the Job in General scale to be utilized in conjunction with the Job Descriptive Index. This tool is designed to be used in conjunction with the Job Descriptive Index to measure global job satisfaction. A number of differences between micro-job satisfaction and macro-job satisfaction contributed to the need for an additional measurement tool. For instance, factors exist that impact one's satisfaction with the job that are not covered by the Job Descriptive Index (e.g., employee benefits or the availability of training). Additionally, time plays an important role, whether long-term job considerations or short-term daily activities (Balzer et al. 2000). Consequently, the Job in General scale measures the macro-satisfaction with the job.

Wanous and Hudy (2001) noted that single item measures are more useful when the following criteria are met: (1) the topic of study is one-dimensional; (2) the topic is clear to the participants; and, (3) the topic is narrow. These factors are clearly not applicable to the study of job satisfaction, as can be seen from the previous discussion of the multi-dimensions of job satisfaction. To utilize a single-item measure in the study of job satisfaction would appear to risk losing or not capturing data that would be valuable to the outcome of the study. 
Demographic Variables in Job Satisfaction Research

Tenure, gender, and age have been theorized and shown to be significant predictors of job satisfaction (Mobley et al., 1979, Williams \& Hazer, 1986). Tenure, or the length a person has been in a position, has had mixed results. Some studies suggest a positive relationship (Grossi \& Bergman, 1991, Zefane, 1994), while others have found no relationship (Curry et al., 1986, Mueller et al., 1994), or even a negative relationship (Buzawa, 1994). Herzberg, Mausner, Perterson, and Capwell (1959) argued that a significant relationship existed between age and job satisfaction. Studies are inconsistent with relation to gender and job satisfaction. Some studies demonstrate that females experience greater job satisfaction that males (Martin, 1990), while some studies show that males experience greater job satisfaction (Britton, 1997). More often than not, gender fails to show any significant relationship with job satisfaction (Grossi \& Berg, 1991, Finebaugh \& Hurley, 1995, Melamed, Ben-Avi, Luz, \& Green, 1995).

\section{Intent to Leave and Job Satisfaction Combined}

Intent to leave and job satisfaction have been established as two of the most important predictors to voluntary employee turnover (Mobley, 1977, 1979, 1982). This section of the literature review will summarize the literature related to intent to leave and job satisfaction related to voluntary employee turnover. It will begin by suggesting intent to turnover as the most significant factor in the turnover equation. The review will then outline research that references job satisfaction and intent to leave.

George and Jones (1996) examined the multifaceted aspects of the work experience and their relationship on intent to leave. Findings suggested that job satisfaction and intent to leave were jointly moderated by value attainment and positive 
mood. The researchers also found that the job satisfaction and intent to leave relationship was strongest when workers' job did not allow for the attainment of terminal values and positive mood was experienced. The relationship was weakest when job helped workers attain terminal values and positive mood was experienced. Thus the interaction that had the most significant impact on intent to leave was the triple interaction of low job satisfaction, high positive mood, and low value attainment

Cote and Morgan (2002) explored the association between emotional regulation (defined as the conscious manipulation of one's public displays of emotion), job satisfaction, and intent to leave. Findings suggested that the suppression of unpleasant emotions decreased job satisfaction. This in turn increased intent to leave. Findings also suggested that the amplification of pleasant emotions increased job satisfaction. There was no significant relationship between the amplification of pleasant emotions and intent to leave.

Rosser and Javinar (2003) conducted a national study examining demographic and work life issues impact on morale and job satisfaction as well as the indirect effect on intent to leave among. The researchers found that the more tenured with an organization and the higher salaried an individual the lower the morale. But it was also found that this group more likely to remain with the organization. In light of that finding, the researchers still found overall that the lower the level of morale the higher the intent to leave. The researchers also found that quality of work life issues had a significant, direct impact on job satisfaction and an indirect effect on intent to leave via job satisfaction. Those work life issues included adequate recognition, strong support from leader, good 
working conditions, and good external relationships. Job satisfaction was the significant predictor or intent to leave.

Cunningham and Saga (2004) examined athletic coaches. The researchers wanted to understand if values alignment led to greater job satisfaction and less intent to leave. The researchers found that when values were similar between organization and coach, there was greater job satisfaction and less intent to leave.

Egan, Young, and Bartlett (2004) examined the relationship between an organization's learning culture, job satisfaction, and intent to leave. The researchers found that organizations that incorporated a learning culture were more likely to see greater job satisfaction among their employees. Intent to leave was found to be negatively related to both organizational learning culture and job satisfaction.

Firth, Mellor, Moore, and Loquet (2004) researched the impact of job stressors on 173 retail employees' intent to leave. The model that included self esteem, supervisor support, feelings of job stress, organizational commitment, and job satisfaction explained 52 percent of variance in intent to leave. The findings suggested that job stressors did not directly impact intent to leave. However, job stressors indirectly impacted intent to leave through job satisfaction, organizational commitment, and feelings of job stress. Thirty percent of the variance explained in job satisfaction was accounted for via a model including supervisor support, low levels of job stress, and low feelings of stress.

Owens (2006) found that the amount of training affected significantly employees' job satisfaction and intent to leave. When distributive justice was combined with training, the combination accounted for a significant proportion of the variance in job satisfaction and intent to leave. When procedural justice was added to the equation, the 
combination explained a significant proportion of the variance in job satisfaction and intent to leave.

Trust in Leader

Trust in leader constitutes the independent variable in this research. To acquire a good understanding of trust in leader, a discussion of leadership theory is in order first. Second this portion of the review will discuss trust theory and the definition of trust followed by a section dedicated to research concerning the antecedents of trust. The next portion will refer to research in which trust in direct leader or organizational leadership acts as a criterion variable or mediating variable on a variety of dependent variables. Leadership Theory

One would be remiss when studying trust in leadership not to include some mention of leadership theory and influential works in the study of leadership along with the concept of trust. Northouse (2004) defines leadership: "Leadership is a process whereby an individual influences a group of individuals to achieve a common goal" (p. 3). Northouse goes on to describe three major terms in the definition. Influence is concerned with how the leader affects the follower. Groups are the context in which leadership takes place. Goals are the task or end that a leader influences a group to achieve. In many ways, trust is what binds the three concepts together.

Two leadership theories make use of the concept of trust quite overtly: LeaderMember Exchange Theory (LMX Theory) and Transformational Leadership. LMX Theory conceptualizes leadership as process that centers on the interactions between leaders and followers (Northouse, 2004). Graen and Uhl-Bien (1991) indicate that the making of quality leader-member exchange develops over time via three phases. The 
first phase was referred to as the "stranger" phase where the relations between the leadermember dyad are generally rule bound, relying heavily on contractual relationships. Leaders and followers conform to organizational roles and the quality of the leadermember exchange is normally low, and followers are in what is referred to as "outgroup" status (Graen, 1976). According to Graen and Uhl-Bien (1995), the motives of the follower are directed towards self-interests rather than the good of the group.

The second phase of LMX theory is referred to as the "acquaintance" phase. According to Graen and Uhl-Bien (1991), the leader or follower, during this phase, makes an offer for career-oriented social exchanges, which involve sharing more resources and personal and work related information. This is considered a testing period to assess if the follower is interested in taking on more roles and responsibility and whether the leader is willing to provide new challenge to the follower. Interactions shift from those governed by job descriptions and roles and moving more towards relationships. During this time, leader-member exchanges improve and greater trust begins to develop between the leader and follower, which allows for the follower to begin entering into what is referred to as the "in-group" (Graen, 1976). However this is also a time where the exchange relationship can become one of distrust. "People are reluctant to negotiate agreements with a leader who cannot be trusted to keep promises (Yukl, 1998, p. 247).

The final phase of the LMX theory is referred to as the "mature" phase. This phase involves high quality exchanges between leader and follower. Dyads that reach this stage enjoy high levels of mutual trust, respect, and obligation towards each other. The parties have tested each other, and understand that each can understand the other. 
There is a great deal of reciprocity which increases the level of trust with each instance. (Graen and Uhl-Bien, 1991).

Transformational leadership represents that second leadership theory that readily refers to trust. Transformational leadership was coined in the work of Burns (1978) who argued that leaders tap the motives of followers in order to better achieve goals shared by the leader and follower. Burns distinguished between two types of leadership: transactional and transformational. Transactional leadership refers to leadership that relies on exchanges that occur between leader and follower. Transformational leadership refers to the process by which people engage with others and engage with others to create a connection that raises the level of motivation and morality in both leader and follower.

Bass (1985) expanded and refined the concept of transformational and transactional leadership. Bass argues that transformational leadership raises followers' levels of consciousness about the importance and value of specified and idealized goals, gets followers to transcend their own self-interest for the sake of the team or organization, and moves followers to address high level needs. According to Bass (1985), transformational leadership demonstrate four characteristics: idealized influence (leaders who act as strong role models, and followers identify with the leader and try to emulate them), inspirational motivation (leaders who articulate high expectations, and inspire through motivation to become committed to the goal, the team, and the organization), intellectual stimulation (leaders influence the innovation and creativity of their followers), and individualized consideration (leaders that provide a supportive climate, listening carefully to followers' individual needs). 
Bennis and Nanus (1985) argued that transformational leaders create trust in their teams and organizations by making their own positions clearly known and then standing by them. In this case, trust has to do with being predictable and reliable, even in situations of uncertainty. Leaders build trust by communicating a direction and then consistently implementing the direction even though the vision may be uncertain. Bennis and Nanus found that when leaders established trust in an organization, it gave the organization a sense of integrity analogous to a healthy identity.

A number of leadership scholars have identified the importance of trust in the leadership equation. Yukl (1998) identified integrity as a important trait of effective leaders. Yukl states, "Integrity is a primary determinant of whether people will perceive a leader to be trustworthy. Unless one is perceived to be trustworthy, it is difficult to retain the loyalty of followers or to obtain cooperation and support from peers and superiors. Moreover, a major determinant of expert and referent power is the perception by others that a person is trustworthy" (p. 247).

Expert and referent power are two power types outlined by French and Raven (1959). Expert power is given to a leader when the follower believes that the leader has a special knowledge about the best way to do something. Ultimately the follower trusts in the knowledge, competence, or ability of that leader. Referent power is power given to a leader when the follower admires or identifies with the leader and wants to gain his/her approval. That cannot occur unless the follower trusts in the leader (French and Raven, 1959; Bass, 1985; Yukl, 1998). The other types of power in the French and Raven taxonomy include reward, coercive, and legitimate power. 
Covey (1990) identified the importance of trust in his work. Covey argues that leaders establish trust through their character and competence. Kouzes and Pozner (1993) found that effective leaders were viewed as credible, credible leaders were first and foremost perceived as honest. Fairholm (1994) stated, "leadership is a process of building a trust environment within which leader and follower feel free to participate toward accomplishment of mutually valued goals using agreed upon processes" (p. viii). Carnevale (1995) argued that high performing organizations require high trust leadership to thrive. Zand (1997) identify three sources of effective leadership: knowledge, trust, and power. Zand argues that trust is an essential competency ensuring the establishment of one's knowledge and power.

Obviously, this portion of the review outlines the importance of trust in building effective organizations and being an effective leader. The power of trust in leader as a criterion variable seems immense. But before getting into research focusing on trust, a discussion of the definition of trust is warranted.

\section{Trust Defined}

Trust between individuals is a difficult concept to define. Several have made the attempt. Deutsch (1957) pioneered the study of trust and defined the concept as, "An individual may be said to have trust in the occurrence of an event if he expects its occurrence and his expectation leads to behavior which he perceives to have greater negative motivational consequences if the expectation is not confirmed than positive motivational consequences if it is confirmed" (p. 266). Giffin (1967) defined trust as, "reliance upon the characteristics of an object, or the occurrence of an event, or the 
behavior of a person in order to achieve a desired but uncertain objective in a risky situation" (p. 105).

Mayer, Davis, and Schoorman (1995) provide the operational definition of the concept of trust employed in the current research. The researchers defined trust as, "the willingness of a party to be vulnerable to the actions of another party based on the expectation that the other will perform a particular action important to the trustor, irrespective of the ability to monitor or control that other party" (p. 711).

Trust obviously involves a great deal to develop and maintain as has been outlined in the previous definitions. Understanding the definition of trust, the literature review will move forward. The next section will focus on the theories that make up trust so as to provide a greater overall understanding of the construct.

\section{Trust Theory}

Deutsch (1958) began the first experimental study of the phenomena of trust.

Deutsch went on to define trust: "An individual may be said to have trust in the occurrence of an event if he expects its occurrence, and his expectation leads to behavior which he perceives to have greater negative motivational consequences if the expectation is not confirmed than positive motivational consequences if it is confirmed" (p. 266). With this in mind, the researcher hypothesized that as the individual's confidence of the fulfillment of trust increased, the probability of that individual to engage in trusting behavior increase. As the ratio of anticipated positive to anticipated negative motivational consequences increased, the probability of that individual engaging in trusting behavior would increase as well. 
Giffin (1967) introduced a theory of the dimensions of interpersonal trust in communication. Giffin conducted a literature review concerning source credibility so as to support hypotheses that one based interpersonal trust upon a listener's perceptions of a speaker's expertness, reliability, intentions, activeness, personal attractiveness, and the majority opinion of the listener's associates. The researcher defined interpersonal trust in the communication process as reliance upon the communication of another person in order to achieve a desired but uncertain objective in a risky situation.

Weber and Carter (1998) conducted a qualitative study that focused on the process through which individuals, in their everyday lives, worked to construct trust in their interactions with others. The researchers collected data from 10 in-depth interviews of sociology students. Weber and Carter discovered several phenomena that helped to construct trust. First, trust was socially constructed. The researchers found that trust failed to exist outside the interchanges with real or imagined others. Thus, Weber and Carter argued that individuals possess some control over the nature of interpersonal relationships by attending to the dynamics of trust. Researchers next found that trust takes time. Through time, a relationship emerged that created its own history. This history provided evidence for trust decisions.

Weber and Carter also found that the trust relationship necessitates reciprocal self-disclosure and affirmative responses. At initial encounters, the revelation of trivial matters of self would lead to a crucial response in determining whether to go to the next more intimate disclosure. Reciprocal self-disclosures and ensuing responses allowed for reciprocal perspective taking as well. Sharing in the conscious lives of others or really getting to know the other became achievable via conversation and evidenced action. The 
researchers found that taking the other's perspective when making decisions led to more trusting relationships.

Vaugen and Huxham (2003) argued of the existence of a trust building loop that contained several components that cycled from one component to the next. For trust to form, an individual formed expectations about the future of the collaboration based on reputation or past behavior or contracts and agreements. The individual then possessed enough trust, and became vulnerable and took a risk to initiate collaboration. Once an individual resolved these issues, he/she would aim for realistic, and initially modest, successful outcomes. Next parties reinforced trusting attitudes, and then gained underpinnings for more ambitious collaboration and that cycle continued throughout the relationship.

The loop conveyed trust building as a cyclical process within which positive outcomes form the basis for trust development and with each consecutive positive outcome trust would build on itself incrementally, over time. The emerged theory suggested that successful management of trust implied both the ability to cope in situations where trust lacked and the ability to build trust in situations where possible. The researchers argued that given the reality of many collaborative situations, practitioners would find themselves in situations where trust was insufficient. Vaugen and Huxham continued to argue that the possible key to success concerned the ability to predict trust in management concerned managing the risk and vulnerability inherent in the collaborative situation.

The theory also clarified different implications for initiating and sustaining the trust-building loop across different situations. The researchers found that a small-wins 
approach to trust building within which people build trust incrementally via successful implementation of modest collaborative initiatives became the preferred strategy. Thus trust management required the assessment of each collaborative situation with regard to level of associated risk, level of trust existing between the partners, and whether trust building employed the small-wins approach.

Mayer, Davis, and Schoorman (1995) outlined what has become one of the foremost scholarly works on trust in organizations and leadership. Mayer et al.'s theory represents the theoretical foundation of the this research from a trust perspective. According the Mayer et al., extending trust to another individual involves (1) the willingness to accept risk that is meaningful to the individual extending trust to the other, and (2) awareness that risk exists in the trust being extended. Thus the researchers define trust as "the willingness of a party to be vulnerable to the actions of another party based upon the expectation that the other will perform a particular action important to the trustor, irrespective of the ability to monitor or control that other party" (p. 712).

Mayer et al. go on to outline what leaders must do in order to develop and maintain trust from followers. Development and maintenance of trust requires that a leader demonstrate high levels of proficiency in the constructs of ability, benevolence, and integrity. The researchers define the three constructs as follows: Ability is that group of skills, competencies, and characteristics that enable a party to have influence within some specific domain. Domain is highly specific because the trustee may be highly competent in one area and not competent in another. Benevolence is the extent to which a trustee is believed to want to do good to the trustor, aside from an egocentric motive, 
such as profit. Integrity is the perception that the trustee adheres to a set of principles that the trustor finds acceptable.

Since ability, benevolence and integrity are seen as predictors of trust and there is evidence to suggest this (Mayer \& Gavin, 2005; Serva, Fuller \& Mayer, 2005; Davis, Schoorman, Mayer \& Tan, 2000; Mayer \& Davis, 1999), this researcher will study each of the antecedents independently as well as trust in leader and their relationship with intent to turnover, job satisfaction, and organizational commitment.

Mayer et al. also outlined another construct referred to as propensity to trust. According to the researchers, propensity to trust is generalized expectation of the trustworthiness of another. The level of propensity to trust is different for everyone, but is a stable within-party factor that will influence the likelihood that a person will trust. Propensity to trust will not be examined in this study.

Antecedents of Trust in Leader/Organization

A number of studies exists testing variables as antecedents or predictors of trust in leader or organization. The ability of employees to participate in decision making has been empirically shown to lead to greater trust in leader and/or organization (Chawla \& Kelloway, 2004; Dirks \& Ferrin, 2002; Korsgaard, Schweiger, \& Sapienza (1995). Quality of communication and information also seems to predict trust (Chawla \& Kelloway, 2004; Nikandrou, Papalexandris, \& Bourantas (2000). Perceived empowerment demonstrated increased levels of trust in leader (Moye, Hinkin, \& Egley (2005). Procedural, distributive, and interactional justice have been demonstrated to predict trust in leader or organization (Chawla \& Kelloway, 2004; Dirks \& Ferrin, 2002; Tan \& Tan, 2005). 
Korsgaard, Schweiger, and Sapienza (1995) examined how decision-making procedures could facilitate the positive attitudes necessary for cooperative relations in decision-making teams. The researchers found that when team leaders showed strong consideration of members' input, team members saw the process as fairer, and consequently, became more committed to the decision, developed greater attachment to the team, and developed greater trust in the leader. In fact the researchers found partial support for the notion that justice perceptions mediated the impact of procedures on commitment, attachment, and trust. One unexpected result the researchers found concerned the finding that feelings of attachment and trust significantly decreased over time when leaders exhibited no specific signs of consideration of that input. In other words, when a decision-maker failed to respond to the input, perceptions of unfairness became more severe than if participants gave no input at all.

Nikandrou, Papalexandris, and Bourantas (2000) conducted a study of employees in various organizations examining the factors that affect trust in management after acquisition. Both frequent communication before and after the acquisition and useful information to employees of the acquired company increased acquired employee perceptions of new management's trustworthiness. Good employee relations with new colleagues, reduced economic uncertainty, and increased tolerance to change, all contributed to management's trustworthiness. According to Nikandrou et al. if an employee population goes through an acquisition, it would benefit the company to invest in more frequent communication that provided useful information to those employees, facilitation of good relations among team members, alleviation of economic fears, and development of staff that could deal with change. 
Tan and Tan (2000) conducted a study to differentiate trust in a supervisor and organizational trust. The researchers contended that although the two variables relate to one another, they differ in their antecedents and outcomes. Ability, benevolence, and integrity accounted for a significant proportion of the variance in trust in supervisor. Procedural justice, distributive justice, and perceived organizational support accounted for a significant proportion of the variance in the dependent organizational trust.

MacKenzie, Podsakoff, and Rich (2001) examined the effects of transformational leadership behaviors on salespeople in the context of transactional leadership behaviors. Core transformational leader behaviors related positively with trust as did individualized support and contingent reward behavior. Trust was significantly related to helping behavior and sportsmanship, which are specific organizational citizenship behaviors. Thus it seemed that the combination of the components of transformational leadership and the transactional component of contingent reward helped to predict trust. And the significance of trust in relation to certain helping behaviors seemed to indicate a mediating effect by trust on leadership and the helping behaviors.

Dirks and Ferrin (2002) examined the findings and implications of the research on trust in leadership via meta-analysis. Meta-analysis indicated that nearly all variables dealing with antecedents of trust had a significant relationship with trust in leadership. Transformational leadership showed the largest relationship, followed by perceived organizational support, interactional justice, procedural justice, participative decision making, unmet expectations, and propensity to trust.

Korsgaard, Whitener, and Brodt (2002) explored the role of attributions in shaping employees' trust in their managers in the context of negative events. The 
researchers examined managerial trustworthy behavior in two forms: open

communication and demonstrating concern for employees. Findings suggested that open communication and demonstrating concern for employees leads to trust in manager and greater organizational citizenship behavior.

Korsgaard et al. found that managerial trustworthiness behaviors associated significantly with less personal attributions for negative events. In other words, when disagreements occurred between manager and employee, employees tended to hold managers less responsible when the manger communicated more openly and demonstrated concern. In addition, attributions partially mediated the relationship between managerial trustworthy behavior and employee trust in leader. The researchers also found managerial trustworthiness behavior related significantly to employee citizenship behavior. This finding suggested that benefits to trustworthy behavior extended beyond the manager-employee relationship to potentially employee's work performance.

Testa (2002) conducted a study to determine if cultural congruence in leadership dyads impacted evaluation and subsequent leadership outcomes. Findings indicated that the congruent groups evaluated leaders higher on consideration, trust in supervisor and satisfaction in supervisor than in incongruent groups. This study lends evidence to the notion that groups that are more aligned culturally will deem leaders higher in consideration, trust, and satisfaction.

Ferrin and Dirks (2003) tested hypotheses asserting that reward structures influenced interpersonal trust. Specifically, the researchers explored the cognitive and behavioral routes through which the effects may occur. The researchers found that 
perceived motives of rewards and actual performance of individual influenced trust. Ferrin and Dirks also found the effects of rewards were contingent on initial trust. Findings also suggested an interaction between initial trust and cooperative rewards. Moye, Hinkin, and Egley (2005) found that those who perceived that they were empowered in their work environments possessed significantly higher levels of interpersonal trust in their leader. The researchers also found that those who found their work personally meaningful work, perceived high levels of autonomy and had substantial influence in their work environment possessed significantly higher levels of perceived interpersonal trust in their leader.

Factors of leadership also lead to trust. A leader's level of self awareness has a significant effect on the level of trust employees have in him/her (Sosik, 2001). Employees that feel that their values are aligned favorably with the organization have higher levels of trust (Testa, 2002). Employees that find that they fear their leaders (and peers) seem to have lower levels of trust (Adams, 2004). Joseph and Winston (2004) found that leaders that ascribed to servant leadership enjoyed higher levels of trust. Several researchers empirically demonstrated a significant effect on trust in leader and organization (Butler, Cantrall, \& Flick, 1999; Dirks \& Ferrin, 2002; Jung \& Avolio, 2000; MacKenzie, Podsakoff, \& Rich, 2001).

Mayer et al. (1995) developed a model that outlined three antecedents of trust in leader and organization, which included integrity, benevolence, and ability (sometimes referred to as competence). Several studies empirically support this model. Mayer and Davis (1999) conducted a 14-month field study of employee trust for top management concerning the administration of performance appraisals. When leaders conducted 
performance appraisals that exhibited more trustworthy behaviors, the results indicated the effect of changes in the performance appraisal on trust in leader was mediated by trustworthiness variables: ability, benevolence, and integrity. Davis, Schoorman, Mayer and Tan (2000) found that integrity, benevolence and ability explained a significant proportion of the variance in trust in leader. Mayer \& Gavin (2005) conducted a study investigating the relationship between an employee's trust in the plant manager and in the top management team with both the employee's in-role performance and organizational citizenship behaviors. The antecedent of trust all correlated significantly with the trust in top management team.

Other studies found antecedents of trust in leader and/or organization. Gillespie and Mann (2004) found that three factors together predicted a significant proportion of the variance in team members' trust in leader: Consulting team members when making decisions, communicating a collective vision, and sharing common values. Joseph and Winston (2004) found that the employee perception of a leader's level of servant leadership had a significant impact on trust in leader and trust in organization.

\section{Trust in Leader/Organization as Criterion or Mediating Variable}

Trust in leader and/or organization has been shown to direct or mediating effect on a variety of other variables. Several instances of research demonstrate trust's significant effect on organizational commitment and support of leader (Brockner, Siegal, Daly, Tyler, \& Martin, 1997; Dirks \& Ferrin, 2002; Muchinsky, 1977). Trust has also been demonstrated to significantly affect power and influence (Frost \& Moussavi, 1992), increased productivity ( Spreitzer \& Mishra, 1999), increased employee morale (Spreitzer \& Mishra, 1999), more innovation (Spreitzer \& Mishra, 1999), team performance (Dirks, 
2000), organizational performance (Jung \& Avolio, 2000), empowerment (Gomez \& Rosen, 2001), justice (Ayree, Budwhar, \& Chen, 2002), organizational citizenship behaviors (Ayree, Budwhar, \& Chen, 2002), and dysfunctional employee behavior (Choi, Dixon, \& Jing, 2005)

Frost and Moussavi (1992) examined the moderating role of trust between leaders' power base, based on French and Raven's research (1959), and their ability to influence their subordinates among 99 hospital managers. Results indicated that trust significantly affected the influence-power base relationships. In fact it seems that loss of trust in leader appeared to result from the leader resorting to legitimate, coercive, or reward power.

Brockner, Siegal, Daly, Tyler, and Martin (1997) examined trust in leadership on perceived outcomes when leadership's decisions were unfavorable. Results indicated that trust in leadership significantly and positively influenced otherwise adverse reactions that employees may exhibit in reaction to decisions yielding unfavorable outcomes. The interaction of trust in leadership and negative outcome favorability accounted for a significant portion of variance in support for supervisor and organizational commitment. In other words, when decisions were perceived unfavorable, trust in leadership became much more important in relation to support for supervisor and organizational commitment.

Spreitzer and Mishra (1999) examined the link between trust, performance information, and incentives to an increased willingness on the part of managers to involve lower echelon employees in decision making and ultimately to organizational performance. Results indicated that managerial trust, the collection and dissemination of 
performance information and the use of performance incentives all increased the likelihood managers would involve lower echelon employees in decision making. The researchers also found that higher levels of managerial involvement of employees associated significantly with all three measures of organizational performance: Increased productivity, increased innovation and enhanced employee morale.

Dirks (2000) examined the relationship between trust, leadership, and team performance among NCAA basketball coaches and their teams. After controlling for several potential determinants performance, trust in coach had a significant effect on winning percentage. Past performance had a significant effect on trust and effect on winning percentage. When trust was added to the third equation, the coefficient for past performance decreased in magnitude and became insignificant. Hence the pattern of results from these three equations provided support for the notion that trust mediated the relationship between past performance and future performance. Trust in leadership and control variables accounted for a substantial portion of the variance in the study.

Jung \& Avolio (2000) conducted an experimental study that examined the causal effects of transformational and transactional leadership and the mediating role of trust and value congruence on follower performance. Significant positive effects existed between transformational leadership and the variables of trust and value congruence. No effect or a strong negative effective occurred between follower performance and transactional leadership. A significant positive effect existed between transactional leadership behaviors and trust as well as a minimal positive effect between transactional leadership and value congruence. Chi-square results also indicated that transformational leadership had both direct and indirect effects on performance mediated through 
followers' trust in the leader and value congruence. Transactional leadership only indicated indirect effects on followers' performance mediated through followers' trust and value congruence.

Gomez \& Rosen (2001) examined the relationship between trust in leader and employee empowerment using the theory of leader-member exchange. The researchers found a significant relationship between trust in leader and quality of leader-member exchange. The researchers also found a significant relationship between the quality of leader-member exchange and employee empowerment. Experience in position related to feeling of empowerment. Researchers also found that trust in leader related significantly to employee empowerment. A mediating effect of leader-member exchange on trust in leader and employee empowerment was also found.

Results indicated several notions according to the researchers. First, it seemed that employees who trusted their managers expressed experiencing a better quality of exchange with managers. Manager's trust in an employee related with the employee's perceptions of being part of the in-group. Employees' perceptions of a high-quality relationship associated significantly with employees' experience of psychological empowerment. Finally, leader-member exchange mediated the relationship between managerial trust and employee empowerment.

Aryee, Budhwar, \& Chen (2002) tested the potential mediating influence of the trust in leader and organization on the relationship between organizational justice and employee work attitudes and behaviors. Results revealed the trust in organization and trust in supervisor to be interrelated but distinct constructs. These findings suggested that employees could develop trust in specific individuals and generalized representatives 
such as an organization. The findings further supported, partially, that the two trust foci would fully but differentially mediate the relationship of organizational justice dimensions and the work attitudes and behaviors examined. The relationship between distributive and procedural justice and the employee work-related attitudes mediated, partially, by trust in organization. Trust in organization fully mediated the influence of interactional justice on all three work attitudes. Further findings revealed interactional justice as a primary source of trust in supervisor.

Trust in supervisor fully mediated the relationship between interactional justice and the work-related behaviors of organization citizenship behaviors directed to individuals, organizational citizenship behaviors directed to the organization, and task performance. Trust in organization mediated the relationship between distributive justice and procedural justice on job satisfaction, turnover intention and organizational commitment. Trust in supervisor mediated the relationship of interactional justice on organizational citizenship behavior directed toward organization, organizational citizenship behavior directed toward individuals and task performance.

Dirks \& Ferrin (2002) examined the findings and implications of the research on trust in leadership via meta-analysis. Findings indicated that trust in leadership appeared to show a significant relationship with each of the outcomes as indicated by uncorrected correlations. For work behaviors and outcomes, trust correlated with each of the organizational citizenship behaviors: altruism, civic virtue, conscientiousness, courtesy and sportsmanship. Trust in leadership had a relatively small, but significant relationship with job performance. Trust in leadership demonstrated a substantial relationship with attitudinal variables. The strongest relationship came from job satisfaction and 
organizational commitment. Trust in leadership also showed sizable relationships with turnover intention, belief in information provided by the leader and commitment to decisions. Trust related significantly with the correlates of satisfaction with leader and leader-member exchange.

Job performance, altruism and job satisfaction were significantly higher when the referent was direct leader as opposed to organizational leadership. The relationship between trust and organizational commitment was higher when the referent was organizational leadership as opposed to direct leader. Interactional justice and procedural justice were higher with direct leader. Perceived organizational support was higher with organizational leadership. Several attitudinal and behavioral outcomes correlated significantly more with cognitive trust when compared to overall trust: Intent to turnover, organizational commitment and job satisfaction. In contrast, overall trust had a larger relationship with civic virtue and performance. The same seemed true for the quality of exchange between leader and employee. Procedural justice showed a significantly higher relationship with cognitive trust when compared to overall trust.

Choi, Dixon, and Jing (2005) investigated the efficacy of trust in leader, participation and, information controls in curbing dysfunctional behavior among salespeople. The researchers found that information provided about a salesperson's capability was positively mediated through trust in leader to reduce dysfunctional behavior. Salesperson participation was also shown to reduce dysfunctional salesperson behavior when mediated by trust in leader. Trust in leader was also found to have a significant and direct impact on the reduction of dysfunctional salesperson behavior. Theory and Research Based on Mayer, Davis, and Schoorman Model (1995) 
Mayer, Davis, and Schoorman's Model of Trust in Leader (1995) presented three factors that act as antecedents to trust. For a leader to garner trust from his/her subordinates, he/she must become proficient at each of the following: Ability, benevolence, and integrity. Mayer et al. defined each as follows. Ability is that group of skills, competencies, and characteristics that enable a party to have influence within some specific domain. In other words, one has confidence that the leader is able to get the job done effectively. Benevolence is the extent to which a trustee is believed to want to do good to the trustor aside from an egocentric profit motive. This suggests an attachment that the leader has for the subordinate, and the subordinate in return perceives that attachment with positive regard. Integrity is the perception that a leader adheres to a set of principles that the subordinate finds acceptable. In other words, there is congruence between the values of the leader and the values of the subordinate.

Mayer et al. also made reference to what the trustee (the person doing the trusting) brings to the relationship. Subordinates fall along a continuum between low and high propensities to trust. Those with a high propensity to trust, are of course easier to build a trusting relationship with. The opposite holds trust of those with a low propensity to trust. With that in mind, the factors that a leader must possess in order to engender trust among his/her subordinates becomes even more important for those lower on the propensity to trust continuum.

In summary, the model outlined by Mayer et al. (1995) could be broken into three areas. First the researchers give us a strong definition of trust, and that will become the operational definition of trust for this study. Second, the researchers operationalized three factors a leader must have in order to garner trust from subordinates. Finally, the 
researchers highlighted the importance of the subordinate's propensity to trust in the superior/subordinate relationship. A number of studies exist testing this model against other important business variables.

Mayer and Davis (1999) found that a change in the performance appraisal system that influenced greater engagement among leaders and subordinates had a significant effect on trust in top management as well as the factors of trustworthiness. Davis, Schoorman, Mayer and Tan (2000) examined trust and its antecedents with the business metrics of sales and profit as well as employee turnover in the restaurant industry. In both studies the researchers found that trust in the leader predicted both increased sales and increased profit. Davis et al. found that trust in leader resulted in reduced employee turnover as well. More discussion of this study and its effect on turnover will occur later in the section that reviews studies that examine both trust in leader and employee turnover.

Mayer and Gavin (2005) conducted a study investigating the relationship between an employee's trust in leader and in the top management team with both the employee's in-role performance and organizational citizenship behaviors. This study provided empirical support for the assertion that trust in management allows employees to focus on the tasks which need done to add value to the organization. The researchers found that the relationship between trust in leader and the ability to focus was significant, as was the relationship between trust in top management team and ability to focus.

In summary, the studies mentioned provide evidence for the credence of Mayer et al.'s theory of trust in leader. Research indicated that with serious changes to a performance appraisal system, organizations could garner higher levels of trust 
throughout the organization from employees. Research has also shown that the theory helps explain increased sales and profits as well as reduced turnover. Research also indicated that trust in leader and organization leads to greater focus on one's task. With regard to this research, the most relevant finding was the one in which trust in leader was found to have a significant impact on turnover in the restaurant industry. Trust in Leader/Organization, Job Satisfaction, and/or Intent to Leave/Turnover Trust in relation to job satisfaction has been tested a few times. Muchinsky (1977) found that trust in leader was significantly associated with a number of variables and most specifically with forms of job satisfaction including work satisfaction, satisfaction with supervisor, satisfaction with pay and satisfaction with coworkers. Podsakoff, MacKenzie, and Brommer (1996) found that leaders who were supportive, provided an appropriate model, clarified vision, fostered acceptance of group goals and did not have unrealistic expectations had employees with greater job satisfaction. The researchers also found that leaders who provided an appropriate model, were supportive and fostered acceptance of group goals had more trust in their leaders, indicating the way a person leads has a significant effect on job satisfaction and trust in leader.

Butler, Cantrell, \& Flick (1999) examined relationships among transformational leadership behaviors, upward trust, and job satisfaction. Both trust in leader and transformational leader behaviors were powerful predictors of satisfaction with supervisor. With regard to satisfaction with work, all transformational leadership behaviors were significantly associated with trust. Four of the six transformational leadership behaviors were significantly related to satisfaction with work with the exceptions of high expectations and support for team members. Researchers regressed 
trust and the transformational leadership behaviors to satisfaction with job. Only trust exhibited significant relationships with satisfaction with job. Thus team members' trust in leader mediated the relationships between four of six leadership behaviors and team members' satisfaction with their work. All six transformational leadership behaviors moderated the relationship between team members' trust in their leader and satisfaction with their work.

Trust in leader has also been studied in relationship to intent to leave. Connell, Ferres, and Travaglione (2003) found that leaders who engendered trust in their relationships with employees were more likely to demonstrate greater organizational support, higher levels of procedural justice, and higher levels of transformational leadership behavior above and beyond the effects of age, gender, and tenure with organization. The study also demonstrated when employees had higher levels of trust in the direct leader, there was higher affective commitment and higher continuance commitment. Those employees that possessed higher levels of trust in their direct leader also reported decreased intent to leave.

Chawla and Kelloway (2004) examined employees going through a merger. The researchers tested level of communication, openness to change, trust in management, procedural justice, and intent to leave. The researchers found that level of communication, job security and participation predicted trust in management via procedural justice. Openness to change and trust in management both predicted intent to leave.

Trust in leader has been studied in relation to both job satisfaction and intent to leave together. Cunningham and MacGregor (2000) presented results indicating that trust 
in leader accounted for a significant amount of variance in absenteeism, performance, job satisfaction, and intent to leave independent of job design, age, sex, and tenure with organization. Ayree, Budhwar, and Chen (2002) examined the potential mediating effect of trust in organization on the relationship between three types of organizational justice and employee work attitudes and behaviors. The researchers found that trust in organization partially mediated the relationship of procedural and distributive justice on job satisfaction, intent to leave and organizational commitment. Mulki, Jararmill, and Locander (2006) found trust in leader had a direct and significant impact on job satisfaction and intent to leave.

Trust in Leader/Organization, Job Satisfaction, Intent to Leave/Turnover in Context of Healthcare and Nursing

Leadership is just as important in the context of nursing and healthcare as with any other profession or industry. Trust in leader, intent to leave and job satisfaction have been studied a great deal in the nursing industry. A sample of those studies will be examined in this section.

Intent to Leave/Turnover and Nursing

Cox (2001) examined unit moral and interpersonal relations among a group of nurses. Co $\mathrm{x}$ found that unit morale and the quality of interpersonal relations had a significant impact on the intent to leave among nurses. Interestingly the results also indicated a significant, negative relationship between age and intent to leave.

Kleinman (2004) examined perceived leadership behaviors (transformational and transactional leadership) of nurse managers and its association with nurse turnover. 
Kleinman found no relationship between transformational leadership and turnover. Only active management-by-exception related positively to nurse turnover.

Hart (2005) investigated the effects of perceived hospital ethical climate on the intent to leave among a cross section of nurses. Perceived ethical climate of a hospital explained a significant proportion of the variance in positional turnover. That is, the nurse leaves the current unit for another unit or another hospital. Perceived ethical climate of a hospital explained a significant proportion of the variance in professional turnover. In other words, when nurses perceive that the climate of the hospital is unethical he/she is might just leave the entire profession of nursing, not just leave the nursing job for another one.

Job satisfaction and Nursing

Blegan (1993) conducted a meta-analysis concerning the job satisfaction of nurses. Blegan found that job satisfaction for nurses was most strongly associated with stress. The researcher also found that job satisfaction related significantly with organizational commitment.

Bratt, Broome, Kelber, \& Lostocco (2000) explored the influence of nurse attributes, unit characteristics, and elements of the work environment on the job satisfaction of nurses. The researchers found that job stress explained a significant proportion of the variance in job satisfaction. Nursing leadership also explained a significant proportion of the variance in job satisfaction, suggesting that job stress and nursing leadership to be the two most influential variables in the creation of job satisfaction among nurses. 
Aiken, Clarke, Sloane, Scohalski, and Silber (2002) conducted a study to determine the effect of nurse-to-patient ratio on patient mortality. The researchers found that as the nurse-to-patient ratio increased the level of job dissatisfaction increased. The researchers cite that job dissatisfaction for nurses is four times greater for nurses than the average for all U.S. workers. As a result, one in five nurses report the intention to leave their current position in one year. Kontoghiorhes and Bryant (2004) explored employees in the healthcare industry noting that the strongest predictors of job satisfaction were satisfaction to the company itself, extent to which one's job advantageously uses an employee's talent and skill, and the extent to which the organization emphasized doing things right the first time.

\section{Job Satisfaction and Intent to Leave/Turnover Combined}

Mobley, Horner, and Hollingsworth (1978) examined Mobley's model of employee withdrawal among hospital employees. The researchers found that intent to leave was the only significant predictor of actual employee turnover. Job satisfaction affected actual turnover indirectly, but was a significant predictor of other variables in the turnover process.

Price \& Mueller (1981) formulated a model of employee turnover and tested it on registered nurses in seven hospitals. The researchers suggest that four factors determine turnover among nurses: intent to stay, opportunity, general training, and job satisfaction. The researchers found that intent to stay had the greatest impact on actual turnover. Job satisfaction did not have a direct effect on actual turnover, but it did interact with other variables in the turnover process. 
Somer (1996) examined employee turnover among nurses. Somer found that age and tenure with the organization had a negative and significant effect on the likelihood that a nurse would leave the organization. The researcher also found that job satisfaction had a negative and significant effect on intent to leave.

Boyle, Bott, Hansen, Woods, and Taunto (1999) examined the effects of nurse manager characteristics with regard to power and influence as well as leadership style on critical care nurses' intent to stay with their organization. One model explained a significant proportion of the variance in nurses' intent to stay. That model included the variables of nurse manager's position power, manager's influence over work coordination, opportunities for nurses to get other employment, promotional opportunities and job satisfaction. The researchers found that job satisfaction had the largest direct link to intent to stay, and also mediated an indirect relationship of job stress on intent to stay.

In a national survey of nurses(Hart 2001), findings indicated several interesting findings.

1. 70 percent of nurses polled indicated that their facility had major or moderate problems with retention.

2. 50 percent of current nurses considered leaving the profession in the past two years of when the poll was conducted, and do something other than retire.

3. 56 percent of those that left the profession left to find something less stressful and less physically demanding. 
4. 63 percent of current nurses said that the overall situation facing nurses where they work is getting worse. Among potential leavers, that percentage increased to 78 percent. 77 percent of former nurses agreed.

5. 68 percent of current nurses rated morale fair or low, and that increased for potential leavers to 81 percent.

6. 55 percent of potential leavers rated job satisfaction fair to low.

7. 57 percent of potential leavers were not satisfied with management support or respect from management. 74 percent of potential leavers indicated they would stay in the profession longer if conditions at their facility improved.

Ding and Lin (2006) examined the direct effect of job satisfaction on intent to turnover and the indirect effect mediated by organizational commitment among Tiawanese and American hospital employees. The researchers found a significant direct effect between job satisfaction and intent to leave among the Tiawanese employees, but not the American employees. The researchers did find an indirect relationship between job satisfaction and intent to leave mediated by organizational commitment for both, but it was larger for the Taiwanese group. The American group showed larger direct and indirect effect with the relationship between career satisfaction and intent to leave. Trust, Job Satisfaction, and Nursing

Spence-Laschinger \& Finegan (2005) evaluated the effects of employee empowerment on perceptions of organizational justice, respect, and trust in management among nurses. Study results indicate that structural empowerment had a direct effect on trust in management. The researchers also found that structural empowerment had a direct effect on job satisfaction. 
Trust, Job Satisfaction, Intent to Leave, and Nursing

Spence-Laschinger, Finegan, and Shamian (2001) conducted a study of nurses to determine the effect of empowerment and organizational trust on job satisfaction, organizational commitment, and intent to leave. The researchers found that empowerment did not have a direct effect on intent to leave, but was strongly associated with trust in management. Trust in management significantly and negatively affected intent to leave, suggesting that when nurses trust management, there is less of a likelihood of the nurse leaving the organization. Trust in management also had a mediating effect between empowerment and organizational commitment. A model including both empowerment and trust in management explained a significant proportion of the variance in job satisfaction. 


\section{CHAPTER III}

\section{METHODOLOGY}

\section{Introduction}

This study investigated the relationship of trust in leader on job satisfaction as it relates to the Job in General Scale (Ironson et al., 1989). This study also examined the relationship of trust in leader on intent to leave present job. To better understand how the researcher tested this, chapter III presents relevant information illustrating data collection and analysis for this study. Sections covered include: research questions, population and sample, instruments employed, procedures utilized, and data analysis employed to answer each of the research questions.

\section{Research Questions}

Research Question 1: After controlling for the demographic variables of age, gender, and tenure in organization, to what extent does trust in leader relate to job satisfaction?

Research Question 2: After controlling for the demographic variables of age, gender, and tenure in organization, to what extent does trust in leader and job satisfaction relate to intent to leave present job?

Research Question 3: Are the effects of trust in leader on intent to leave present job all direct effects, or are some or all of the effects indirect, through the variable job satisfaction?

Survey Procedure, Population, and Sample 
The survey for this study was conducted online via SurveyMonkey.com.

SurveyMonkey.com provided a link that potential respondents could connect to the survey and take. It was the responsibility of the researcher to instruct respondents in how to access the link. SurveyMonkey.com compiled and saved the data over the eight months of data collection.

The sample for this study came from two healthcare organizations. The first healthcare organization was medium sized organization encompassing three inpatient hospital facilities as well as some small outpatient clinics. All facilities were located around a mid-sized city in southern Indiana. All nurses at each of the hospital facilities had the opportunity to take the survey.

Communication to nurses occurred over five time periods with the first communication initiating contact with the nursing population. The first communication functioned as an announcement of the coming survey, introduction of the researcher and research to the nurses of the healthcare organization, and a request to take the online survey via a link to be provided at a later time. Administration at the healthcare organization sent communication via a variety of channels during the first contact period. Administration began with a global email going out to all employees announcing the upcoming survey. A second email correspondence went to nurse managers as well as council chairs/chair-elects/liaisons also announcing the survey. Paper flyers with the same announcement went to all nursing units and more flyers went on the wall racks where nurses normally look for upcoming continuing education.

Four subsequent waves of communication followed the initial communication with the purpose of survey administration. Hospital administration placed the link to the 
online survey on its web in-service program, which is the program used by the nursing of this organization to take online training and education. Once per week, over four weeks, email announcements to nurse managers and council chairs/chair-elects/liaisons as well as paper flyers to nursing units and wall racks went out requesting participation in the survey and instructions on where to go to take the online survey. One hundred ninety seven nurses out of a possible 978 participated in the study.

The second healthcare organization was comprised of one small community hospital located in southern Indiana. Ninety seven out of a potential of 310 nurses participated. The 310 nurses were comprised of those nurses working for the hospital that had intranet email access. The researcher obtained permission from the Chief Nursing Officer of the hospital to conduct the study. A member of the hospital's staff developed a list serve of all nurses with email.

The administration of the survey came in four waves of email correspondence. The first wave of correspondence was an email introducing the researcher to the nurses to be surveyed, a request for participation, and an announcement of the upcoming survey. The second wave of correspondence resulted in the initial administration of the survey. Nurses receiving the email received a link that led the respondent to the survey online. The third wave of communication reminded respondents about the survey along with the link to the online survey. The final wave of communication was a note thanking the respondents for participation and one final reminder to those that had not take the survey that they still could participate for another week along with the link to the online survey. Measuring Demographic Variables 
Three demographic variables were used in this study: age, gender, and tenure with organization. To measure age, the researcher asked participants to indicate if they are under $21,21-29,30-39,40-49,50-59,60-69$, and over 70. To measure gender, participants indicated whether they are male or female. To measure tenure with organization, participants were asked two questions: "How long have you been in your current position," and "how long have you been with your current organization?"

\section{Measuring Intent to Leave Present Job}

Intent to leave present job was measured by the statement "Indicate whether you have plans to leave your current job in the next two years." This item was answered by asking participants to respond on a continuum that went from $1-10$ with 1 equating to "Definitely DO NOT plan to leave current job" and 10 equating to "Definitely plan to leave current job."

\section{Measuring Job Satisfaction}

The Job in General scales (JIG; Ironson, Smith, Brannick, Gibson, \& Paul, 1989) (Smith, Kendall, \& Hulin, 1969; Balzer, Kihm, Irwin, Bachiochi, Robie, Sinar, \& Parra, 1997) were utilized to measure job satisfaction. JIG is an 18-item scale that measures job satisfaction on a global level (Balzar et al., 1997). Each item was answered using one of three responses: "1" for "yes, it applies," "2" for "no, it does not apply," or "3" for "undecided or unknown." To arrive at an overall score for job satisfaction, the researcher summed the scores of each respondent, which provided a single job satisfaction score. As demonstrated by Balzer et al. (1997), these measures of job satisfaction have been utilized numerous times in job satisfaction research. The instruments have demonstrated considerable evidence of reliability and validity. Internal reliability estimates for JIG is 
$(\alpha=.92, N=1629)$ (Balzer, 1997). Ironson, et al. (1989) also demonstrated strong reliability $(\alpha=.91, \mathrm{~N}=1149)$ and $(\alpha=.91-.95, \mathrm{~N}=3566)$. Ironson et al. demonstrated convergent validity by correlating JIG with four other general job satisfaction scales. Resulting correlation of JIG ranged from .66 to .80 indicating acceptable convergent validity.

Job in General Index

The decision was made to measure only a global score for job satisfaction even though the JIG is often used as an extension of another instrument called the Job Descriptive Index (Smith, Kendall \& Hulin, 1969). The Job Descriptive Index measures five facets of job satisfaction, which include satisfaction with: work, pay, opportunities for promotion, supervision, and coworkers. When investigating job satisfaction, researchers have explored various relationships at both the individual job component (facet) and global levels of satisfaction. Results have been contradictory when reviewing correlations between individual job characteristics and overall job satisfaction. Ferratt (1981) demonstrated that one could not simply sum up the ratings of individual aspects of the job and obtain the overall job satisfaction. His study found that individual job facets account for approximately fifty percent of an employee's overall job satisfaction suggesting that factors other than job specific traits impact satisfaction. Supporting the need to measure overall satisfaction, Nagy (2002) argued that using a single-item approach to measure facet job satisfaction might be easier to use and take less time to complete. The results from Nagy's 2002 study suggested that the single-item approach was highly correlated with the facet components of the Job Descriptive Index ( $r$ ranged from .62 to .70$)$. 
It is not uncommon for researchers to be interested in both individual job components and overall job satisfaction. While several validated instruments exist that one might choose for measuring satisfaction, one of the common measurement instrument for measuring job satisfaction is the Job Descriptive Index (e.g., Balzer et al. 2000; Ferratt, 1981). This instrument measures individual job components including work on the present job, pay, opportunities for promotion, supervision, and people on your present job. The Job Descriptive Index (originally developed in 1969) has demonstrated convergent validity and internal reliability.

In 1989 Ironson, Smith, Brannick, Gibson, and Paul developed the Job in General scale to be utilized in conjunction with the Job Descriptive Index. A number of differences between facets of job satisfaction and overall job satisfaction contributed to the need for an additional measurement tool. For instance, factors exist that impact one's satisfaction with the job that are not covered by the Job Descriptive Index (e.g., employee benefits or the availability of training). Additionally, time plays an important role, whether long-term job considerations or short-term daily activities (Balzer et al. 2000). Consequently, the Job in General scale measures the overall satisfaction with the job. This scale demonstrated both construct and convergent validity and consistently correlates with other global measures of satisfaction. As previously mentioned, even though JIG is often used in conjunction with the Job Descriptive Index, this research will only employ the JIG scale to get a global score.

Measuring Trust in Leader

Trust in leader was measured using dimensions of the Mayer and Davis scale (1999). For the purposes of this study, trust was defined as the willingness to be 
vulnerable to the actions of another party with the expectation that the trustee will perform a particular action important to the trustor (Mayer et al. 1995). One caveat concerns the notion that the trustor cannot or will not possess the ability to monitor or control the trustee. Answers to trust in leader questions (whether the employee trusts the leader) were reported on a 5-point Likert type scale developed by Mayer and Davis (1999). Mayer et al. (1995) developed the theoretical underpinnings for this instrument, which tests three factors of trust: ability, benevolence, and integrity. The instrument also tests overall trust as well, which was the only portion of the survey used. Reliability and validity have been proven in the studies outlined below

The reliability of the ten-item ability scale was found to be 0.93 in the study piloted with the Doctors of Veterinary Medicine (Schoorman et al. 1996). Schoorman et al. (1996) conveyed the trust scale possessed strong internal consistency and reported a reliability coefficient of 0.82 .

Mayer and Garvin (1999) reported reliability coefficients of .0 .81 and 0.72 for trust in plant managers and top management respectively.

\section{Procedure}

Analysis 1: Analysis 1 answered the research question: After controlling for the demographic variables of age, gender, and tenure in organization, to what extent does trust in leader relate to job satisfaction? An ordinary least squares (OLS) hierarchical regression was calculated. The dependent variable was job satisfaction. The demographic variables were entered first, followed by trust in leader. The analysis revealed the proportion of variance in the dependent variable accounted for by each set of predictor variables. 
Analysis 2: An ordinary least squares (OLS) hierarchal regression was calculated. The dependent variable was intent to leave present job. The demographic variables were entered first, followed by trust in leader, and finally job satisfaction. The analysis revealed the proportion of variance in the dependent variable accounted for by each set of predictor variables.

Analysis 3: Multiple regression analysis allowed a mediation analysis, to test if job satisfaction mediates the effect of trust on intent to leave present job or that trust directly affects intent to leave present job without any mediation by job satisfaction.

The table below shows the relationship among the variables for the mediation analysis. 
Table 3

Variables Used in This Study for Meditational Analysis

General Name of Variable

Independent $(\mathrm{X})$

Mediator

Outcome in This Study

Trust

Job satisfaction

Intent to leave present job

Regression was performed with trust as the predictor variable and job satisfaction the dependent variable. A significantly positive regression coefficient would be evidence that trust has a direct positive effect on the mediator job satisfaction.

Hierarchical regression was performed with trust entered as the first predictor variable and intent to leave present job the dependent variable. A significant regression coefficient would be evidence that trust is positively associated with intent to leave present job. This is the total effect of the independent variable (trust) on the outcome variable (intent to leave present job) ignoring the mediator (job satisfaction).

In the second step of the hierarchical regression, the mediator variable job satisfaction was entered into the equation. The resulting regression would have two partial regression coefficients, estimating the effects of: (a) trust on intent to leave present job, controlling for job satisfaction, and (b) job satisfaction on intent to leave present job, controlling for trust.

Mediation analysis 
Procedures described by Berger (2004) were used to perform the mediation analysis. Table 4 shows the regression coefficients that were used for the analysis.

\section{Table 4}

Source of Regression Coefficients for Mediation Analysis

\begin{tabular}{|c|c|c|c|}
\hline $\begin{array}{l}\text { Regression } \\
\text { coefficient }\end{array}$ & Effect of predictor variable on dependent variable & Equation & $\begin{array}{l}\text { Step of } \\
\text { equation }\end{array}$ \\
\hline $\mathrm{a}$ & Trust predicting Job satisfaction & 1 & 1 \\
\hline $\mathrm{c}$ & Trust predicting Intent to leave present job & 2 & 1 \\
\hline$c^{\prime}$ & $\begin{array}{l}\text { Trust predicting Intent to leave job, } \\
\text { controlling for Job satisfaction }\end{array}$ & 2 & 2 \\
\hline b & $\begin{array}{l}\text { Job satisfaction predicting Intent to leave job, } \\
\text { controlling for Trust }\end{array}$ & 2 & 2 \\
\hline
\end{tabular}

Note. Notation for regression coefficients derived from Berger (2004)

If the regression analyses indicate that regression coefficients $a$ and $b$ shown in Table 4 are statistically significant, this would be evidence that mediation has occurred. If only regression coefficient $\mathrm{c}$ is significant, then the effect of trust on intent to leave present job is a direct effect, i.e., the effect of trust is not mediated by job satisfaction. These patterns of results are hypothetical, because the study may reveal no significant effects of any kind.

Research Design

Nurses participating in this study were asked to assess the level of trust they have in their nurse manager, who is a nurse's most immediate supervisor or leader. The level of trust a nurse has in his/her nurse manager (leader) constitutes the independent variable 
for this study. The nurses were also asked to evaluate their own level of job satisfaction as well as level of intent to leave present job in the next one year. Job satisfaction and intent to leave present job constituted the dependent variables in this study. The nurses were also asked their age range, gender, and tenure with current organization. These variables constituted demographic variables that trust in leader were tested against in reference to job satisfaction and intent to leave present job.

\section{Survey Administration}

The seven-step Tailored Designed Method outlined by Dillman (2000) was used in this study. Step one of the Tailor Designed Method requires the identification of experts to review the survey to ensure that the scales possess content validity. Content validity is achieved when the measurement instrument accurately captures the items to be measured (Vogt, 1993). This had already been accomplished by previous researchers, so this step was not performed in this research. Step two requires the completion of a pilot study. This was not necessary since all instruments used in the study had been used in a number of previous studies.

Step three requires the selection of the sample. The sample came from two different nursing populations. The first population came from every nurse who had email access at a small community hospital in southern Indiana (hospital 2). The second population came from every nurse working inside healthcare network of three hospitals in southern Indiana. Every nurse employed inside the network of hospitals was eligible to participate. Step four calls for the mailing of a pre-notification postcard to participants. The pre-notification was sent by email to all nurses with email access at the small community based hospital. The pre-notification was sent by flyer to every nursing unit 
inside the healthcare network. Step five requires the distribution of the survey. Surveys were sent out to the entire nursing population via email with instructions to follow a link to SurveyMonkey.com and complete the survey. This was done for hospital 2. For hospital 1 , instructions were given for nurses to go to hospital computer, find link to survey on the hospital continuing education website, and follow the link to SurveyMonkey.com to complete. Step six calls for the distribution of follow-up survey packets. Follow-up occurred via email for hospital 2. Follow up occurred via flyers distributed to all nursing units for hospital 1. Step seven calls for a final postcard followup. This occurred, again via email for hospital 1 for all nurses who had email access, and final follow up occurred for all nurses via distribution of final flyer to every nursing unit for hospital 1.

Data Analysis

The analysis described in this study was conducted on the full data set from the survey. The information obtained from participants were entered into an SPSS database, which allowed for statistical manipulation. The SPSS database allowed for the development of descriptive statistics and the examination of psychometric properties of the variables as well as the more complex multiple regression necessary to answer the research questions.

Descriptive statistics were used to examine the participants, provide information as to the group of individuals represented, and establish how they relate to each other in terms of demographic and organizational characteristics. Descriptive statistics were calculated in relation to all independent-control and dependent variables. 


\section{CHAPTER IV}

\section{RESULTS}

\section{Introduction}

This chapter presents results of the data analyses that were performed to address the research questions. First, there is an explanation of the participants and the data collection process. Then descriptive statistics are presented on demographic variables and scale variables measured on participants. Finally, separate sections are presented that contain the analyses for the research questions.

\section{Participants and Data Collection}

The original plan was to collect data from a single hospital in Louisville, Kentucky. However, due to policy changes at that hospital, data collection from that institution proved impossible. Consequently, permission was sought to carry out the study from two other hospitals. Permission was obtained and the survey data were collected from the two hospitals from October 5, 2010-November 15, 2010 for hospital 1 and from April 22, 2010 to May 22, 2010 for hospital 2.

For the purpose of this study, the organizations were designated Hospital 1 ( $n=$ $233)$ and Hospital $2(n=97)$. Hospital 1 is located in southern Indiana and provides health care services to people in Indiana, Kentucky and Illinois. At hospital 1 data was collected from three hospitals within the system with well over 500 beds within the system of hospitals. Hospital 2 was a small community-based hospital located in southern Indiana. Hospital 2 offers 241 beds to people in Indiana and Kentucky. 
In terms of response rate, the 233 participants from Hospital 1 constitute a $27 \%$ response percentage. The 97 participants from Hospital 2 constitute a $31 \%$ response percentage.

Data were collected by using the Survey Monkey online survey program. All participants received a survey preamble, in accordance with the plan approved by the University of Louisville Institutional Review Board (IRB) for human subjects research (and the hospital IRBs). Those who wished to participate completed the online survey after reading the preamble. Data were stored in a file for subsequent analysis.

Data collection between the two hospitals differed slightly. Hospital 1 sent a global email to all employees announcing the coming survey and sent a memo to nurse managers and council chairs/chair-elects/liaisons making the same announcement. Paper flyers were also sent to nursing units and were placed on wall racks where nurses normally look for upcoming education. The survey was placed on the hospital's Web Inservice program. Nurses were instructed to go to this site and open the link to the survey. Paper flyers were sent in four waves to each of the nursing units, one per week.

Hospital 2 sent emails to those nurses with email access asking them to participate in the study. Four emails were sent to nurses over a one month period with a link to the survey in the email message. Once respondents opened the email, they could click the link that took them directly to the survey.

Descriptive Statistics on Demographic Variables and Scale Variables

Results were presented that compare and contrast the two hospitals and that show data for the overall sample combining both institutions. Data were shown for both demographic variables and for the three scale variables that are used for the research questions posted in Chapter 3 . 
Table 5 shows results for the variables age, decade degree was earned, and gender. Regarding age, the majority of respondents were in the age range from 21 through 59. Compared with Hospital 1, Hospital 2 had a larger percentage of respondents in the older age range. Data for the variable decade degree was earned is consistent with age. Most respondents received their college degree in the years from 1991 to 2010 with Hospital 2 having a comparatively larger percentage earning their degree in earlier years. The great majority of respondent were female. 
Table 5

Numbers and Percentages of Nurses for Age, Decade Degree was Earned, and Gender

\begin{tabular}{|c|c|c|c|c|c|c|c|}
\hline & & \multicolumn{6}{|c|}{ Hospital } \\
\hline & & \multicolumn{2}{|c|}{1.00} & \multicolumn{2}{|c|}{2.00} & \multicolumn{2}{|c|}{ Total } \\
\hline & & $\mathrm{n}$ & $\%$ & $n$ & $\%$ & $n$ & $\%$ \\
\hline \multirow[t]{7}{*}{ Age } & 70 or + & 0 & $.0 \%$ & 0 & $.0 \%$ & 0 & $.0 \%$ \\
\hline & $60-69$ & 19 & $8.2 \%$ & 8 & $8.5 \%$ & 27 & $8.3 \%$ \\
\hline & $50-59$ & 49 & $21.1 \%$ & 32 & $34.0 \%$ & 81 & $24.8 \%$ \\
\hline & $40-49$ & 54 & $23.3 \%$ & 20 & $21.3 \%$ & 74 & $22.7 \%$ \\
\hline & $30-39$ & 50 & $21.6 \%$ & 20 & $21.3 \%$ & 70 & $21.5 \%$ \\
\hline & $21-29$ & 60 & $25.9 \%$ & 14 & $14.9 \%$ & 74 & $22.7 \%$ \\
\hline & Under 21 & 0 & $.0 \%$ & 0 & $.0 \%$ & 0 & $.0 \%$ \\
\hline
\end{tabular}

\begin{tabular}{|c|c|c|c|c|c|c|c|}
\hline & & \multicolumn{6}{|c|}{ Hospital } \\
\hline & & \multicolumn{2}{|c|}{1.00} & \multicolumn{2}{|c|}{2.00} & \multicolumn{2}{|c|}{ Total } \\
\hline & & $\mathrm{n}$ & $\%$ & $n$ & $\%$ & $n$ & $\%$ \\
\hline \multirow{5}{*}{$\begin{array}{l}\text { Decade that } \\
\text { nursing degree } \\
\text { was earned }\end{array}$} & $2001-2010$ & 114 & $50.2 \%$ & 31 & $32.0 \%$ & 145 & $44.8 \%$ \\
\hline & $1991-2000$ & 46 & $20.3 \%$ & 20 & $20.6 \%$ & 66 & $20.4 \%$ \\
\hline & $1981-1990$ & 39 & $17.2 \%$ & 20 & $20.6 \%$ & 59 & $18.2 \%$ \\
\hline & $1971-1980$ & 23 & $10.1 \%$ & 21 & $21.6 \%$ & 44 & $13.6 \%$ \\
\hline & Before 1971 & 5 & $2.2 \%$ & 5 & $5.2 \%$ & 10 & $3.1 \%$ \\
\hline
\end{tabular}

\begin{tabular}{|c|c|c|c|c|c|c|c|}
\hline & & \multicolumn{4}{|c|}{ Hospital } & & \\
\hline & & \multicolumn{2}{|c|}{1.00} & \multicolumn{2}{|c|}{2.00} & \multicolumn{2}{|c|}{ Total } \\
\hline & & $\mathrm{n}$ & $\%$ & $\mathrm{n}$ & $\%$ & $n$ & $\%$ \\
\hline \multirow[t]{2}{*}{ Gender } & Female & 215 & $95.6 \%$ & 85 & $88.5 \%$ & 300 & $93.5 \%$ \\
\hline & Male & 10 & $4.4 \%$ & 11 & $11.5 \%$ & 21 & $6.5 \%$ \\
\hline
\end{tabular}

Table 6 shows results for the variables ethnic group and education level.

Regarding ethnic group, the great majority of respondents for both hospitals were white.

Compared to hospital 1 , hospital 2 had a greater percentage of respondents with bachelor degrees whereas hospital 1 had a greater number of respondents with associate degrees. 
Table 6

Numbers and Percentages of Nurses for Ethnic Group and Educational Level (Degree)

\begin{tabular}{|c|c|c|c|c|c|c|c|}
\hline & & \multicolumn{6}{|c|}{ Hospital } \\
\hline & & \multicolumn{2}{|c|}{1.00} & \multicolumn{2}{|c|}{2.00} & \multicolumn{2}{|c|}{ Total } \\
\hline & & $\mathrm{n}$ & $\%$ & $\mathrm{n}$ & $\%$ & $\mathrm{n}$ & $\%$ \\
\hline \multirow{7}{*}{$\begin{array}{l}\text { Ethnic } \\
\text { group }\end{array}$} & American Indian & 1 & $.4 \%$ & 0 & $.0 \%$ & 1 & $.3 \%$ \\
\hline & Asian & 4 & $1.7 \%$ & 2 & $2.1 \%$ & 6 & $1.8 \%$ \\
\hline & African-American & 0 & $.0 \%$ & 0 & $.0 \%$ & 0 & $.0 \%$ \\
\hline & Hispanic & 1 & $.4 \%$ & 0 & $.0 \%$ & 1 & $.3 \%$ \\
\hline & Native Hawaiian-Pacific & 1 & $.4 \%$ & 0 & $.0 \%$ & 1 & $.3 \%$ \\
\hline & White & 223 & $95.7 \%$ & 94 & $96.9 \%$ & 317 & $96.1 \%$ \\
\hline & Other & 3 & $1.3 \%$ & 1 & $1.0 \%$ & 4 & $1.2 \%$ \\
\hline
\end{tabular}

\begin{tabular}{|c|c|c|c|c|c|c|c|}
\hline & & \multicolumn{6}{|c|}{ Hospital } \\
\hline & & \multicolumn{2}{|c|}{1.00} & \multicolumn{2}{|c|}{2.00} & \multicolumn{2}{|c|}{ Total } \\
\hline & & $\mathrm{n}$ & $\%$ & $\mathrm{n}$ & $\%$ & $n$ & $\%$ \\
\hline Education & $A A$ & 127 & $61.1 \%$ & 26 & $28.3 \%$ & 153 & $51.0 \%$ \\
\hline level & BS & 74 & $35.6 \%$ & 52 & $56.5 \%$ & 126 & $42.0 \%$ \\
\hline (Degree) & MS & 7 & $3.4 \%$ & 14 & $15.2 \%$ & 21 & $7.0 \%$ \\
\hline
\end{tabular}

Table 7 shows results for the variables years employed in current organization and years employed in current position. Regarding years employed in current organization, the majority of respondents ranged between 1 and 20 plus years with current organization. Compared with Hospital 1, Hospital 2 had a larger percentage of respondents ranging from 10 and 20 plus years whereas the majority of respondents with Hospital 1 ranged between 1-10 years. Regarding years employed in current position, the majority of respondents ranged between less than 1 year and 15 years. The only major difference between the two hospitals with regard to years employed in current position 
would be that the number of respondents with less than 1 year in current position in Hospital 1 was more pronounced than in Hospital 2.

Table 7

Numbers and Percentages of Nurses for Years Employed in Current Organization and Years Employed in Current Position

\begin{tabular}{|c|c|c|c|c|c|c|c|}
\hline & & \multicolumn{6}{|c|}{ Hospital } \\
\hline & & \multicolumn{2}{|c|}{1.00} & \multicolumn{2}{|c|}{2.00} & \multicolumn{2}{|c|}{ Total } \\
\hline & & $\mathrm{n}$ & $\%$ & $\mathrm{n}$ & $\%$ & $\mathrm{n}$ & $\%$ \\
\hline \multirow{7}{*}{$\begin{array}{l}\text { Years employed } \\
\text { in current } \\
\text { organization }\end{array}$} & $>20$ & 24 & $10.3 \%$ & 25 & $26.0 \%$ & 49 & $14.9 \%$ \\
\hline & $15-20$ & 11 & $4.7 \%$ & 17 & $17.7 \%$ & 28 & $8.5 \%$ \\
\hline & $10-15$ & 28 & $12.1 \%$ & 17 & $17.7 \%$ & 45 & $13.7 \%$ \\
\hline & $5-10$ & 44 & $19.0 \%$ & 14 & $14.6 \%$ & 58 & $17.7 \%$ \\
\hline & $3-5$ & 50 & $21.6 \%$ & 9 & $9.4 \%$ & 59 & $18.0 \%$ \\
\hline & $1-3$ & 52 & $22.4 \%$ & 14 & $14.6 \%$ & 66 & $20.1 \%$ \\
\hline & $<1$ & 23 & $9.9 \%$ & 0 & $.0 \%$ & 23 & $7.0 \%$ \\
\hline
\end{tabular}

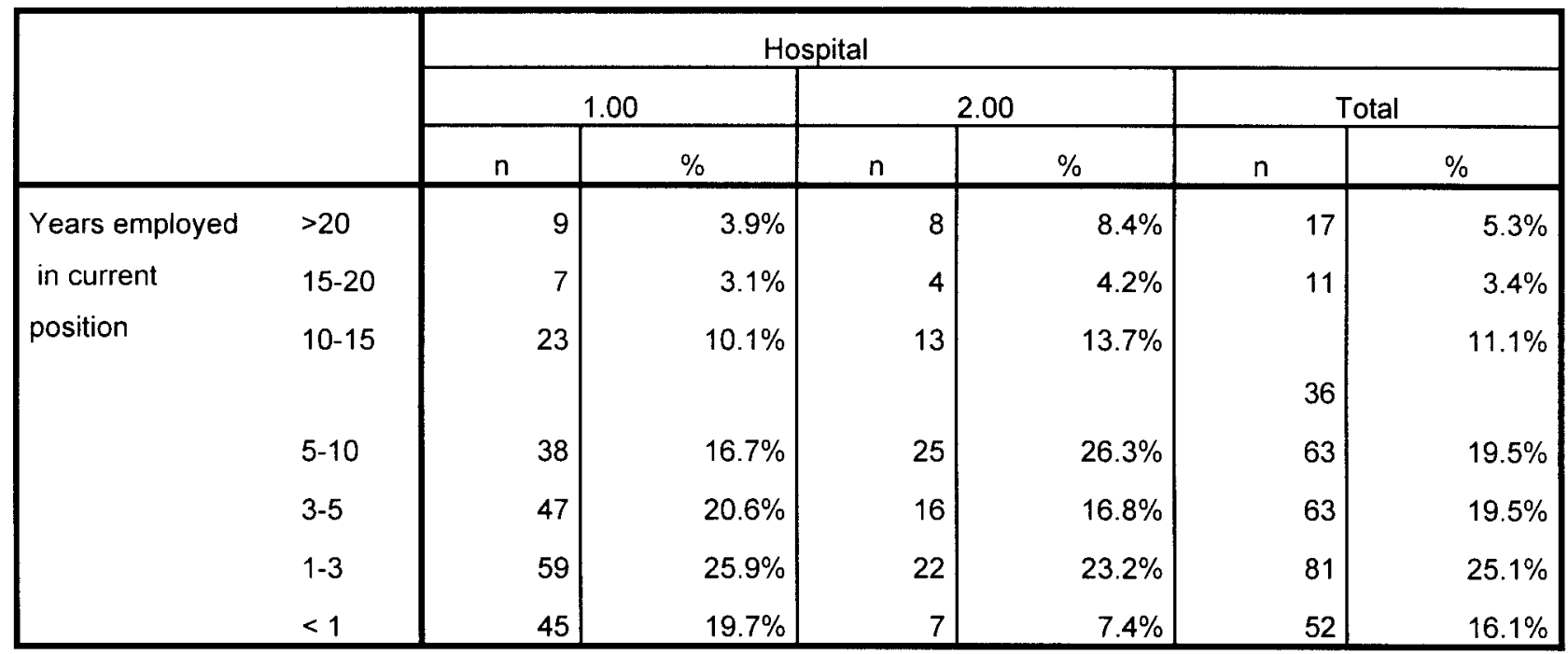

Table 8 shows results for the variable number of years of experience with current nurse manager. The majority of respondents ranged from less than 1 year to 10 years of experience with current nurse manager. Hospital 1 had a much greater percentage of respondents with less than 1 year of experience with current nurse manager than did hospital 2. 


\section{Table 8}

Numbers and Percentages of Nurses for Years of Experience With Current Nurse Manager

\begin{tabular}{|c|c|c|c|c|c|c|c|}
\hline & & \multicolumn{6}{|c|}{ Hospital } \\
\hline & & \multicolumn{2}{|c|}{1.00} & \multicolumn{2}{|c|}{2.00} & \multicolumn{2}{|c|}{ Total } \\
\hline & & $\mathrm{n}$ & $\%$ & $n$ & $\%$ & $\mathrm{n}$ & $\%$ \\
\hline Years of experience & $>20$ & 1 & $.4 \%$ & 3 & $3.2 \%$ & 4 & $1.2 \%$ \\
\hline with current Nurse & $15-20$ & 3 & $1.3 \%$ & 2 & $2.1 \%$ & 5 & $1.5 \%$ \\
\hline \multirow[t]{5}{*}{ Manager } & $10-15$ & 4 & $1.7 \%$ & 10 & $10.5 \%$ & 14 & $4.3 \%$ \\
\hline & $5-10$ & 19 & $8.2 \%$ & 17 & $17.9 \%$ & 36 & $11.0 \%$ \\
\hline & $3-5$ & 42 & $18.2 \%$ & 19 & $20.0 \%$ & 61 & $18.7 \%$ \\
\hline & $1-3$ & 100 & $43.3 \%$ & 36 & $37.9 \%$ & 136 & $41.7 \%$ \\
\hline & $<1$ & 62 & $26.8 \%$ & 8 & $8.4 \%$ & 70 & $21.5 \%$ \\
\hline
\end{tabular}

Table 9 shows descriptive statistics for the variables trust in manager, job satisfaction, and intent to leave by hospital. Compared to Hospital 1, Hospital 2 had a larger mean score for trust in manager and job satisfaction. Hospital 2 had a larger mean score for intent to leave than did Hospital 1. 
Table 9

Descriptive Statistics for Trust in Manager, Job Satisfaction, and Intent to Leave by Hospital

\begin{tabular}{|lc|r|r|r|}
\hline & Hospital & \multicolumn{1}{c|}{ Mean } & Std. Deviation & \multicolumn{1}{|c|}{$\mathrm{N}$} \\
\hline Trust in manager & 1.00 & 3.2764 & .75124 & 213 \\
& 2.00 & 3.8150 & .53022 & 89 \\
& Total & 3.4351 & .73497 & 302 \\
\hline Job satisfaction & 1.00 & 38.4977 & 13.22113 & 213 \\
& 2.00 & 42.8427 & 14.50854 & 89 \\
& Total & 39.7781 & 13.73287 & 302 \\
\hline \multirow{2}{*}{ Intent to Leave } & 1.00 & 2.7919 & 1.20358 & 213 \\
& 2.00 & 1.8464 & .91571 & 89 \\
& Total & 2.5132 & 1.20492 & 302 \\
\hline
\end{tabular}

Statistical Comparisons of Hospitals 1 and 2

Comparisons using independent $t$-tests: Inferential statistical comparisons were made of Hospital 1 and 2 to confirm or disconfirm differences that seemed apparent in the frequency distributions. First, a set of independent $t$-tests were performed. In each of these, the independent variable was hospital (coded 1 or 2 ). The dependent variables were demographic variables that were numerically coded on a continuum from high to low. All of the variables were measurements of time in years. For example, age was coded as follows: $1=$ less than $21,2=21-29,3=30-39,4=40-49,5=50-59,6=60-69$, $7=70$ or greater. The seven numbers for the variable ranged from 1 (youngest in age) to 7 (oldest in age). Similar coding procedures were used for three other time-related variables: years in current organization, years in current position, and years working for nurse manager. For all of these variables, the higher the number, the greater the age or the greater the number of years. 
As can be seen in Table 10, there were significant differences $(\mathrm{p}<.0125)$ between the hospitals. Hospital 2 had higher mean scores than Hospital 1 on average years in current organization, years in current position, and years working for nurse manager. The significance value .0125 was used was to avoid inflation of Type I error for the set of four comparisons. With $p=.0125$, the family-wise error rate was .05 for the set of four comparisons.

Table 10

Comparisons of Hospitals on Four Time-Related Variables Using Independent t-tests

\begin{tabular}{|l|c|c|c|c|}
\hline \multicolumn{1}{|c|}{ Variable } & \multicolumn{2}{c|}{ Hospital Means } & $\begin{array}{l}\text { Obtained } \\
t(\mathrm{df})\end{array}$ & Obtained $p$ \\
\hline & $M_{1}$ & $M_{2}$ & & \\
\hline Age & 3.64 & 4.00 & $2.30(324)$ & $<.03$ \\
\hline Years in current organization & 3.56 & 4.93 & $6.41(326)$ & $<.001^{*}$ \\
\hline Years in current position & 2.96 & 3.62 & $3.34(321)$ & $<.002^{*}$ \\
\hline Years working for nurse manager & 2.20 & 3.03 & $5.07(142)$ & $<.001^{*}$ \\
\hline
\end{tabular}

Note. Bonferonni-corrected statistical significance probability $=.05 / 4=.0125$.

* $p<.0125$

Comparisons using chi-square tests of independence: Several demographic

variables were nominally scaled, or had so few categories as to render independent t-tests inappropriate for comparisons between the hospitals. For these variables,

crosstabulations were performed between the independent variable hospital (coded 1 and

2) and the demographic variable and chi-square tests of independence were calculated.

Table 11 presents the crosstabulations. There was no significant association between hospital and gender, and between hospital and ethnicity. (The variable ethnicity was recoded into White and Not White because the original coding of the variable resulted in very small numbers of individuals who identified themselves as an ethnic category other than White). For the variable education, there was a significant association (using the Bonferroni-corrected significance value of .017). Hospital 2 had a 
higher percentage of nurses with more advanced levels of education (e.g., $56.5 \%$ of Hospital 2 nurses had a BS degree, compared to only $35.6 \%$ of Hospital 1 nurses). 


\section{Table 11}

Comparisons of Hospitals on Three Demographic Variables Using Chi-Square Tests of Independence

\begin{tabular}{|lll|r|r|r|}
\hline & & \multicolumn{2}{|c|}{ Gender } & \multirow{2}{*}{} \\
\cline { 4 - 6 } & & Female & \multicolumn{1}{|c|}{ Male } & \multicolumn{1}{c|}{ Total } \\
\hline Hospital & 1.00 & Count & 215 & 10 & 225 \\
& & $\%$ within Hospital & $95.6 \%$ & $4.4 \%$ & $100.0 \%$ \\
\cline { 2 - 5 } & 2.00 & Count & 85 & 11 & 96 \\
& & $\%$ within Hospital & $88.5 \%$ & $11.5 \%$ & $100.0 \%$ \\
\hline \multirow{2}{*}{ Total } & Count & 300 & 21 & 321 \\
& & $\%$ within Hospital & $93.5 \%$ & $6.5 \%$ & $100.0 \%$ \\
\hline
\end{tabular}

\begin{tabular}{|lll|r|r|r|}
\hline \multirow{2}{*}{} & & \multicolumn{2}{|c|}{ Ethnic Recode } & \multirow{2}{*}{} \\
\cline { 3 - 5 } & & Not White & White & \multicolumn{1}{c|}{ Total } \\
\hline Hospital & 1.00 & Count & 10 & 223 & 233 \\
& & $\%$ within Hospital & $4.3 \%$ & $95.7 \%$ & $100.0 \%$ \\
\cline { 2 - 5 } & 2.00 & Count & 3 & 94 & 97 \\
& \% within Hospital & $3.1 \%$ & $96.9 \%$ & $100.0 \%$ \\
\hline \multirow{2}{*}{ Total } & Count & 13 & 317 & 330 \\
& \% within Hospital & $3.9 \%$ & $96.1 \%$ & $100.0 \%$ \\
\hline
\end{tabular}

\begin{tabular}{|c|c|c|c|c|c|c|}
\hline & & & \multicolumn{3}{|c|}{ Education } & \multirow[b]{2}{*}{ Total } \\
\hline & & & $\mathrm{AA}$ & BS & MS & \\
\hline \multirow[t]{4}{*}{ Hospital } & 1.00 & Count & 127 & 74 & 7 & 208 \\
\hline & & $\%$ within Hospital & $61.1 \%$ & $35.6 \%$ & $3.4 \%$ & $100.0 \%$ \\
\hline & 2.00 & Count & 26 & 52 & 14 & 92 \\
\hline & & $\%$ within Hospital & $28.3 \%$ & $56.5 \%$ & $15.2 \%$ & $100.0 \%$ \\
\hline \multirow[t]{2}{*}{ Total } & & Count & 153 & 126 & 21 & 300 \\
\hline & & $\%$ within Hospital & $51.0 \%$ & $42.0 \%$ & $7.0 \%$ & $100.0 \%$ \\
\hline
\end{tabular}

Note. Bonferonni-corrected statistical significance probability $=.05 / 3=$ .017 .

Obtained chi-square for Education, $\chi 2(2, \mathrm{~N}=300)=32.92, p<.017$. 
Comparisons of the two hospitals revealed that nurses were statistically different on several variables. As a consequence, when the research questions of the study were addressed, data were analyzed for each hospital separately, as well as for the samples combined.

Reliability of Scales Used in the Study

For the three scales used in the study, Cronbach's alpha internal consistency reliability coefficient was computed. Table 12 shows the alpha coefficients. Each of these exceeded the criterion of .70 that is used as the minimum acceptable value for research (Nunnally \& Bernstein, 1994).

\section{Table 12}

Cronbach's Alpha Internal Consistency Reliability Coefficients for Scales Used in the Study

$\underline{\text { Scale }}$

Number of items $\quad$ Cronbach's alpha

$\underline{\text { coefficient }}$

Trust in Nurse Manager

10

.88

Job in General (JIG) ${ }^{\mathrm{a}}$

18

Intent to Leave Job

3

.94

\footnotetext{
${ }^{\mathrm{a}}$ Job in General was the scale used to measure job satisfaction.
}

\section{Statistical Analysis for Research Question 1}

Research question 1 addressed the issue of how much variance in job satisfaction was predicted by demographic variables and trust in nurse manager. For this analysis, hierarchical regression was used. The dependent variable was score on the Job in General scale, a measure of job satisfaction. In the first step of the equation, three 
demographic predictor variables were entered into the regression equation: age, gender, and years of experience in the organization. In the second step of the equation, the score on the Trust in Nurse Manager scale was entered into the equation. One purpose of the analysis was to determine if Trust in Nurse Manager was a significant predictor of job satisfaction, after demographic variables were controlled.

Table 13 summarizes the regression for all cases from both hospitals. The demographic variables entered in step 1 had a significant association with the dependent variable, $F(3,293)=3.89, \mathrm{p}<.01$. The significant predictor among the three demographic variables was gender, $t=3.29, \mathrm{p}<.01$. This significant coefficient meant that females had a higher job satisfaction score than males. The variable trust in manager was entered in step 2 and accounted for significant proportion of variance in job satisfaction, $F$ change $(1,292)=51.95, p<.01$. Trust in nurse manager (controlling for demographic variables) was positively associated with job satisfaction $(\beta=.383)$. All predictors in the final model accounted for about $17 \%$ of the variance in job satisfaction (i.e., adjusted $\mathrm{R}$ squared $=.172$ ). 
Table 13

Regression Coefficients for Demographic Variables and Trust in Nurse Manager Predicting Job Satisfaction: All Cases $(n=297)$

\begin{tabular}{|ll|r|r|r|c|}
\hline & & \multicolumn{2}{|c|}{ Unstandardized Coefficients } & \\
\cline { 2 - 5 } & \multicolumn{1}{|c|}{$\mathrm{B}$} & Std. Error & \multicolumn{1}{c|}{ Beta } & $\mathrm{t}$ \\
\hline Step 1 & (Constant) & 53.645 & 4.431 & & 12.108 \\
& Age & -.830 & .760 & -.076 & -1.092 \\
& Gender & 10.931 & 3.324 & .189 & $3.289^{* *}$ \\
& Years in Current Org. & .165 & .516 & .022 & .319 \\
\hline \multirow{2}{*}{ Step 2 } & (Constant) & 28.117 & 5.410 & & 5.198 \\
& Age & -.752 & .702 & -.069 & -1.071 \\
& Gender & 9.478 & 3.075 & .164 & $3.083^{* *}$ \\
& Years in Current Org. & -.020 & .477 & -.003 & -.042 \\
& Trust in Nurse Manager & 7.149 & .992 & .383 & $7.208^{* *}$ \\
\hline
\end{tabular}

Note. At step 1, $\mathrm{R}^{2}=038, p<.01$. At step $2, \mathrm{R}^{2}=.184, p<.001$ (adjusted $\mathrm{R}^{2}=.172$ ).

Table 14 summarizes the regression for each hospital separately. The same procedures were used as for the previously reported regression: first demographic variables were entered and then trust in manager. Standardized partial regression coefficients (beta coefficients) are shown in the table.

Hospital 1 The demographic variables entered in step 1 did not have a significant association with the dependent variable, $F(3,206)=2.55, p>.05$. However, examination of the individual beta coefficients revealed that gender was significant, $t=$ $2.47, \mathrm{p}<.05$. Females had a higher job satisfaction score than males. The variable trust in nurse manager was entered in step 2 and accounted for a significant proportion of variance in job satisfaction, $F$ change $(1,205)=47.84, p<.01$. Trust in nurse manager (controlling for demographic variables) was positively associated with job satisfaction ( $\beta$ 
$=.433$ ). All predictors in the final model accounted for about $20 \%$ of the variance in job satisfaction (i.e., adjusted R squared $=.203$ ).

Hospital 2 The demographic variables entered in step 1 did not have a significant association with the dependent variable, $F(3,83)=2.45, p>.05$. However, examination of the individual beta coefficients revealed that gender was significant, $t=$ $2.60, \mathrm{p}<.05$. Females had a higher job satisfaction score than males. The variable trust in nurse manager was entered in step 2 and did not account for a significant proportion of variance in job satisfaction, $F$ change $(1,82)=1.46, p>.05$. All predictors in the final model accounted for about $5 \%$ of the variance in job satisfaction (i.e., adjusted $\mathrm{R}$ squared $=.053)$.

Summary of Research Question 1

All predictors accounted for 17 percent of the variance in job satisfaction, which is a reasonably large effect size. For all participants and for Hospital 1, trust in the nurse manager was positively associated with job satisfaction. This finding was obtained after controlling for age, gender, and number of years working for the organization. For all participants and for each of the hospitals, gender was associated with job satisfaction. Males consistently had a lower JIG general score (job satisfaction measure) that females. 
Table 14

Regression Coefficients for Demographic Variables and Trust in Nurse Manager Predicting Job Satisfaction: Hospital $1(n=210)$ and Hospital $2(n=87)$

\begin{tabular}{|c|c|c|c|c|c|}
\hline \multirow{2}{*}{ Mode } & & \multicolumn{2}{|c|}{ Hospital 1} & \multicolumn{2}{|c|}{ Hospital 2} \\
\hline & & Beta & $t$ & Beta & $t$ \\
\hline \multirow[t]{4}{*}{1} & (Constant) & & 9.427 & & 7.658 \\
\hline & Age & -.045 & -.563 & -.103 & -.722 \\
\hline & Gender & .169 & $2.467^{\star}$ & .275 & $2.596^{\star}$ \\
\hline & Years in Current Org & -.061 & -.767 & .009 & .065 \\
\hline \multirow[t]{5}{*}{2} & (Constant) & & 3.439 & & 3.601 \\
\hline & Age & -.029 & -.402 & -.132 & -.915 \\
\hline & Gender & .117 & 1.877 & .260 & $2.454^{*}$ \\
\hline & Years in Current Org & -.019 & -.266 & .011 & .075 \\
\hline & Trust mean & .433 & $6.917^{\star \star}$ & .131 & 1.207 \\
\hline \multirow{3}{*}{\multicolumn{2}{|c|}{$\begin{array}{l}\text { R squared for Model } 2 \\
\text { Adjusted } \\
\text { R squared for Model } 2\end{array}$}} & .218 & & .097 & \\
\hline & & & & & \\
\hline & & 203 & & .053 & \\
\hline
\end{tabular}

${ }^{*} \mathrm{p}<.05,{ }^{* *} \mathrm{p}<.01$

\section{Statistical Analysis for Research Question 2}

Research question 2 addressed the issue of how much variance in the variable intent to leave present job was predicted by demographic variables, trust in nurse manager, and job satisfaction. Hierarchical regression was used. The dependent variable was the score on the intent to leave scale. In the first step of the equation, three demographic predictor variables were entered into the regression equation: age, gender, and years of experience in the organization. In the second step, the score on the Trust in Nurse Manager scale was entered into the equation. In the third step was entered the score on the Job in General scale, a measure of job satisfaction. A purpose of the 
analysis was to determine if trust in nurse manager and job satisfaction were significant predictors of intent to leave the job, after demographic variables were controlled.

Table 15 summarizes the regression for all cases from both hospitals. The demographic variables entered in step 1 had a significant association with the dependent variable, $F(3,285)=4.20, \mathrm{p}<.01$. The significant predictor among the three demographic variables was years in the organization, $t=-2.99, p<.01$. This significant negative coefficient meant that the fewer years working for the organization, the higher the score on the intent to leave scale. The variable trust in manager was entered in step 2 and accounted for significant proportion of variance in intent to leave, $F$ change $(1,284)$ $=124.86, p<.01$. Trust in nurse manager (controlling for demographic variables) was negatively associated with intent to leave $(\beta=-.543)$, meaning the lower the trust in nurse manager score the greater the score on intent to leave. Finally, the variable job satisfaction was entered in step 3 and accounted for a significant proportion of variance in intent to leave present job, $F$ change $(1,283)=32.16, p<.01$. Job satisfaction (controlling for demographic variables and trust in manager) was negatively associated with intent to leave present job $(\beta=-.290)$, meaning the lower the job satisfaction the greater the score on intent to leave present job. All predictors in the final model accounted for about $39 \%$ of the variance in intent to leave the job (i.e., adjusted $R$ squared $=.392$ ) 
Table 15

Regression Coefficients for Demographic Variables, Trust in Nurse Manager, and Job Satisfaction Predicting Intent to Leave Job: All Cases $(n=289)$

\begin{tabular}{|c|c|c|c|c|c|}
\hline \multirow[b]{2}{*}{ Mod } & & \multicolumn{2}{|c|}{$\begin{array}{c}\text { Unstandardized } \\
\text { Coefficients }\end{array}$} & \multirow[b]{2}{*}{ Beta } & \multirow[b]{2}{*}{$t$} \\
\hline & & B & Std. Error & & \\
\hline \multirow[t]{4}{*}{1} & (Constant) & 3.150 & .340 & & 9.265 \\
\hline & Age & .014 & .067 & .015 & .207 \\
\hline & Gender & -.167 & .289 & -.033 & -.576 \\
\hline & Years in Current Org. & -.137 & .046 & -.211 & $-2.988^{* \star}$ \\
\hline \multirow[t]{5}{*}{2} & (Constant) & 5.951 & .379 & & 15.714 \\
\hline & Age & -.001 & .056 & -.001 & -.012 \\
\hline & Gender & .019 & .242 & .004 & .080 \\
\hline & Years in Current Org. & -.110 & .038 & -.170 & $-2.872^{\star *}$ \\
\hline & Trust in Nurse Manager & -.885 & .079 & -.543 & $-11.174^{\star *}$ \\
\hline \multirow[t]{6}{*}{3} & (Constant) & 6.176 & .362 & & 17.075 \\
\hline & Age & -.020 & .054 & -.021 & -.378 \\
\hline & Gender & .267 & 234 & .054 & 1.140 \\
\hline & Years in Current Org. & -.108 & .036 & -.167 & $-2.979^{\star \star}$ \\
\hline & Trust in Nurse Manager & -.702 & .082 & -.431 & $-8.585^{\star \star}$ \\
\hline & Job satisfaction & -.025 & .004 & -.290 & $-5.671^{\star \star}$ \\
\hline
\end{tabular}

** $p<.01$

Note. At step $1, \mathrm{R}^{2}=.042, p<.01$. At step $2, \mathrm{R}^{2}=.335, p<.001$. At step $3, \mathrm{R}^{2}=$ .403 ,

$p<.001$. (Adjusted $\mathrm{R}^{2}=.392$ ).

Table 16 summarizes the regression for each hospital separately. The same procedures were used as for the previously reported regression: first demographic variables were entered, then trust in nurse manager, then job satisfaction. Standardized partial regression coefficients (beta coefficients) are shown in the table. 
Hospital 1 The demographic variables entered in step 1 did not have a significant association with the dependent variable, $\mathrm{F}(3,200)=1.43, p>.05$. The variable trust in nurse manager was entered in step 2 and accounted for a significant proportion of variance in intent to leave present job, $F$ change $(1,199)=84.89, p<.01$. Trust in nurse manager (controlling for demographic variables) was inversely related with intent to leave $(\beta=-.549)$. This meant that the lower the trust, the higher was the intent to leave. At step 3, the variable job satisfaction was entered and accounted for a significant increment in variance, $F$ change $(1,198)=28.15, p<.01$. Job satisfaction (controlling for demographic variables and trust in nurse manager) was inversely related with intent to leave $(\beta=-.331)$. This meant that the lower the job satisfaction, the higher was the intent to leave. All predictors in the final model accounted for about $38 \%$ of the variance in job satisfaction (i.e., adjusted $\mathrm{R}$ squared $=.384$ ).

Hospital 2 The demographic variables entered in step 1 did not have a significant association with the dependent variable, $\mathrm{F}(3,81)=1.78, p>.05$. The variable trust in nurse manager was entered in step 2 and accounted for a significant proportion of variance in intent to leave present job, $F$ change $(1,80)=5.42, p<.05$. Trust in manager (controlling for demographic variables) was inversely related with intent to leave ( $\beta=$ .251). This meant that the lower the trust, the higher was the intent to leave. At step 3 , the variable job satisfaction was entered and accounted for a significant increment in variance, $F$ change $(1,79)=4.25, p<.05$. Job satisfaction (controlling for demographic variables and trust in nurse manager) was inversely related with intent to leave present job $(\beta=-.224)$. This meant that the lower the lower was the job satisfaction, the higher 
was the intent to leave. All predictors in the final model accounted for about $11 \%$ of the variance in job satisfaction (i.e., adjusted $\mathrm{R}$ squared $=.113$ ).

Summary of Research Question 2

All predictors accounted for 39 percent of the variance in intent to leave present job, which is a very large effect size. For all participants and for Hospital 1, these three variables were inversely related to intent to leave the job: years in current organization, trust in nurse manager, and job satisfaction. This meant that the fewer the years that a person worked with the organization and lower his or her trust in nurse manager and job satisfaction, the higher was the score on intent to leave. This finding was obtained after controlling for age and gender. For participants in Hospital 2, results were the same, but with one exception. Years in current organization was not a significant predictor. 
Table 16

Regression Coefficients for Demographic Variables, Trust in Nurse Manager, and Job Satisfaction Predicting Intent to Leave Job: Hospital $1(n=210)$ and Hospital $2(n=$ 87)

\begin{tabular}{|c|c|c|c|c|c|}
\hline & & \multicolumn{2}{|c|}{ Hospital 1} & \multicolumn{2}{|c|}{ Hospital 2} \\
\hline \multicolumn{2}{|c|}{ Model } & Beta & $t$ & Beta & $t$ \\
\hline \multirow[t]{4}{*}{1} & (Constant) & & 7.917 & & 5.881 \\
\hline & Age & .027 & .321 & -.183 & -1.252 \\
\hline & Gender & -.127 & -1.803 & .022 & .204 \\
\hline & Years in Current Org. & -.083 & -1.002 & -.086 & -.587 \\
\hline \multirow[t]{6}{*}{2} & (Constant) & & 13.081 & & 5.329 \\
\hline & Age & .003 & .040 & -.130 & -.903 \\
\hline & Gender & -.059 & -.989 & .050 & .469 \\
\hline & Years in Current Org. & -.130 & -1.880 & -.087 & -.606 \\
\hline & Trust in Nurse & -.549 & $-9.214^{\star \star}$ & -.251 & $-2.328^{*}$ \\
\hline & Manager & & & & \\
\hline \multirow[t]{7}{*}{3} & (Constant) & & 14.408 & & 5.749 \\
\hline & Age & -.011 & -.162 & -.152 & -1.072 \\
\hline & Gender & -.018 & -.322 & .113 & 1.039 \\
\hline & Years in Current Org. & -.133 & $-2.036^{*}$ & -.090 & -.640 \\
\hline & Trust in Nurse & -.406 & $-6.552^{\star \star}$ & -.220 & $-2.061^{\star}$ \\
\hline & Manager & & & & \\
\hline & Job Satisfaction & -.331 & $-5.306^{\star \star}$ & -.224 & $-2.063^{*}$ \\
\hline & R squared for Model 3 & .399 & & .166 & \\
\hline & Adjusted & & & & \\
\hline & R squared for Model 3 & .384 & & .113 & \\
\hline
\end{tabular}

${ }^{*} \mathrm{p}<.05, * * \mathrm{p}<.01$ 
Statistical Analysis for Research Question 3

Research question 3 addressed the issue of mediation. Specifically, the question was addressed of whether job satisfaction mediated the influence of trust in nurse manager on intent to leave present job, or if the influence of trust in nurse in manager was primarily direct. Two multiple regression analyses were used for this research question, following procedures outlined by Berger (2004). Equation 1 had the predictor variable trust in nurse manger predicting job satisfaction. Equation 2 had two predictor variables: trust in nurse manger and job satisfaction. The dependent variable was score on the intent to leave scale. In the first step of the equation the score on the trust in nurse manager scale was entered into the equation. In the second step the score on the Job in General scale (a measure of job satisfaction) was entered. Thus, in the second step of the equation the dependent variable intent to leave had two predictor variables: trust in nurse manger and job satisfaction.

Analysis for all cases in both hospitals The regression equations for research question 3 (all participants) is summarized in Tables 17 and 18. As can be seen in Table 17, all regression coefficients for all predictors were statistically significant $(\mathrm{p}<.01)$. Table 18 shows the standardized partial regression coefficients (betas) from the two equations that can be used for the mediation analysis. Figure 2 shows the mediation model in graphic form. The beta coefficients from Table 18 are inserted into the model.

Trust in nurse manager was related to intent to leave in two ways: (a) a significant direct effect $(\beta=-.556)$, and (b) an indirect effect through the mediation of job satisfaction $(\beta=.383$ and $\beta=-.267)$. The effect of trust in nurse manager on intent to 
leave job controlling for job satisfaction is $\beta=-.452$. This is larger than the effect of job satisfaction controlling for trust in nurse manager, $\beta=-.267$.

While job satisfaction predicts intent to leave and is a mediating variable, trust in nurse manager is a stronger predictor of intent to leave than job satisfaction.

Table 17

Regression Summaries for Mediation Analysis: All Cases ( $N=302)$

\begin{tabular}{|c|c|c|c|c|c|}
\hline \multirow{2}{*}{$\begin{array}{l}\text { Equation } 1 \\
\text { Dependent variable: Job satisfaction }\end{array}$} & \multicolumn{2}{|c|}{$\begin{array}{c}\text { Unstandardized } \\
\text { Coefficients }\end{array}$} & \multirow{2}{*}{$\begin{array}{l}\text { Standardized } \\
\text { Coefficients } \\
\text { Beta }\end{array}$} & \multirow[b]{2}{*}{$t$} & \multirow[b]{2}{*}{ Sig. } \\
\hline & $\mathrm{B}$ & Std. Error & & & \\
\hline (Constant) & 14.759 & 3.479 & & 4.243 & .000 \\
\hline Trust in nurse manager & 7.225 & .992 & .383 & 7.287 & .000 \\
\hline
\end{tabular}

\begin{tabular}{|c|c|c|c|c|c|}
\hline \multirow{2}{*}{$\begin{array}{l}\text { Equation } 2 \\
\text { Dependent variable: Intent to leave }\end{array}$} & \multicolumn{2}{|c|}{$\begin{array}{c}\text { Unstandardized } \\
\text { Coefficients }\end{array}$} & \multirow{2}{*}{$\begin{array}{c}\text { Standardized } \\
\text { Coefficients } \\
\text { Beta }\end{array}$} & \multirow[b]{2}{*}{$t$} & \multirow[b]{2}{*}{ Sig. } \\
\hline & $\mathrm{B}$ & Std. Error & & & \\
\hline Step 1 (Constant) & 5.642 & .276 & & 20.407 & .000 \\
\hline Trust in nurse manager & -.911 & .079 & -.556 & -11.572 & .000 \\
\hline Step 2 (Constant) & 5.988 & .272 & & 21.988 & .000 \\
\hline Trust in nurse manager & -.740 & .082 & -.452 & -9.057 & .000 \\
\hline Job satisfaction & -.023 & .004 & -.267 & -5.352 & .000 \\
\hline
\end{tabular}


Table 18

Regression Coefficients (Beta) Used to Test Mediation: All Cases $(N=302)$

Regression coefficient

\section{Effect of predictor variable on dependent variable}

Step of

Equation equation

$.383 \quad \mathrm{a}$

$-.556 \quad c$

$-.452 \quad c^{\prime}$

$-.267 \quad b$

Trust predicting Job satisfaction

1

Trust predicting Intent to leave job

2

Trust predicting Intent to leave job,

$2 \quad 2$
controlling for Job satisfaction

1

1

2

Job satisfaction predicting Intent to leave job, controlling for Trust

2




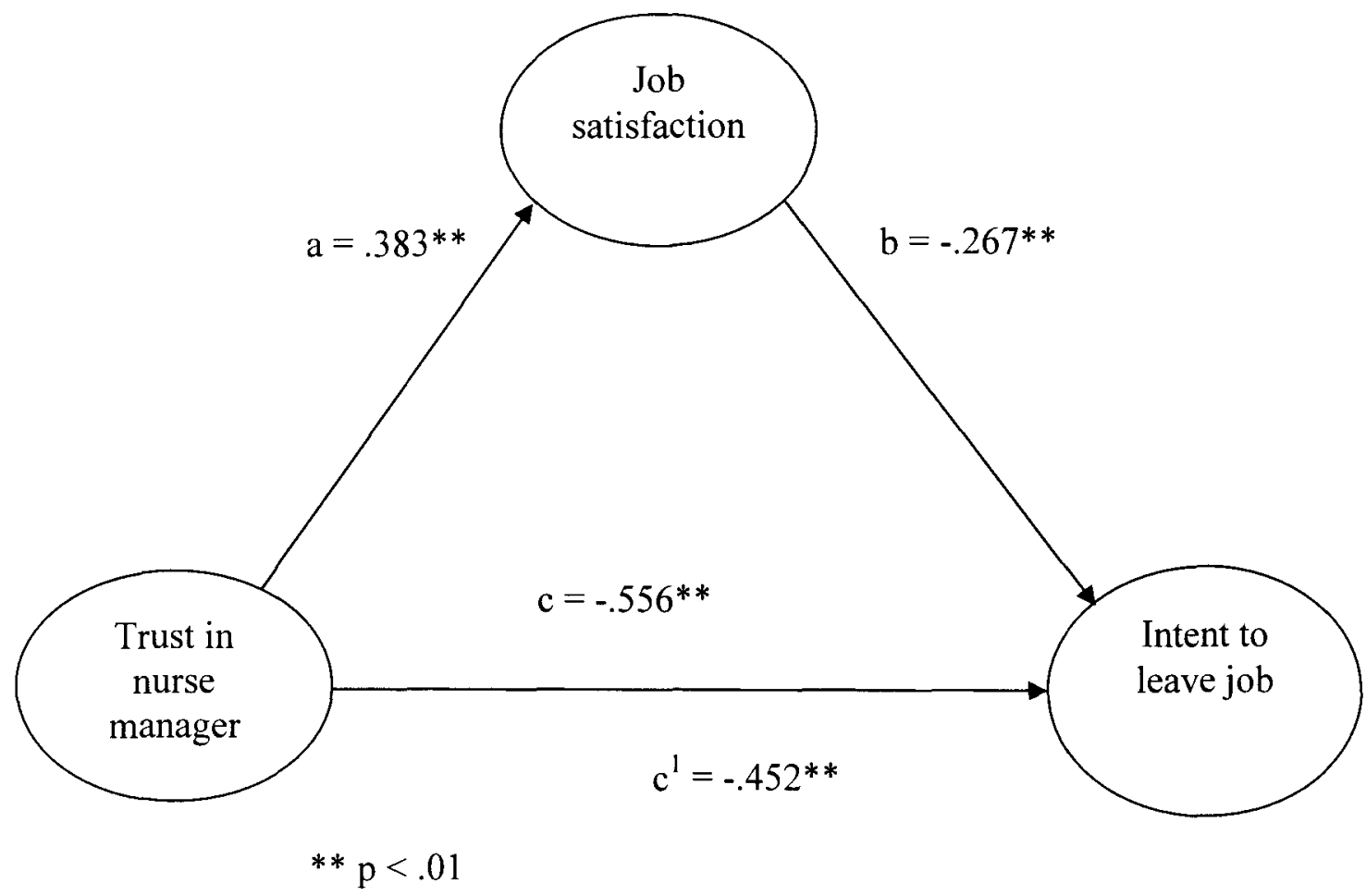

Figure 2. Mediation Model for Intent to Leave Predicted by Trust in Nurse

Manager and

Job Satisfaction (All Cases). 
Analysis for Hospital 1 The regression equations for research question 3 (Hospital 1) are summarized in Tables 19 and 20. As can be seen in Table 19, all regression coefficients for all predictors were statistically significant $(\mathrm{p}<.01)$. Table 20 shows the standardized partial regression coefficients (betas) from the two equations that can be used for the mediation analysis. Figure 3 shows the mediation model with beta coefficients added.

The data are similar to the previous analysis with all cases. Trust in nurse manager had: (a) a significant direct effect $(\beta=-.556)$, and (b) an indirect effect through the mediation of job satisfaction $(\beta=.383$ and $\beta=-.267)$. The effect of trust in nurse manager on intent to leave job controlling for job satisfaction was $\beta=-.452$. This is larger than the effect of job satisfaction controlling for trust in nurse manager, $\beta=-.267$. As with the previous analysis with all cases, trust in nurse manager was a stronger predictor of intent to leave that was job satisfaction.

\section{Table 19}

Regression Summaries for Mediation Analysis: Hospital $1(N=213)$

\begin{tabular}{|c|c|c|c|c|c|}
\hline \multirow{2}{*}{$\begin{array}{l}\text { Equation } 1 \\
\text { Dependent variable: Job satisfaction }\end{array}$} & \multicolumn{2}{|c|}{$\begin{array}{c}\text { Unstandardized } \\
\text { Coefficients }\end{array}$} & \multirow{2}{*}{$\begin{array}{c}\text { Standardized } \\
\text { Coefficients } \\
\text { Beta }\end{array}$} & \multirow[b]{2}{*}{$t$} & \multirow[b]{2}{*}{ Sig. } \\
\hline & $\mathrm{B}$ & Std. Error & & & \\
\hline (Constant) & 11.967 & 3.605 & & 3.320 & .001 \\
\hline Trust in nurse manager & 8.074 & 1.074 & .454 & 7.515 & .000 \\
\hline
\end{tabular}

\begin{tabular}{|c|c|c|c|c|c|}
\hline \multirow{2}{*}{$\begin{array}{l}\text { Equation } 2 \\
\text { Dependent variable: Intent to leave }\end{array}$} & \multicolumn{2}{|c|}{$\begin{array}{c}\text { Unstandardized } \\
\text { Coefficients }\end{array}$} & \multirow{2}{*}{$\begin{array}{c}\text { Standardized } \\
\text { Coefficients } \\
\text { Beta }\end{array}$} & \multirow[b]{2}{*}{$t$} & \multirow[b]{2}{*}{ Sig. } \\
\hline & $\mathrm{B}$ & Std. Error & & & \\
\hline Step 1 (Constant) & 5.636 & .312 & & 18.090 & .000 \\
\hline Trust in nurse manager & -.868 & .093 & -.542 & -9.365 & .000 \\
\hline Step 2 (Constant) & 6.019 & .299 & & 20.116 & .000 \\
\hline Trust in nurse manager & -.621 & .097 & -.388 & -6.393 & .000 \\
\hline Job satisfaction & -.031 & .006 & -.340 & -5.601 & .000 \\
\hline
\end{tabular}


Table 20

Regression Coefficients (Beta) Used to Test Mediation: Hospital $1(N=213)$

Regression

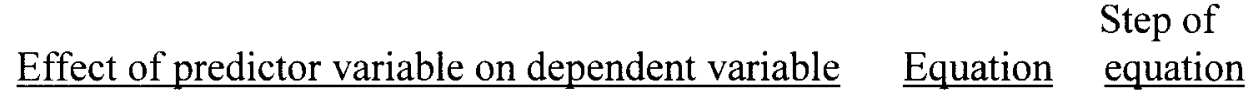

coefficient

Trust predicting Job satisfaction

1

$-.542 \mathrm{c} \quad$ Trust predicting Intent to leave job

2

1

-.388 c' Trust predicting Intent to leave job,

$2 \quad 2$

$-.340 \mathrm{~b} \quad$ Job satisfaction predicting Intent to leave job,

2

2 controlling for Trust 


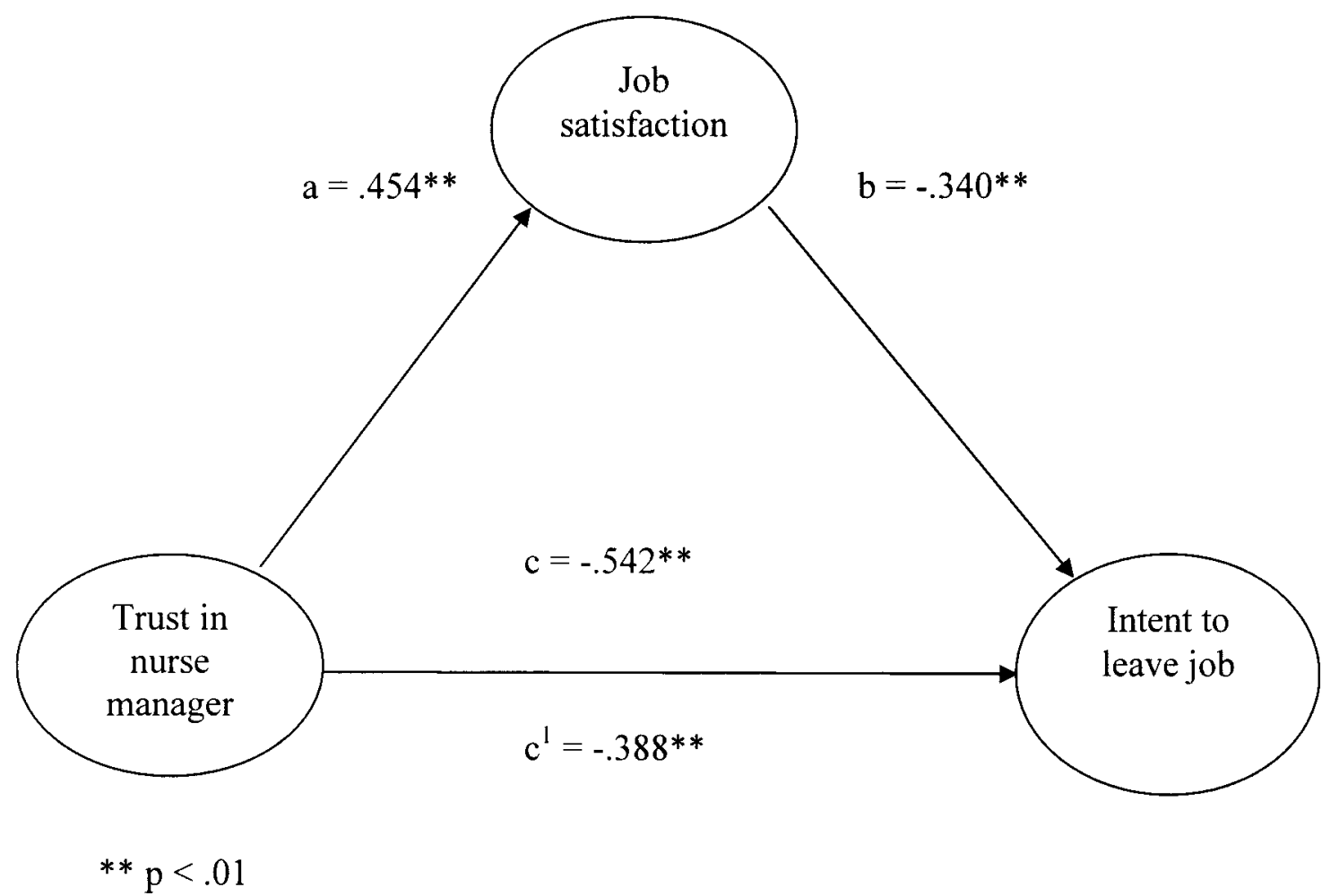

Figure 3. Mediation Model for Intent to Leave Predicted by Trust in Nurse

Manager and

Job Satisfaction (Hospital 1). 
Analysis for Hospital 2 The regression equations for research question 3

(Hospital 2) are summarized in Tables 21 and 22. As shown in Table 21, there were two significant relationships $(p<.05)$ : (a) the effect of trust in nurse manager on intent to leave, and (b) the effect of trust in nurse manager on intent to leave, controlling for job satisfaction. Table 22 shows the standardized partial regression coefficients (betas) from the two equations that can be used for the mediation analysis. Figure 4 shows the mediation model with beta coefficients added.

Contrary to the previous analyses, there was no significant mediation, because the link from trust in nurse manager to job satisfaction $(\beta=.109)$ was not statistically significant. However, trust in nurse manager had a significant direct effect $(\beta=-.287)$ on intent to leave. Furthermore, the relationship between trust in nurse manager and intent to leave was present when job satisfaction was controlled $(\beta=-.269)$.

Table 21

Regression Summaries for Mediation Analysis: Hospital $2(N=89)$

\begin{tabular}{|l|r|r|r|r|r|}
\hline \multirow{2}{*}{$\begin{array}{l}\text { Equation 1 } \\
\text { Dependent variable: Job satisfaction }\end{array}$} & \multicolumn{2}{|c|}{$\begin{array}{c}\text { Unstandardized } \\
\text { Coefficients }\end{array}$} & $\begin{array}{r}\text { Standardized } \\
\text { Coefficients }\end{array}$ & & \\
\cline { 2 - 6 } & \multicolumn{1}{|c|}{$\mathrm{B}$} & Std. Error & Beta & $\mathrm{t}$ & Sig. \\
\hline (Constant) & 30.849 & 11.287 & & 2.733 & .008 \\
Trust in nurse manager & 3.018 & 2.931 & .109 & 1.030 & .306 \\
\hline
\end{tabular}

\begin{tabular}{|c|c|c|c|c|c|}
\hline \multirow{2}{*}{$\begin{array}{l}\text { Equation } 2 \\
\text { Dependent variable: Intent to leave }\end{array}$} & \multicolumn{2}{|c|}{$\begin{array}{c}\text { Unstandardized } \\
\text { Coefficients } \\
\end{array}$} & \multirow{2}{*}{$\begin{array}{c}\text { Standardized } \\
\text { Coefficients } \\
\text { Beta }\end{array}$} & \multirow[b]{2}{*}{$\mathrm{t}$} & \multirow[b]{2}{*}{ Sig. } \\
\hline & $\mathrm{B}$ & Std. Error & & & \\
\hline Step $1 \quad$ (Constant) & 3.735 & .683 & & 5.467 & .000 \\
\hline Trust in nurse manager & -.495 & .177 & -.287 & -2.791 & .006 \\
\hline Step 2 (Constant) & 4.012 & .707 & & 5.673 & .000 \\
\hline Trust in nurse manager & -.465 & .178 & -.269 & -2.616 & .011 \\
\hline Job satisfaction & & .006 & & -1.410 & .162 \\
\hline
\end{tabular}


Table 22

Regression Coefficients (Beta) Used to Test Mediation: Hospital $2(N=89)$

Regression coefficient

$.109 \quad \mathrm{a}$

$-.287 \mathrm{c}$

$-.269 \mathrm{c}^{\prime}$

$-.145 \quad b$

\section{Effect of predictor variable on dependent variable}

Trust predicting Job satisfaction

Trust predicting Intent to leave job

Trust predicting Intent to leave job, controlling for Job satisfaction

Job satisfaction predicting Intent to leave job, controlling for Trust
Step of

Equation equation

$1 \quad 1$

$2 \quad 1$

$2 \quad 2$

2

2 


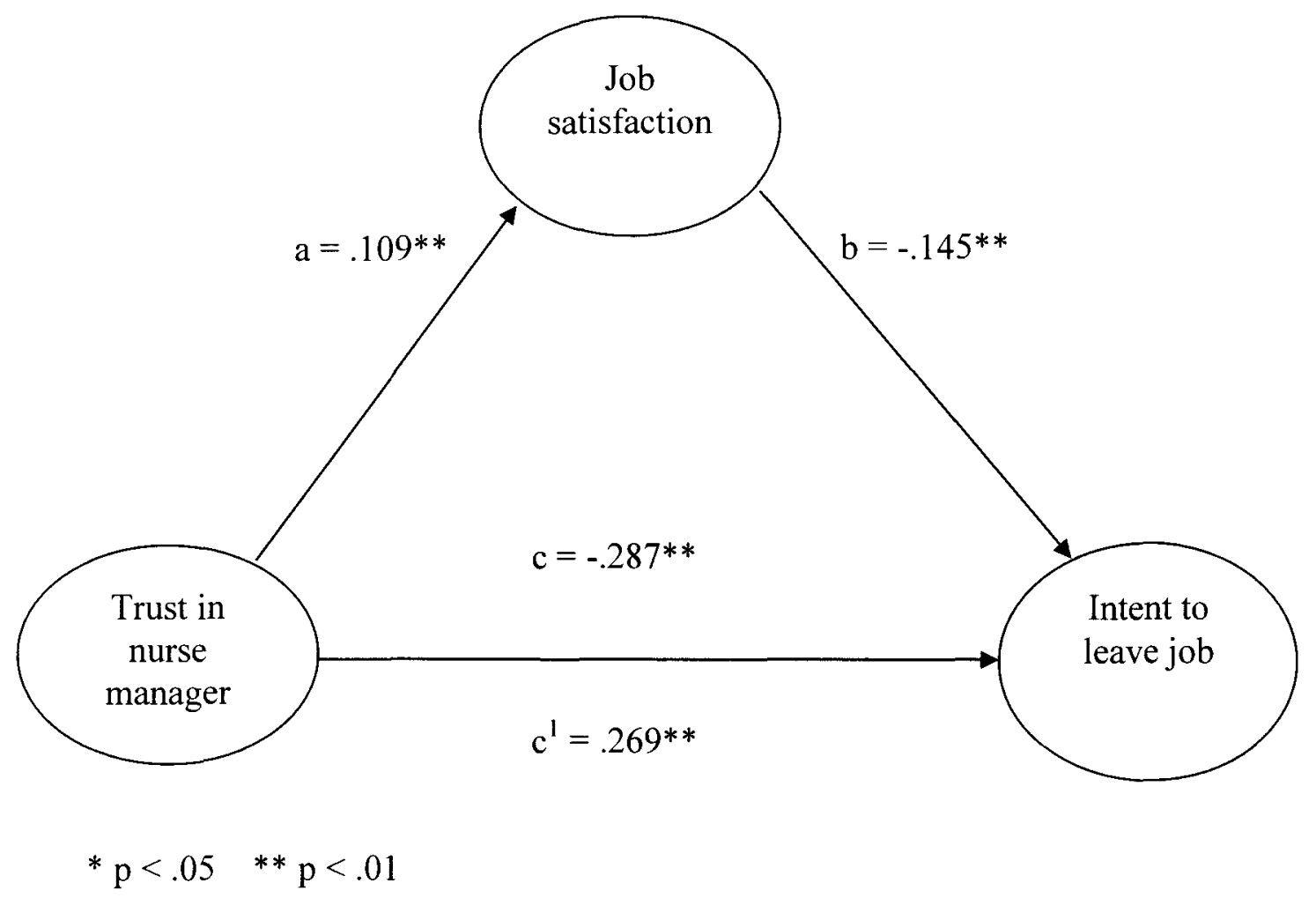

Figure 4. Mediation Model for Intent to Leave Predicted by Trust in Nurse

Manager and

Job Satisfaction (Hospital 2). 
Additional meditational analysis with control variables The mediation analyses that were presented were the "classic" mediation analyses that involved only three variables. However, it is possible to further illuminate the data by examining mediation in light of the control variables used in research questions 1 and 2. For research question 1, Table 13 (Step 2) gives the relationship between trust in nurse manager and job satisfaction, controlling for age, gender, and years in the current organization. The coefficient for trust in nurse manager ( $\beta=.383$ ) is coefficient $a$ in a mediation model. For research question 2, Table 15 (Steps 2 and 3) give three coefficients for mediation, controlling for age, gender, and years in the current organization. These are: coefficient $c$ $(\beta=-.543)$, coefficient $c^{\prime}(\beta=-.431)$, and coefficient $b(\beta=-.290)$.

Figure 5 shows the resulting model. When compared with Figure 1, it reveals that the relationships among the three key variables are similar after controlling for three demographic variables. 


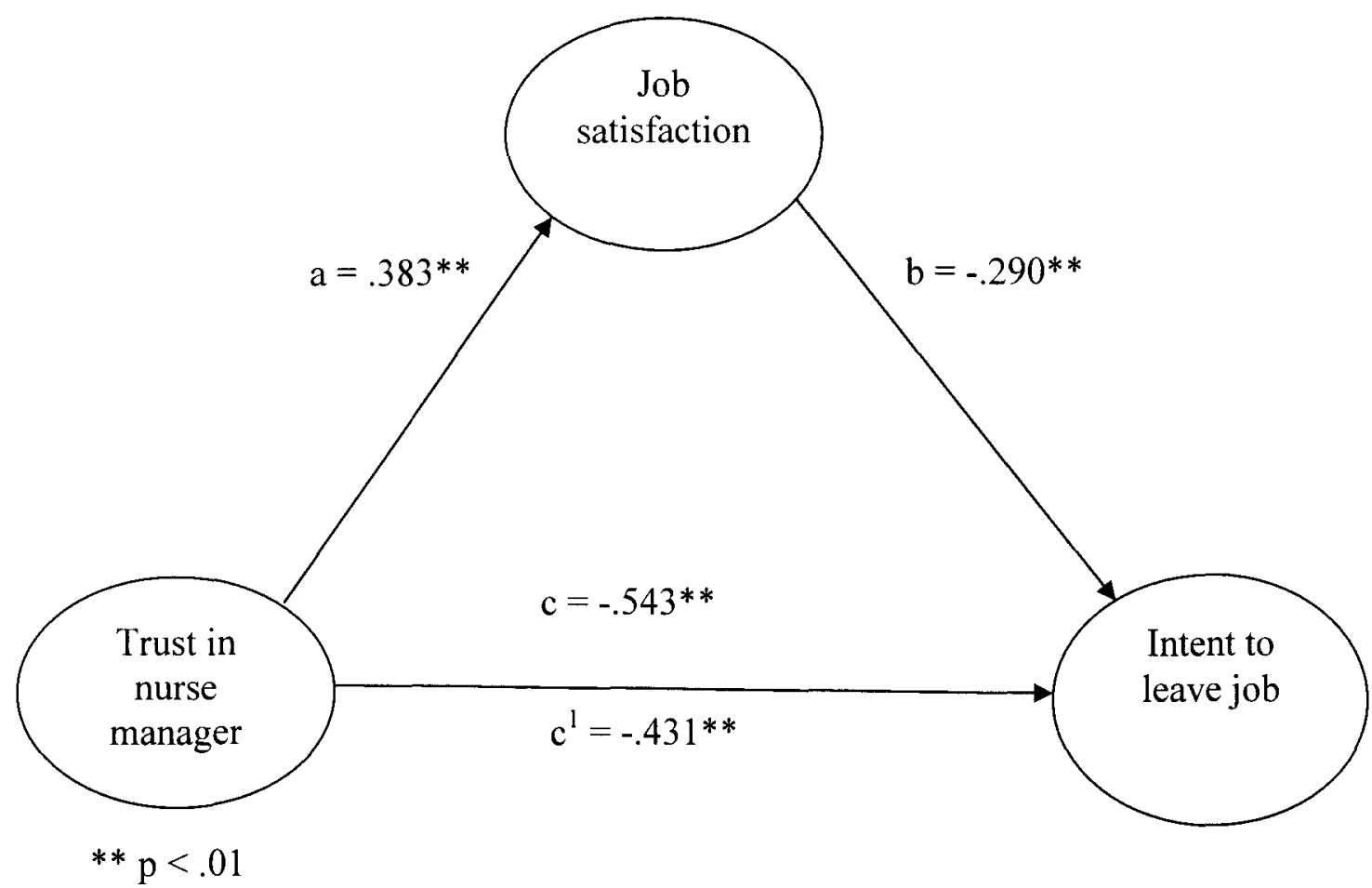

Figure 5. Mediation Model for Intent to Leave Predicted by Trust in Nurse

Manager and

Job Satisfaction. All Cases, with Age, Gender, and Years in Current Organization Controlled for Each Regression. 
Summary of Data Analysis

Three research questions made up the focus of the study. First, after controlling for demographic variables of age, gender, and tenure in organization, to what extent does trust in leader (nurse manager) relate to job satisfaction? Next, after controlling for demographic variables of age, gender, and tenure in organization, to what extent does trust in leader and job satisfaction relate to intent to leave present job? Finally, are the effects of trust in leader on intent to leave present job all direct effects, or are some or all of the effects indirect through the variable of job satisfaction?

The results were mixed for the first research question. Analysis determined that in hospital 2 trust in leader did not have a signification association with job satisfaction. However, overall results and results from hospital 1 indicate a significant positive association between trust in leader and job satisfaction controlling for demographic variables $(\beta=.383$ and $\beta=.433)$. These results would suggest that the higher the nurse scored the nurse manger on trust the higher that nurse's job satisfaction score was, and the lower the nurse scored the nurse manager on trust the lower the nurse's job satisfaction.

The results for the second research question suggest that after controlling for the demographic variables of age, gender, and tenure in organization, trust in leader $(\beta=-$ $.543, \beta=-.549$, and $\beta=-.251)$ and job satisfaction $(\beta=-.290, \beta=-.331$, and $\beta=-.224)$ demonstrate significant negative relationships with intent to leave for all respondents as well as hospital 1 and hospital 2 separately. The data ultimately suggest that the higher the trust in leader and the higher the job satisfaction of a respondent the less intent to leave the present job that respondent will have. The reverse would be the case as well. 
The lower the trust in leader and lower the job satisfaction of a respondent the higher that respondent's intent to leave present job.

The final research question addressed whether job satisfaction mediated the influence of trust in leader on intent to leave present job, or if the influence of trust in leader was a direct effect. Analysis on the overall population demonstrated that trust in leader had a direct effect on intent to leave present job $(\beta=-.556)$, but also an indirect effect through the mediation of job satisfaction $(\beta=.383$ and $\beta=-.267)$. Analysis for hospital 1 replicated these results showing that trust in leader had a direct effect on intent to leave present job $(\beta=-.556)$, but also an indirect effect through the mediation of job satisfaction $(\beta=.383$ and $\beta=-.267)$. Analysis for hospital 2 demonstrated that trust in leader had a direct effect on intent to leave present job $(\beta=-.287)$, but showed no significant mediation through job satisfaction.

When controlling for job satisfaction, trust in leader had a significant direct effect on intent to leave overall $(\beta=-.452)$, hospital $1(\beta=-.452)$, and hospital $2(\beta=-.269)$. When controlling for trust in leader, job satisfaction had a significant direct effect on intent to leave overall $(\beta=-.267),(\beta=-.267)$, and $(\beta=-.145)$. When controlling for each other, trust in leader came out as a stronger predictor variable than job satisfaction on intent to leave present job. When controlling for the three demographic variables, the relationships between the three key variables were similar as well. 
Table 23

Summary of Major Findings for each Research Question

\begin{tabular}{|c|c|}
\hline Research Question & Major Findings \\
\hline $\begin{array}{l}\text { Research Question 1: After controlling for } \\
\text { the demographic variables of age, gender, } \\
\text { and tenure in organization, to what extent } \\
\text { does trust in leader relate to job } \\
\text { satisfaction? }\end{array}$ & $\begin{array}{l}\text { Significant positive association between } \\
\text { trust in leader and job satisfaction } \\
\text { independent of demographic variables in } \\
\text { the overall population and hospital } 1 .\end{array}$ \\
\hline \multirow{2}{*}{$\begin{array}{l}\text { Research Question 2: After controlling for } \\
\text { the demographic variables of age, gender, } \\
\text { and tenure in organization, to what extent } \\
\text { does trust in leader and job satisfaction } \\
\text { relate to intent to leave present job? }\end{array}$} & $\begin{array}{l}\text { Significant negative association of trust in } \\
\text { leader on intent to leave present job } \\
\text { independent of demographic variables } \\
\text { across all populations. }\end{array}$ \\
\hline & $\begin{array}{l}\text { Significant negative association of job } \\
\text { satisfaction on intent to leave present job } \\
\text { independent of demographic variables } \\
\text { across all populations. }\end{array}$ \\
\hline \multirow{2}{*}{$\begin{array}{l}\text { Research Question 3: Are the effects of } \\
\text { trust in leader on intent to leave present job } \\
\text { all direct effects, or are some or all of the } \\
\text { effects indirect through the variable of job } \\
\text { satisfaction? }\end{array}$} & $\begin{array}{l}\text { Trust in leader had significant direct effect } \\
\text { on intent to leave as well as an indirect } \\
\text { effect mediated through job satisfaction. }\end{array}$ \\
\hline & $\begin{array}{l}\text { When controlling for job satisfaction, trust } \\
\text { in leader was found to be a stronger } \\
\text { predictor variable on intent to leave present } \\
\text { job than job satisfaction was when } \\
\text { controlling for trust in leader. }\end{array}$ \\
\hline
\end{tabular}




\section{CHAPTER V}

\section{DISCUSSION}

\section{Introduction}

This study addressed the effect of trust in leader on job satisfaction and intent to leave present job in the context of the nursing profession. Data were collected from nurses working for a hospital system made of three hospitals (hospital 1) and a community hospital (hospital 2) both located in the southern region of Indiana. Three research questions made up the basis for this research. (1) After controlling for the demographic variables of age, gender, and years in current organization, to what extent does trust in leader relate to job satisfaction? (2) After controlling for the demographic variables of age, gender, and years in current organization, to what extent does trust in leader and job satisfaction relate to intent to leave present job? (3) Are the effects of trust in leader on intent to leave present job all direct effects, or are some or all of the effects indirect through the variable of job satisfaction?

The results of regression analysis regarding research question 1indicate that trust in leader has a significant positive effect on job satisfaction. The model of age, gender, tenure in organization, and trust in leader accounted for more than 17 percent of the variance in job satisfaction, with trust in leader having the most significant effect independent of the other variables. These results demonstrate the importance of trust in leader on a very important organizational variable. 
Regression analysis from research question 2 yields some interesting results as well. Trust in leader and job satisfaction had a significant negative effect on intent to leave. This means that the higher the level of trust and job satisfaction the less likely a nurse was to leave a position. All predictors (age, gender, tenure in organization, trust in leader, and job satisfaction) accounted for 39 percent of the variance in intent to leave present job, which is quite high. And trust in leader and job satisfaction had the most significant effect on intent to leave independent of the demographic variables.

Multiple regression answering research question 3 illuminated the most interesting results of this study. Trust was shown to have both a direct and an indirect effect on via job satisfaction on intent to leave present job. When the effect of trust on leader on intent to leave independent of job satisfaction and vice versa, trust in leader had the strongest effect on intent to leave. This finding suggests that trust in leader is a more important link to intent to leave and possibly actual turnover than what has been argued and demonstrated as one of, if not the most important precursor to intent to leave.

The ultimate problem addressed in this research was the loss of nurses during a time where there is a shortage of nurses across the United States. Specifically, the projected number of vacancies by 2020 will be 400,000 (Bureau of Labor Statistics, 2006). With the number of newly hired nurses leaving the profession within the first few years of hire date is not making up for the difference (Waldman and Sanjear, 2004). The 400,000 projected vacancies comes from other sources as well, such as, the number of veteran nurses retiring in the next decade is expected to increase, and the lack of graduate level instructors available to teach the next generation of nurses is not enough to justify 
the number of seats needed to keep up with the demand at universities and community colleges (Bureau of Labor Statistics, 2006).

Job satisfaction and intent to leave present job are the two most nominated antecedents to actual turnover in the literature (Tett and Meyer, 1993). There is some evidence to suggest that trust in leader may affect job satisfaction (Butler, Cantrell, and Flick, 1999, \& Dirks and Ferrin, 2002) and intent to leave present job (Davis, Schoorman, Mayer, and Tan, 2000; \& Dirks and Ferrin, 2002). Research exists demonstrating a mediating effect of organizational trust on job satisfaction and intent to leave present job among nurses (Spence-Laschinger, Finegan, and Shamian, 2001). Nothing exists studying the effect of trust in one's immediate leader on job satisfaction and intent to leave present job in any industry much less the nursing profession. This study eliminated that void.

The results of the research indicated that trust in manager was a significant predictor of job satisfaction and intent to leave present job. The results were independent of the demographic variables used in the study. The most interesting result was that trust in manager was a stronger predictor of intent to leave present job than was job satisfaction. A more detailed discussion of results follows.

\section{Descriptive Statistics}

The researcher collected survey data between October and November of 2010 from hospital 1 and between April and May of 2010 from hospital 2. The study participants were nurses working for both hospital $1(n=233)$ and hospital $2(n=97)$. Respondents were asked to assess the level of trust they had in their nurse manager as well as to assess their own level of job satisfaction and intent to leave present job. The 
response rate for hospital 1 was 27 percent and 31 percent for hospital 2. All nurses from hospital 1 had the opportunity to take the survey, and all nurses with email access at hospital 2 had the opportunity to take the survey.

A number of demographic variables were assessed in this research: age, year degree earned, education level, years employed with current organization, years employed in current position, years of experience with current nurse manager, gender, and ethnicity. The majority of respondents ranged in age from 21 to 59 and earned their college degrees between 1991 and 2010. A larger percentage of nurses were in the older age range and earned their college degree earlier for hospital 2 than for hospital 1. Education level was higher for hospital 2 than in hospital 1 overall as were the number of years employed with current organization. There were no real discrepancies between the two hospitals with regard to years employed in current position except that hospital 1 had more nurses with less than 1 year in current position, 19.7 percent as opposed to 7.4 percent for hospital 2. There were no real differences between the two hospitals with regards to years of experience with current nurse manager except at the less than one year level where hospital 1 had 26.8 percent of the respondent population at this level and hospital 2 had 8.4 percent. Ninety-four percent of the respondent population was female and 96 percent of the respondent population was white.

The descriptive statistics demonstrated that two different nursing populations existed with regard to age, year degree earned, and years employed with current organization. Each of these variables made up what could amount to experience, where hospital 1 has a nursing population with less experience and hospital 2 has a nursing population with more experience. There were no significant differences in the other four 
variables. Gender and ethnicity gave the researcher very little to compare since most everyone in the study was white and female.

Data Analysis

Statistical analysis for this study consisted of descriptive and inferential statistical procedures that are appropriate for each research question. The statistical procedures conducted and a brief summary of the results are as follows.

Mean scores were obtained to compare and contrast the two hospitals regarding the primary variables under study: trust in manager, job satisfaction, and intent to leave present job, as well as demographic variables: age, ethnicity, gender, degree earned, date degree was earned, years in current organization, years in current position, and years with current nurse manager. Mean scores for hospital 2 were larger than for hospital 1 with regard to trust in manager and job satisfaction. The mean score of 3.815 for trust in manager for hospital 2 demonstrated that nurses agreed that they trusted their nurse manger. For hospital 1 the mean score was 3.28, which illustrated that nurse neither agreed nor agreed that they trusted the nurse manager overall. The mean score for job satisfaction at hospital 2 was 42.84 indicating that job satisfaction among nurses at hospital 2 was high. The mean score for job satisfaction at hospital 1 was 38.50 indicating that job satisfaction among nurses at hospital 1 was moderately high. The mean score for intent to leave present job was higher for hospital 1 than for hospital 2. The mean score for hospital 2 with regard to intent to leave present job was 1.85. This indicated that the intent to leave present job among nurses at hospital 2 was low. The mean score for hospital 1 with regard to intent to leave present job was 2.79 . 
This mean score demonstrated that the nurses at hospital 1 neither agreed nor agreed that they intended to leave their present job in the near future.

The differences in mean scores between the two hospitals regarding trust in manager, job satisfaction, and intent to leave present job illustrated that comparisons could be made between the two institutions. The mean scores between the two institutions allow the researcher to look at an organization where trust in manager and job satisfaction is high, and where intent to leave present job was low, and compare it to an organization where job satisfaction is moderately high, but trust in manager and intent to leave present job were neutral in degree.

Inferential statistical comparisons were made of hospital 1 and hospital 2 to confirm or disconfirm the differences that seemed apparent in frequency distributions. Significant differences existed between hospitals. Hospital 2 had higher mean scores than hospital 1 on average years employed with current organization, average years employed in current position, average years working for current nurse manger. The mean score of 4.93 for average years employed with current organization means that nurses at hospital 2 averaged between $10-15$ years with their organization. The mean score of 3.56 for years employed with current organization straddles two data points. This indicated that nurses for hospital 1 were employed with their current organization between 3 and 10 years. With regard to years employed in current position, hospital 2 had a mean score of 3.62 indicating that respondents averaged $5-10$ years in their current position. The mean score of 2.96 indicated that nurses at hospital 1 averaged $3-5$ years employed in their current position. With regard to average years working for current nurse manager, hospital 2 had a mean score of 3.03 indicating that nurses at hospital 2 
averaged $3-5$ years working for their current nurse manager. At hospital 1 the mean score for years working for current nurse manager was 2.02 , which meant that nurses worked for the current nurse manager on average $1-3$ years at hospital 1 .

The contrast between the mean scores in years employed in current organization, years employed in current position, and years working for current nurse manger indicated that the level of experience of nurses at hospital 2 was higher than the level of experience at hospital 1 . Hospital 2 had a higher percentage of nurses with more advanced degrees than hospital 1 . This also indicated greater experience and learning for nurses at hospital 2. Testing the associations between trust in manager, job satisfaction, and intent to leave against the experience and learning based variables provided a richer source of data from which to make conclusions. No significant associations existed between hospital and other demographic variables. Most nurses responding were white and female.

To address the first research question, how much variance in job satisfaction was predicted by demographic variables and trust in manager, hierarchal regression was employed. The only significant association of a demographic variable and job satisfaction resulted in gender. The results indicated that females were more satisfied with their jobs than were males. Trust in manager accounted for a significant proportion of the variance in job satisfaction. Controlling for demographic variables, trust in manager was positively associated with job satisfaction. The findings suggest the higher the trust in one's nurse manager the higher the level of job satisfaction for the nurse. These findings answer the first research question in the following way: Trust in manager does significantly affect job satisfaction in a positive way independent of demographic variables. 
Hierarchal regression was also used to answer the issue raised in the second research question: how much variance in the variable intent to leave present job was predicted by demographic variables, trust in manager, and job satisfaction. The only demographic variable with a significant association with intent to leave present job was years employed in current organization. The resulted indicated that the fewer years a nurse worked with a hospital the higher the level of intent to leave for that nurse was. Trust in manager and job satisfaction accounted for a significant proportion of the variance in intent to leave present job even after controlling for demographic variables. Trust in manager was associated negatively with intent to leave present job as was job satisfaction. The results indicate that the lower the level of trust in manager the higher the level of intent to leave and vice versa. The results also indicated that the lower the level of job satisfaction the higher the level of intent to leave present job and vice versa.

The results of this regression analysis were also interesting when the results for the two hospitals were separated. The results for hospital 1 indicated that trust in manager was a significant predictor for intent to leave present job. The same was true for job satisfaction for hospital 1 . If a nurse had a higher level of job satisfaction then that same nurse was likely to have a lower level intent to leave present job. The results for hospital 2 indicated that trust in manager was a significant predictor for intent to leave present job. The same was true for job satisfaction for hospital 2. If a nurse had a higher level of job satisfaction then that same nurse was likely to have a lower level intent to leave present job.

These results demonstrated that trust in manager and job satisfaction were significant predictors of intent to leave present job. The results are more meaningful 
since they are all but identical across two different healthcare institutions. The answer for the final research question illuminated even more the importance of trust in manager and job satisfaction on intent to leave present job.

Mediation analyses were employed to address the third research question. The research question addressed the issue of whether job satisfaction mediated the influence of trust in manager on intent to leave present job, or if the influence of trust in nurse manager was primarily direct. Two multiple regression analyses were employed to answer this research question.

Analyses for all respondents showed that all predictors (trust in manager and job satisfaction) were statistically significant. The analyses found that trust in manager related significantly to intent to leave present job in two ways. First, there was a significant direct effect. Second there was a significant indirect effect mediated through job satisfaction. The effect of both trust in manager and job satisfaction on intent to leave present job were tested by controlling for the other variable. The findings were interesting. Trust in manager was the stronger predictor of intent to leave present job. The analyses of hospital 1 independently addressing the third research question resulted in similar findings.

The analyses of hospital 2 independently addressing the third research question were also similar, but had one interesting result that differed from the two previous analyses that at the same time reinforced the previous findings. Trust in manager was shown to have a direct effect on intent to leave present job. However, there was no significant mediation via job satisfaction of trust in manager on intent to leave present job. While controlling for job satisfaction, trust in nurse manager on intent to leave 
present job resulted in demonstrating a strong direct effect of trust in manager of intent to leave present job independent of job satisfaction.

The findings of this research demonstrated that trust in nurse manager is a significant predictor of job satisfaction and intent to leave. Even when controlling for demographic variables, trust in nurse manager predicted job satisfaction and intent to leave present job. The current research reinforced the literature that suggests that the level of job satisfaction directly affects intent to leave present job.

The most interesting and significant finding of this research concerned the findings related to the third research question. Those findings suggested that trust in nurse manger and ultimately trust in leader may influence intent to leave present job more than job satisfaction. While there was a mediating effect on trust in nurse manager and intent to leave present job via job satisfaction, there was an even stronger direct effect of trust in nurse manager on intent to leave present job while controlling for job satisfaction. This suggested that trust in nurse manger was an even more important predictor of intent to leave present job than job satisfaction among the nurses participating in this study. How the Study Relates to Past Research

This research reinforces and extends earlier research on intent to leave, job satisfaction, and trust in leader. One way that the research adds to past research is that it gives a potential new answer to why nurses leave their organizations, and if senior leadership in healthcare organizations were to focus their efforts on decreasing turnover by increasing job satisfaction and trust in leader, those leaders might see a greater return on their investment. 
The average annual turnover among employees has been cited as 25 percent of that employee's annual salary (Amig \& Amig, 2001). Direct and indirect cost of turnover could be as high as 17 percent of an organization's total revenue (Saige, Rirati, \& Tziner, 2002; Waldman \& Sanjear), and 3.4 - 5.8 percent of a healthcare organization's total operating budget (Waldman, Kelly, Sanjear, \& Smith, 2004). Emphasis on trust building and maintenance for those in leadership positions and attempts to increase job satisfaction may lead to an alleviation of these costs and a greater bottom line. And this increased focus on these important variables could lead to a decrease in turnover among nurses in their first four years, which can be a turnover rate between 22 and 59 percent (Waldman et al., 2004).

Theory concerning actual turnover has consistently included job satisfaction and intent to leave, as well as other variables like organizational commitment, job embeddedness, perceived job alternatives, intrinsic motivation, promotional opportunities, pay, and burnout (March \& Simon, 1958; Mobley, 1979; Mowday, Porter, \& Steers, 1981; Mobley, 1982; Hom \& Griffeth, 1995). On the other hand, trust in leader has received very little attention in the turnover literature. The results of this study indicate that this may have been an oversight. Since the link between intent to leave (the best predictor to actual turnover) and actual turnover can be suppressed via positive feelings towards one's leader (Vandenberg \& Nelson, 1999), what better variable to include in any model of actual turnover than trust in leader.

This research reinforces earlier research concerning the influence of job satisfaction on intent to leave. The literature suggests that employees leave organizations for a variety of reasons. Intent to leave is considered the most important antecedent to 
voluntary employee turnover (Mobley, 1977; Roberts et al., 1999; Lichtenstein et al., 2004). Job satisfaction is one of the most cited antecedents to intent to leave (Mobley, 1977; Hom \& Griffith, 1991; Tett \& Meyer, 1993; Breukelen et al., 2004; Lichtenstein et al., 2004). Research in healthcare also suggests that intent to leave as a causal link to employee turnover (Price \& Mueller, 1981, Andrews \& Dziegiclewski, 2005). The results of this study reinforce the importance of job satisfaction in that relationship. However, high levels of trust in leader lead to lower intent to leave one's organization independent of job satisfaction. This may be the most significant finding in the study. Trust in leader has a profound effect on intent to leave.

This research found that trust in nurse manager influenced job satisfaction among two different populations of nurses. The research also found that trust in nurse manager was a stronger predictor of intent to leave present job than was job satisfaction. This is significant, because, as mentioned previously, job satisfaction has been often cited as an antecedent to job satisfaction where trust in leader has not.

Trust in leader was also found to have positive significant results on job satisfaction. That is high levels of trust in leader lead to higher level of job satisfaction among employees. The trust in leader variable makes intuitive sense when looking at Herzberg's Motivation-Hygience Theory (1966) of job satisfaction. According to the theory, certain intrinsic and extrinsic factors lead to job satisfaction. Some of the extrinsic factors on Herzberg's theory include supervision and interpersonal relationships. It is not a huge jump to speculate that increased trust in leader leads to greater satisfaction with leader (supervision) and interpersonal relations. Vroom (1964) also indicated that positive attitudes result in greater job satisfaction. Trust in leader likely enhances 
positive attitudes among employees, which would obviously lead to greater job satisfaction.

Often individual facets of job satisfaction are included and would certainly make up job satisfaction globally. The individual facets of job satisfaction include satisfaction with pay, work, promotional opportunities, peers, and supervision. Trust in leader would most likely enhance satisfaction with supervision, based on the results of this study. However, trust in leader might affect the other facets of job satisfaction as well. Various leadership theories suggest the importance of trust. Leader-Member Exchange (LMX) and Transformational Leadership theories may convey this importance more than any other leadership theories. Under LMX (Grauen \& Uhl-Bien, 1991) the quality of exchange develops over three phases: stranger, acquaintance, and mature. Engendering trust by a leader would likely increase the speed at which the LMX exchange travels through the three phases, leading to mature relationships between leader and employee based on mutual trust and respect.

Leadership has also been shown to be more than a series of exchanges. Transformational Leadership argues that effective leaders get followers to identify with them as well as emulate them, inspire motivation, influence innovation/creativity, and provide a supportive climate in which the leader considers each employee individually. It seems that trust in leader would be an outcome of this type of leadership and ultimately so would job satisfaction and intent to leave.

These findings build on the trust in leader literature which suggest that trust in leader has an influence on a number of outcomes including organizational commitment (Brockner et al, 1997), increased productivity (Spreitzer \& Mishra, 1999), and 
organizational performance (Jung \& Avolio, 2000). Dirks and Ferrin (2002) in a metaanalysis found an association between trust in leader and job satisfaction and intent to leave, but did not assess direct effect or indirect effect through multiple regression. Davis et al. (2000) found an association between trust in restaurant manager and actual employee turnover. Again, the statistical analysis was not has sophisticated, and the researchers had to extend the length of the study to get the results they were looking for. While this research did not study the effect of trust in leader on actual employee turnover, the results of the research certainly suggest that an effect might exist if it were studied in the future.

Ultimately the results of this study build on the work of Mayer, Davis, and Schoorman (1995). Mayer et al. argued that trust was an important organizational variable, and this study reinforces that notion. Mayer et al. indicated that working together often involves interdependence and people must therefore depend on others to accomplish personal and organizational goals. Organizations cannot operate by simple compliance alone in an environment with less interpersonal similarity and greater diversity. Trust becomes an important component to consider. Job satisfaction and intent to leave are two of the more important organizational measures. The effect of trust in leader was shown to be a significant organizational measure as well. With that in mind, this study lends credence to Mayer et al.'s argument that trust is an important organizational variable to emphasize. Implications for Practice

The implications of this research on Human Resource Development are important. Highlighting trust in leader as a credible antecedent for job satisfaction and 
intent to leave present job gives HRD practitioners an important new measure in their battle against employee turnover. All functions inside an organization normally have important outcomes for which they are responsible Turnover is one of those outcomes for the HRD practitioner. Job satisfaction and intent to leave present job have often been cited as antecedents to actual turnover. This research reinforces this notion, at least in terms of the effect of job satisfaction on intent to leave present job. However, trust in leader was found to be the stronger predictor variable on intent to leave present job when job satisfaction and trust in leader were tested against each other.

Since trust in leader was such a strong predictor of intent to leave present job as well as on job satisfaction, it makes sense to advise HRD professionals to implement this measure in their future assessments of those in leadership positions. New leaders coming into an organization should be assessed prior to hiring for their potential ability as a builder of trust. Training and development of leaders at every level in an organization should implement trust building and maintenance seminars and coaching. Assessment of current leaders should include the ability to engender trust as part of the 360 degree feedback system as well as the leader's performance appraisal. The ability to engender and maintain trust should become a part of the leader's job description, and become a focus for competency modeling of leaders. In essence, trust in leader should become a primary area of focus for HRD, just as much as job satisfaction, intent to leave, organizational commitment, stress, or any other important measure normally associated with the discipline.

This research had ramifications outside of HRD as well. Those who study and practice leadership may find the results of the research illuminating. Turnover affects 
various types of institutions in problematic ways. The costs are direct and indirect. This study illustrates the importance of trust in one's immediate leader with regard to their job satisfaction and intent to leave present job. It would make sense for anyone operating in a leadership role to take note of this. Engendering trust among those that work for them could ensure higher retention of their employee base, and might even affect other important business outcomes like productivity, innovation, and profit. Leaders should look for self-improvement opportunities with regards to trust and make it a part of their strategic management.

While this study's respondent base was nurses, the goal of this research was meant to be much broader. That stated the role of the nurse manager on nurses seems to affect important aspects of his/her work life. The nurse manager that focuses on important outcomes like job satisfaction and intent to leave, and that works to increase their levels of trust among their teams are more apt to be more successful. Hospital administration should also look to their HRD professionals to develop plans to increase the level of job satisfaction and trust in leader and decrease intent to leave throughout their organization. Doing so decreases the cost of turnover and may ultimately help alleviate the effects of the nursing shortage.

\section{Limitations and Future Research}

This research has several limitations. First there was very little diversity with the demographic variable gender. Ninety-four percent of the respondent population was female. With that in mind, one should be skeptical of the results controlling for gender until there is a similar study with a more even distribution of males and females under study. 
This research collected data on other demographic variables other than the three control variables. Other research should include the other demographic variables as control variables. Determining if trust and job satisfaction affect intent to leave present job independent of these of demographic variables increases the reliability of the results.

Mayer et al. (1995) developed a theory of trust development and maintenance that employed three antecedents for trust to develop and exist (integrity, benevolence, and ability) as well as a variable measuring the propensity to trust of the trustor. This study failed to employ any of those variables. To acquire a more in depth understanding of why trust in leader affects job satisfaction and intent to leave present job, future research could measure the antecedents of trust and the propensity to trust of the respondent population and determine if indirect effects exist on job satisfaction and intent to leave mediated by trust in leader.

This research focused only on one's immediate leader. Future research could include trust in senior leadership as a variable. Testing the effect of trust in one's immediate leader as well as senior leadership could deepen the richness of the results.

This study employed a general job satisfaction index. There are individual facets to job satisfaction as well, such as, satisfaction with co-workers, satisfaction with boss, and satisfaction with pay. These individual facets are addressed in the Job Descriptive Index, which is often used in conjunction with the overall job satisfaction measure, Job in General Index. Studying the relationships of the individual facets of job satisfaction on trust in leader and intent to leave could lead to interesting results.

This research was conducted in a healthcare setting within a particular profession. The results within other industries and professions may provide different results. This 
research or research like it should be replicated across a variety of industries and professions.

Conclusion

The study of trust in leader has become more prominent in the past several years. The seminal work of Mayer et al. (1995) underlies its importance. Trust in leader has been shown to affect organizational commitment, organizational citizenship behaviors, and many other important outcomes in organizations. This study builds on their work by demonstrating the effect of trust in leader on job satisfaction and intent to leave present job. The more trust a leader engenders with his/her employees the more satisfied they are in their job and the less intention they will have to leave that job independent of job satisfaction.

Job satisfaction and intent to leave should be continued areas of emphasis for HRD professionals and leaders. At the same time, trust in leader should become an important emphasis point for HRD and leaderships as well. Without trust the leader likely loses credibility. When the leader fails to build and maintain trust job satisfaction decreases and intent to leave increases. With high levels of trust in leader, job satisfaction increases and intent to leave decreases. It only makes sense to include trust in leader as a primary measure when job satisfaction, intent to leave, and possibly even actual turnover are a concern. 


\section{REFERENCES}

Aiken, L.H., Clarke, S.P., Sloane, D.M., Scohalski, J., \& Silber, J.H. (2002). Hospital nurse staffing and patient mortality, nurse burnout, and job dissatisfaction. Journal of American Medical Association, 288(16), 1987-1993.

Aguilar, J.L. (1984). Trust and exchange: Expressive and instrumental dimensions of reciprocity in a peasant community. Ethos, 12, 3-29.

Amig, J. \& Amig, S. (2001). Managing human capital. Behavioral Health Management, $21(2), 22-26$.

Arnold, K.A., Barling, J. \& Kelloway, E.K. (2001). Transformational leadership or the iron cage: Which predicts trust, commitment, and team efficacy? Leadership \& Organization Development, 22, 315-321.

Aryee, S., Budhwar, P.S., \& Chen, Z.X. (2002). Trust as a mediator of the relationship between organizational justice and work outcomes: Test of a social exchange model. Journal of Organizational Behavior, 23, 267-285.

Ballard, D.I.,\& Seibold, D.R. (2006). The experience of time at work: Relationship to communication load, job satisfaction, and interdepartmental communication. Communication Studies, 57(3), 317-340.

Balzer, W.K., Kihm, J.A., Smith, P.C., Irwin, J.L., Bachiochi, P.D., Robie, C., Sinar, E.F., \& Parra, L.F. (1997). Users' manual for the job descriptive index (JDI 1997 revision) and the job in general (JIG) scales. Bowling Green: Bowling Green State University.

Bass, B.M. (1985). Leadership and Performance Beyond Expectations. New York: The Free Press.

Bauer, T.N.; Erdogen, B.; Linden, R.C.; \& Wayne, S.S. (2006). A longitudinal study of the moderating role of extraversion: Leader-member exchange, performance, and turnover during new executive development. Journal of Applied Psychology, 91, 298-310.

Bennis, W., \& Nanus, B. (1985). Leaders: The Strategies for Taking Charge. New York: Harper \& Row. 
Benson, G. (2006). Employee development, commitment, and intention to turnover: A test of employability policies in action. Human Resources Management Journal, $16,172-192$.

Berger, D. E. (2004). Using regression analysis. In J. S. Wholey, H. P. Hatry, \& K. E. Newcomer (Eds.), Handbook of practical program evaluation $\left(2^{\text {nd }}\right.$ ed.) (pp. 479505). San Francisco: Jossey-Bass.

Blegen, M. (1993). Nurses' job satisfaction: A meta-analysis of related variables. Nursing Research, 44(4), 246-253.

Boyle, D.K., Bott, M.J., Hansen, H.E., Woods, C.Q., \& Taunto, R.L. (1999). Managers' leadership and critical care nurses' intent to stay. American Journal of Critical Care, 8(6), 361-371.

Bratt, M.M., Broome, M., Kelber, S., \& Lostocco, L. (2000). Influence of stress and Nursing leadership on job satisfaction of pediatric intensive care unit nurses. American Journal of Critical Care, 9(5), 307-317.

Breukelen, W.V.; Van Der List, R.; \& Steensma, H. (2004). Voluntary employee turnover: Combining variables from traditional turnover literature with the theory of planned behavior. Journal of Organizational Behavior, 25, 893-914.

Britton, D. (1997). Perceptions of the work environment among corrections officers: Do race and sex matter? Criminology, 35, 85-105.

Brockner, J., Siegal, P.A., Daly, J.P., Tyler, T. \& Martin, C. (1997). When trust matters: The moderating effect of outcome favorability. Administrative Science Quarterly, $42,558-583$.

Bureau of Labor Statistics (2006). U.S. Department of Labor. Occupational Outlook Handbook, 2007-2008 Edition. Retrieved from http://bls.gov/oco/ocos083.htm.

Burns, J.M. (1978). Leadership. New York: Harper \& Row.

Butler, J.K., Cantrell, R.S., \& Flick, R.J. (1999). Transformational leadership behaviors, upward trust, and satisfaction in self-managed work teams. Organization Development Journal, 17, 13-28.

Buzawa, E. (1994). The role of selected sociodemographic and job specific variables in predicting patrol officer job satisfaction: A reexamination ten years later. American Journal of Police, 13, 71-75.

Carnevale, D.G. (1995). Trustworthy Government: Leadership and Management Strategies for Building Trust and High Performance. San Francisco: Jossey-Bass. 
Chawla, A. \& Kelloway, E.K. (2004). Predicting openness to change. The Leadership and Organization Development Journal, 25, 485-499.

Choi, N.H.; Dixon, A.L.; \& Jing, J.M. (2005). Dysfunctional behavior among sales representatives: The effect of supervisory trust, participation and information controls. Journal of Personal Selling and Sales Management, 24, 181-198.

Connell, J.; Ferres, H.; \& Travaglione, T. (2003). Engendering trust in manager subordinate relationship: Predictors and outcomes. Personnel Review, 32(5), 569 587.

Cote, J. \& Morgan, L. (2002). A longitudinal analysis of the association between emotion regulation, job satisfaction, and intention to quit. Journal of Organizational Behavior, 23, 947-962.

Cotton, J.L., \& Tuttle, J.M. (1986). Employee turnover: A meta-analysis and review of implications for research. Academy of Management Review, 11(1), 55-70.

Covey, S.R. (1990). Principle-centered Leadership. New York: Fireside.

Cox, K.B. (2001). The effects of unit morale and interpersonal relations on conflict in the nursing unit. Journal of Advanced Nursing, 35(1), 17-25.

Cropanzano, R.; Rupp, D.E.; \& Byrbem Z.S. (2003). The relationship of emotional exhaustion to work attitudes, job performance and organizational citizenship behaviors. Journal of Applied Psychology, 88, 160-169.

Cunningham, G.B. \& Saga, M. (2004). Examining main effect and interactive effect of deep- and surface-level diversity on job satisfaction and organizational turnover intentions. Organizational Analysis, 12(3), 319-322.

Cunningham, J.B. \& MacGregor, J. (2000). Trust and the design of work: Complimentary constructs in satisfaction and performance. Human Relations, 53(12), 1575-1591.

Curry, J., Wakefield, D., Price, J., \& Mueller, C. (1986). On the causal ordering of job satisfaction and organizational commitment. Academy of Management Journal, 29, 849-88.

Davis, J.H., Schoorman, F.D., Mayer, R.C., \& Tan, H.H. (2000). The trusted general manager and business unit performance: Empirical evidence of a competitive advantage. Strategic Management Journal, 21, 562-576.

Deutsch, M. (1958). Trust and suspicion. Journal of Conflict Resolution, 2, 265-279. 
Ding, C.C., \& Lin, C. (2006). Comparing the effects of determinants of turnover intentions between Taiwanese and U.S. hospital employees. Human Resource Development Quarterly, 17(4), 403-421.

Dirks, K.T., \& Ferrin, D.L. (2002). Trust in leadership: Meta-analytic findings and implications for research and practice. Journal of Applied Psychology, 87, 611628.

Dirks, K.T. (2000). Trust in leadership and team performance: Evidence from NCAA basketball. Journal of Applied Psychology, 85, 1004-1012.

Driscoll, J.W., (1978). Trust and participation in organizational decision making as predictors of satisfaction. Academy of Management Journal, 21, 44-56.

Egan, T.M.; Young, B.; \& Bartlett, K.R. (2004). The effects of organizational learning culture and job satisfaction on motivation to transfer learning and turnover intention. Human Resource Development Quarterly, 15, 279-301.

Eisenberger, R.; Stinglhamber, F.; Vandenbugeh, C.; Sucharski, I.; \& Rhodes, L. (2002). Perceived supervisor support: Contributions to perceived organizational support and employee retention. Journal of Applied Psychology, 87, 565-573.

Elangovan, A.R. (2001). Causal ordering of stress, satisfaction, and commitment and the intention to quit. Leadership and Organization Development Journal, 22, 159 165 .

Fairholm, G.W. (1994). Leadership and the Culture of Trust. Connecticut: Praeger.

Ferratt, T.W. (1981). Overall job satisfaction: Is it a linear function of facet satisfaction. Human Relations, 34(6), 463-474.

Ferrin, D.L., \& Dirks, K.T. (2003). The use of rewards to increase and decrease trust: Mediating processes and differential effects. Organization Science, 14, 18-31.

Firebaugh, G. \& Hurley, B. (1995). Trends in job satisfaction in the United States by race, gender and type of occupation. Research in the Sociology of Work, 5, 87104.

Firth, L.; Mellor, D.J.; Moore, K.A.; \& Loquet, C. (2004). How can managers reduce employee intentions to quit? Journal of Managerial Psychology, 19, 170-187.

French, J.R.P., \& Raven, B. (1959). The basis of social power. In Cartwright, D. (Ed.), Studies in Social Power. University of Michigan Press, Ann Arbor, MI, 529-569.

Frost, T.F., \& Moussaui, F. (1992). The relationship between leader power base influence: The moderating role of trust. Journal of Applied Business, 8, 9-15. 
George, J.M. \& Jones, G.R. (1996). The experience of work and turnover intentions: Interactive effects of value attainment, job satisfaction, and positive mood. Journal of Applied Psychology, 81, 218-225.

Geurts, S.; Schaufeli, W.; \& DeJonge, J. (1998). Burnout and intention to leave among Mental healthcare professionals: A social psychological approach. Journal of Social and Clinical Psychology, 17, 341-363.

Gillespie, N.A. \& Mann, L. (2004). Transformational leadership and shared values: The building blocks of trust. Journal of Managerial Psychology, 19, 588-607.

Gomez, C., \& Rosen, B. (2001). The leader-member exchange as a link between managerial trust and employee empowerment. Group \& Organization Management, 26, 53-69.

Giffin, K. (1967). The contribution of studies of source credibility to a theory of interpersonal trust in the communication process. Psychological Bulletin, 68 , 104-120.

Graen, G.B., \& Uhl-Bien. (1995). Relationship-based approach to leadership: Development of Leader-Member Exchange (LMX) theory over 25 years: Applying multi-level multi-domain perspective. Leadership Quarterly, 6, 219247.

Grossi, E. \& Berg, B. (1991). Stress and job satisfaction among correctional officers: An unexpected finding. International Journal of Offender Therapy and Comparative Criminology, 35, 73-87.

Hamilton, K.S. (1990). Organizational culture and head nurse leadership. The relationship to nurses' job satisfaction and turnover in hospital settings. Unpublished Dissertation. Georgia State University.

Harris, G.E. \& Cameron, J.E. (2005). Multiple dimensions of organizational identification as predictors of turnover intentions and psychological well-being. Canadian Journal of Behavioral Science, 37, 159-169.

Hart, P.D. (2001). The nursing shortage: Perspectives from current direct care nurses and former direct care nurses. [online article; retrieved 2/15/2007]. http://www.aft.org/pubs.reports/healthcare/Hart.Report.pdf.

Harvey, S.; Kelloway, E.K.; \& Duncan-Leiper, L. (2003). Trust in management as a buffer of the relationship between overload and strain. Journal of Occupational and Health Psychology, 8, 306-315.

Herzberg, F. (1966). Work and the Nature of Man. New York: World. 
Herzberg, F., Mausner, B., \& Snyderman, B. (1959). The Motivation to Work. (2 ${ }^{\text {nd }}$ ed.) New York: John Wiley \& Sons, Inc.

Hinkin, T.R., \& Tracey, J.B. (2000). The cost of turnover. Cornell Hotel and Restaurant Administration Quarterl,. 41(3), 14-21.

Hom, P.W., \& Griffeth, R.W. (1991). Structural equations modeling test of a turnover theory: Cross-sectional and longitudinal analysis. Journal of Applied Psychology, $76(3), 350-366$.

Hoppock, R. (1935). Job Satisfaction. New York: Harper.

HRSA (2002). The registered nurse population: Findings from the 1996 national sample survey of registered nurses. Retrieved October, 2003 from ftp://ftp.hrsa.gove/bhpr/nursing/samplesurveys/1996sampsur.pdf.

Ironson, G.H., Smith, P.C., Bannick, M.T, Gibson, W.M., Paul, K.B. (1989). Construction of a Job in General Scale: A comparison of global, composite, and specific measures. Journal of Applied Psychology, 74(2), 193-200.

Jones, D.A. \& Skarlicki, D.P. (2003). The relationship between perceptions of fairness and voluntary turnover among retail employees. Journal of Applied Social Psychology, 33, 226-243.

Joseph, E.E. \& Winston, B.E. (2004). A correlation of servant leadership, leader trust and organizational trust. Leadership and Organization Development Journal, 26, 622.

Jung, D.I. \& Avolio, B.J. (2000). Opening the black box: An experimental investigation of the mediating effects of trust and value congruence on transformational and transactional leadership. Journal of Organizational Behavior, 21, 949-964.

Kleinman, (2004). The relationship between managerial leadership behaviors and staff nurse retention. Hospital Topics, 82, 2-10.

Korsgaard, M.A., Schweiger, D.M., \& Sapienza, H.J. (1995). Building commitment, attachment, and trust in strategic decision-making teams: The role of procedural justice. Academy of Management Journal, 38, 60-84.

Korsgaard, M.A., Whitener, E.M., \& Brodt, S.E. (2002). Trust in the face of conflict: The role of managerial trustworthy behavior and organizational context. Journal of Applied Psychology, 87, 312-319.

Kouzes, J.M., \& Posner, B.Z. (1993). The Leadership Challenge. San Francisco: JosseyBass. 
Lichtenstein, R., Alexander, J.A., MaCarthy, J.F., \& Wells, R. (2004). Status differences in cross functional teams: Effects on individual member participation, job satisfaction, and intent to quit. Journal of Health and Social Behavior, 45(3), 322-335.

Levering, R. (1996). Employability and trust. A Great Place to Work Institute. 1-6.

Levering, R. (1993). Trust and cooperation: the payoff from a great place to work. Prism, 4, 33-43.

Locke, E.A. (1976). The nature and causes of job satisfaction. In M.D. Dunnet (Ed.), Handbook of Industrial and Organizational Psychology. (pp. 1297-1349). Chicago: Rand McNalley College Publishing.

Lucas, M., Atwood, J., \& Hagaman, R. (1993). Replication and validation of anticipated turnover model for urban registered nurses. Nursing Research, 42, 29-35.

MacKenzie, S.B., Podsakoff, P.M., \& Rich, G.A. (2001). Transformational and transactional leadership and salesperson performance. Academy of Marketing Science Journal, 29, 115-134.

March, J.C., \& Simon, H.A. (1958). Theories of bureaucracy. In J.M. Shafritz \& J.S. Ott (Eds.), Classics of Organizational Theory (pp. 146-155). Illinois: Dorsey.

Martin, J.K. (1990). Modeling the turnover process. Journal of Management Studies, 17, 261-274.

Maslow, A. (1954). Motivation and Personality. New York: Harper and Row.

Mayer, R.C., Davis, J.H., \& Schoorman, F.D. (1995). An integrative model of organizational trust. Academy of Management Review, 20 (3), 709-734.

Mayer, R.C., \& Davis, J.H. (1999). The effect of the performance appraisal system on trust for management: A field quasi-experiment. Journal of Applied Psychology, $84,123-136$.

Mayer, R.C. \& Gavin, M.B. (2005). Trust in management and performance: Who minds the shop while the employees watch the boss? The Academy of Management Journal, 48(5), 874-888.

Melamed, S., Ben-Avi, I., Luz, J., \& Green, M. (1995). Objective and subjective work monotony. Effects on job satisfaction, psychological distress, and absenteeism in blue collar workers. Journal of Applied Psychology, 80, 29-42. 
Mirsha, A.K. (1996). Organizational responses to crisis: The centrality of trust. In R.M. Kramer, and T.R. Tyler (Eds.), Trust in Organizations: Frontiers of Theory and Research (pp. 261-287). Thousand Oaks, CA: Sage.

Mobley, W.H. (1977). Intermediate linkages in the relationship between job satisfaction and employee turnover. Journal of Applied Psychology, 62(2), 237-240.

Mobley, W.H. (1982). Some unanswered questions in turnover and withdrawal research. The Academy of Management Review, 7, 111-116.

Mobley, W.H., Griffeth, R.W., Hand, H.H., \& Meglino, B.M. (1979). Review and conceptual analysis of the employee turnover process. Psychological Bulletin, $86(3), 493-522$.

Mobley, W.H., Horner, S., \& Hollingsworth, A. (1978). An evaluation of the precursors of hospital employee turnover. Journal of Applied Psychology, 63, 408-414.

Mowday, R.T.; Koberg, C.S.; \& McArthur, A.W. (1984). The psychology of the withdrawal process: A cross-validation test of Mobley's intermediate linkages model of turnover in two samples. The Academy of Management Journal, 27, 79 94.

Moye, M.J.; Hinkin, A.B.; \& Egley, R.J. (2005). Teacher principle relationships: Exploring linkages between empowerment and interpersonal trust. Journal of Educational Administration, 43, 260-277.

Muchinsky, P.M. (1977). Organization communication: Relationships to organizational climate and job satisfaction. Academy of Management Journal, 20, 592-607.

Mulki, J.P.; Jararmill, F.; \& Locander, W.B. (2006). Effects of ethical climate and supervisory trust on salesperson's job attitudes and intentions to quit. Journal of Personal Selling and Sales Management, 26(1), 19-26.

Nagy, M.S. (2002). Using a single-item approach to measure facet job satisfaction. Journal of Occupational and Organizational Psychology, 75, 77-87.

Nikandrou, I., Papalexandris, N., Bourantas, D. (2000). Gaining employee trust after acquisition: Implications for managerial action. Employee Relations, 22, 334346.

Northouse, P.G. (2004). Leadership: Theory and Practice. ( $3^{\text {rd }}$ ed.), Thousand Oaks: Sage Publications.

Owens, P.L. (2006). One more reason not to cut your training budget: The relationship between training and organizational outcomes. Public Personnel Management, $35(2)$, 
163-171.

Parry, K.W., \& Proctor-Thomson, S.B. (2002). Perceived integrity of transformational in organizational settings. Journal of Business Ethics, 35, 75-96.

Peter, M. (1994). Making the hidden obvious: Management education through survey feedback. Journal of Nursing Administration, 24, 13-19.

Podsakoff, P.M., MacKenzie, S.B., Moorman, R.H., and Fetter, R. (1990). Transformational leader behaviors and their effects on followers' trust in leader, satisfaction, and organizational citizenship behaviors. Leadership Quarterly, 1 (2), 107-142.

Podsakoff, P.M., MacKenzie, S.B., \& Bommer, W. H. (1996). Transformational leader behaviors and substitutes for leadership as determinants of employee satisfaction, commitment, trust, and organizational citizenship behaviors. Journal of Management, 22(2), 259-298.

Price, J.L., \& Mueller, C.W. (1981). A causal model of turnover for nurses. The Academy of Management Journal, 24(3), 543-565.

Roberts, J.A., Coulson, K.R., \& Chonko, L.B. (1999). Salesperson behaviors and justice and their impact on organizational commitment and intent to turnover. Journal of Marketing Theory and Practice, 7(1), 1-16.

Roolli, L. \& Savicki, V. (2006). Impact of fairness, leadership and coping on strain, burnout, turnover in organizational change. International Journal of Stress Management, 13, 351-377.

Rosser, V.J. \& Javinar, J.M. (2003). Midlevel student affairs leaders' intentions to leave: Examining the quality of their professional and institutional work life. Journal of College Student Development, 44(6), 813-830.

Sagie, A., Birati, A., \& Tziner, A. (2002). Assessing the costs of behavioral and psychological withdrawal: A new model and an empirical illustration. Applied Psychology: An International Review, 51(1), 67-89.

Schoorman, F.D., Mayer, R.C., \& Davis J.H. (1996). Empowerment in veterinary clinics: The role of trust in delegation. In $11^{\text {th }}$ Annual Meeting of the Society for Industrial and Organizational Psychology.

Serva, M.A., Fuller, M.A., \& Mayer, R.C. (2005). The reciprocal nature of trust: A longitudinal study of interacting teams. Journal of Organizational Behavior, 26, 625-648.

Smith, P.C., Kendall, L.M., \& Hulin, C.L. (1969). The Measurement of Satisfaction in 
Work and Retirement. Chicago: Rand McNally.

Somer, M.J. (1996). Modeling employee withdrawal behavior over time. A study of turnover using survival analysis. Journal of Occupational and Organizational Psychology, 69, 315-326.

Sosik, J.J. (2001). Self-other agreement on charismatic leadership: Relationships with work attitudes and managerial performance. Group \& Organization Management, 26, 484-511.

Spence-Laschinger, H.K., Finegan, J., Shamian, J. (2001). The impact of workplace empowerment and organizational trust on staff nurses work satisfaction and organizational commitment. Health Care Management Review, 26, 7-23.

Spence-Laschinger, H.K., \& Finegan, J. (2005). Using empowerment to build trust and respect in the workplace: A strategy for addressing the nursing shortage. Nursing Economics, 23, 6-13.

Spencer, D.G. (1986). Employee voice and employee retention. Academy of Management Journal, 79, 488-502.

Spencer, D.G. \& Steers, R.M. (1980). The influence of personal factors and perceived work experiences on employee turnover and absenteeism. Academy of Management Journal, 23, 567-572.

Spreitzer, G.M., \& Mishra, A.K. (1999). Giving up control without losing control: Trust and its substitutes' effects on managers' involving employees in decision making. Group \& Organization Management, 24, 155-187.

Tan, H.H., \& Tan, C.S.F. (2000). Toward the differentiation of trust in supervisor and trust in organization. Genetic, Social, and General Psychology Monographs, 126, 241-260.

Testa, M.R. (2002). Leadership dyads in the cruise industry: The impact of cultural congruency. International Journal of Hospitality Management, 21, 425-441.

Tett, R.P., \& Meyer, J.P. (1993). Job satisfaction, organizational commitment, turnover intention, and turnover: Path analyses based on meta-analytic findings. Personnel Psychology, 46(2), 259-293.

Tumulty, G., Jernigan, E., \& Cohut, G. (1994). The impact of perceived work environment on job satisfaction on hospital staff nurses. Applied Nursing Research, 7(2), 84-90.

Van Dyne, L., Vandewalle, D., Kostova, T., Latham, M.E., \& Cummings, L.L. (2000). Collectivism, propensity to trust and self-esteem as predictors of organizational 
citizenship in a non-work setting. Journal of Organizational Behavior, 21, 3-23.

Vandenberg, R.J. \& Nelson, J.B. (1999). Disaggregating the motives underlying turnover intentions: When do intentions predict turnover behavior? Human Relations, 52(10), 1313-1336.

Vangen, S., \& Huxham, C. (2003). Nurturing collaborative relations: Building trust in interorganizational collaboration. The Journal of Applied Behavioral Science, 39, $5-31$.

Vroom, V.M. (1964). Work and Motivation. New York: Wiley.

Waldman, J.D.; Kelly, F; Sanjear, A. \& Smith, H. (2004). The shocking cost of turnover in healthcare. Healthcare Management Review, 29(1), 2-7.

Waldman, J.D., \& Sanjear, A. (2004). Measuring retention rather than turnover. A different and complimentary HR calculus. HR Human Resource Planning, 27(3), 6-9.

Wanous, J.P., \& Hudy, M.J. (2001). Single-item reliability: A replication and extension. Organizational Research Methods, 4(4), 361-375.

Weber, L.R. \& Carter, A. (1998). On constructing trust: Temporality, self-disclosure, and perspective-taking. International Journal of Sociology and Social Policy, 18, 7-26.

Williams, L.J., \& Hazer, J.T. (1986). Antecedents and consequences of satisfaction and commitment in turnover models: A reanalysis using latent variable structural equation methods. Journal of Applied Psychology, 71(2), 219-231.

Yukl, G. (1998). Leadership in Organizations. ( $4^{\text {th }}$ ed.), Upper Saddle River: Prentice Hall.

Zand, D.E. (1972). Trust and managerial problem solving. Administrative Science Quarterly, 17, 229-239.

Zand, D.E. (1997). The Leadership Triad: Knowledge, Trust, and Power. New York: Oxford University. 


\begin{abstract}
APPENDIX A
TEXT OF THE COMMUNICATION SENT TO NURSES PARTICIPATING IN HOSPITAL 1 AND HOSPITAL 2

Dear Team Member,

In the next few days you will be invited to participate in a research study sponsored by the Department of Leadership, Foundations, and Human Resources Education at the University of Louisville and conducted by Joseph Petrosko, Ph.D. and David Gibson, a doctoral student.

This study is being conducted for the purpose of completing a doctoral dissertation. The study seeks to explore the effect of trust in leader on job satisfaction and intent to leave present job. Your participation would consist of completing the online questionnaire. It will take about 15 minutes to complete.

While leadership at Deaconess Hospital has granted permission to conduct this research, only aggregated results will be shared. No individual data will be shared. Please consider participating in the study and thank you in advance for your participation. Best regards,

David Gibson

Candidate for Doctorate

Department of Leadership, Foundations and Human Resource Education

University of Louisville
\end{abstract}


Dear team members,

As mentioned in a previous communication, you have been invited to participate in a research study sponsored by the Department of Leadership, Foundations, and Human Resources Education at the University of Louisville and conducted by Joseph Petrosko, Ph.D. and David Gibson, a doctoral student. This research will culminate in the completion of a doctoral dissertation.

The survey is six pages in length. The first two pages are instructional in nature, so read over the information prior to taking the survey. The last four pages contain questions or statements for you to respond to. It should take you less than 15 minutes to complete. To get to the survey, go to this link: http://www.surveymonkey.com/s/GPPWV8N Thank you for taking the time to complete the survey.

Sincerely,

David Gibson

Candidate for the Doctorate

Department of Leadership, Foundations, and Human Resources Education

University of Louisville 
Dear team members,

Last week you received a communication requesting your participation in a survey. If you have filled out the survey, thank you. If you have not, please consider participating in this study. Again this is a research study sponsored by the Department of Leadership, Foundations, and Human Resources Education at the University of Louisville and conducted by Joseph Petrosko, Ph.D. and David Gibson, a doctoral student. This research will culminate in the completion of a doctoral dissertation.

The survey is six pages in length. The first two pages are instructional in nature, so read over the information prior to taking the survey. The last four pages contain questions or statements for you to respond to. It should take you less than 15 minutes to complete. To get to the survey, go to this link: http://www.surveymonkey.com/s/GPPWV8N Thank you for taking the time to complete the survey.

Sincerely,

David Gibson

Candidate for the Doctorate

Department of Leadership, Foundations, and Human Resources Education

University of Louisville-

David Gibson 
Dear team members,

Thank you to all those that completed the survey that came out a couple of weeks ago. You are helping a graduate student complete his Ph.D., and I am grateful to you. To those that have not filled out the survey, I will keep the link open for another week or so. I would be extremely grateful to anyone else who would be willing to complete the survey. Again this is a research study sponsored by the Department of Leadership, Foundations, and Human Resources Education at the University of Louisville and conducted by Joseph Petrosko, Ph.D. and David Gibson, a doctoral student.

The survey is six pages in length. The first two pages are instructional in nature, so read over the information prior to taking the survey. The last four pages contain questions or statements for you to respond to. It should take you less than 15 minutes to complete. To get to the survey, go to this link: http://www.surveymonkey.com/s/GPPWV8N Again thank you!

David Gibson

Candidate for the Doctorate

Department of Leadership, Foundations, and Human Resources

University of Louisville 


\section{APPENDIX B \\ EMAIL TEXT FROM PARTICIPATING HOSPITALS GRANTING PERMISSION TO CONDUCT RESEARCH}

This is to confirm that Clark Memorial Hospital is willing to be a site for the research that will be conducted to examine trust in leader on job satisfaction and intent to leave. This research will examine the perception of trust that nurses have in their nurse manager and test its effect on nurse job satisfaction and intent to leave in the next 2 years. This research will be done via a survey to the staff nurses with email addresses at Clark Memorial Hospital and permission has been granted. I would like to have next week to work with you to load the emails and the actual contact could begin being made to the staff April 5, 2010, If this timeframe is not acceptable to meet your deadline; please let me know.

Kathy Neuner, RN MSN

Clark Memorial Hospital

VP, Inpatient Clinical Services

812-283-2061 Work

This is to confirm that Deaconess Hospital is willing to be a site for the research that will be conducted to examine trust in leader on job satisfaction and intent to leave. This research will examine the perception of trust that nurses have in their nurse manager and test its effect on nurse job satisfaction and intent to leave in the next 2 years. This research will be done via a survey to the staff nurses with email addresses at Deaconess and permission has been granted. Actual contact could begin being made to the staff October 5, 2010.

Cherona Hajewski MSN, RN, NEA-BC

Vice President of Patient Care Services

Chief Nursing Officer

Deaconess Hospital600 Mary St.

Evansville, IN 47747

Contact person is:

Linda Cason MSN, RN-BC, NE-BC, CNRN

Manager

Employee Education and Development

Deaconess Hospital600 Mary St.

Evansville, IN 47747812-450-2079 


\section{APPENDIX C \\ EMAIL TEXT FROM DR. ROGER MAYER GRANTING PERMISSION TO USE TRUST SCALE IN THIS RESEARCH}

Hello David,

Thanks for your email. It's always nice to year from young scholars who are interested in studying trust. The measures of ability, benevolence, integrity, propensity, and trust were published in JAP 1999 Mayer \& Davis. I see that you are not using a .edu email account, so I don't know how fast your download speed is. If it's fast, I can send you what you need. The measures are all published, so you can use them provided you appropriately cite the sources. Mark Gavin (new assoc editor of Org Research Methods) and I have a study coming out in AMJ next month that has a longer measure of trust w/ higher alpha reliability. I can send you that as well. I would be happy to send you a couple of others that you may or may not have if you are interested, I think that you would find them interesting for your purposes. One just came out this month in JOB, it looks at reciprocal trust between management and developer teams. Another finds an empirical relationship between trust in management and financial performance of an organization--the only such published study in the literature to my knowledge. Work like this is helpful as a lead-in so that readers can see that what you are studying matters.

Let me know if your connection speed is reasonable, I'll be happy to send these to you to save you some digging. The measures are in the papers. Let me know if you still need a letter from me, I know how tight some organizations get even when you are doing things by the book.

I look forward to hearing from you,

Roger 
APPENDIX D

\section{The Effect of Trust in Leader on Job Satisfaction and Intent to Leave}

\section{Preamble}

The Effect of Trust in Leader on Job Satisfaction and Intent to Leave Present Job in the Context of the Nursing Profession

October 5, 2010

Dear Team Member:

You are being invited to participate in a research study about the relationship between trust in leader and job satisfaction on intent to leave present job. There are no known risks for your participation in this research study. The information collected may not benefit you directly. The information learned in this study may be helpful to others. The information you provide will be analyzed for the completion of the doctoral dissertation of William David Gibson. Your completed survey data will be stored at the office of the Department of Educational Leadership, Foundations, and Human Resource Education. The survey will take approximately 15 minutes to complete.

Individuals from the Department of Educational Leadership, Foundations, and Human Resource Education, the Institutional Review Board (IRB), the Human Subjects Protection Program Office (HSPPO), and other regulatory agencies may inspect these records. In all other respects, however, the data will be held in confidence to the extent permitted by law. Should the data be published, your identity will not be disclosed

Taking part in this study is voluntary. By completing this survey you agree to take part in this research study. You do not have to answer any questions that make you uncomfortable. You may choose not to take part at all. If you decide to be in this study you may stop taking part at any time. If you decide not to be in this study or if you stop taking part at any time, you will not lose any benefits for which you may qualify.

If you have any questions, concerns, or complaints about the research study, please contact: Joseph Petrosko, PhD (502) 852-0638 or William David Gibson (954) 609-4844.

If you have any questions about your rights as a research subject, you may call the Human Subjects Protection Program Office at (502) 852-5188. You can discuss any questions about your rights as a research subject, in private, with a member of the Institutional Review Board (IRB). You may also call this number if you have other questions about the research, and you cannot reach the research staff, or want to talk to someone else. The IRB is an independent committee made up of people from the University community, staff of the institutions, as well as people from the community not connected with these institutions. The IRB has reviewed this research study.

If you have concerns or complaints about the research or research staff and you do not wish to give your name, you may call 1-877-852-1167. This is a 24 hour hot line answered by people who do not work at the University of Louisville.

Sincerely,

Joseph M. Petrosko, PhD

William David Gibson 


\title{
The Effect of Trust in Leader on Job Satisfaction and Intent to Leave
}

\author{
Employee Attitude Survey
}

Overview.

Purpose of the Study: The purpose of this survey is to explore the relationships between perceptions of trust in leader, job satisfaction, and intent to leave present job. Your assistance in this project is kindly requested. Your participation is strictly voluntary and all individual responses will be kept completely confidential. Only aggregated data will be shared with your organization. In no way will the aggregated data identify you. Completion of this survey should take approximately 15 minutes.

Instructions: Please complete each section of the survey, following the instructions in each section. Upon completion hit the "Next" button at the bottom of the screen. When you have completed the entire survey remember to hit the "Done" icon on the last page. Thank you in advance for your participation. 


\section{The Effect of Trust in Leader on Job Satisfaction and Intent to Leave}

\section{Section I: Ceneral Information}

Instructions: Please place a check in the box that best corresponds to you for each statement.

1. Your age

Under 21

(50-59

21-29

(60-69

30-39

O 70 or over

(0-49

\section{Your gender}

Female

Male

\section{Your race/ethnic background}
American Indian or Alaskan Native
African American
$\bigcirc$ Asian American
Hispanic

Native Hawaiian or other Pacific Islander

Caucasian

\section{Your highest level of education}
Associate's degree
Master's degree
Bachelor's degree
Other (please specify)

5. How long have you been with your current organization?
Less than one year
10-15 years
1-3 years
15-20 years
3.5 years
More than 20 years
5-10 years 


\section{The Effect of Trust in Leader on Job Satisfaction and Intent to Leave}

6. How long have you been in your current position?
Less than one year
10-15 years
1.3 years
15-20 years
3-5 years
More than 20 years
5-10 years

7. During which decade did you complete your nursing degree?
○2001.2010
(1971-1980
$\bigcirc+991-2000$
Prior to 1971
O $1981-1990$

8. How long have you worked for your current nurse manager?
Less than one year
10-15 years
1.3 years
15-20 years
3.5 years
More than 20 years
5-10 years

9. Which hosptial do you work with primarily?
Deaconess Main Campus
Deaconess Gateway Campus
Other

Other (please specify) 


\section{The Effect of Trust in Leader on Job Satisfaction and Intent to Leave}

\section{Section Il: Job Attitudes}

Instructions: Think of your job in general. All in all, what is it like most of the time? Check the best answer.

1 for "Yes" if it describes your job

2 for "No" if it does not describe it

3 for "?" if you cannot decide

1. Thinking of your job in general, what is it like most of the time.

Pleasant
Bad
Waste of time
Good
Undesirable
Worthwhile
Worse than most
Acceptable
Superior
Better than most
Disagreeable
Makes me content
Inadequate
Excellent
Rotten
Enjoyable
Poor




\section{The Effect of Trust in Leader on Job Satisfaction and Intent to Leave}

\section{Section III: Opinions about Nurse Manager}

Instructions: Please provide the answer that best describes the way you feel about each statement.

1. If I had my way, I wouldn't let my nurse manager have any influence over issues that are important to me.

Strongly Agree

Agree

Neither Agree nor Disagree

Disagree

Strongly Disagree

2. I would be willing to let my nurse manager to have complete control over my future in this organization.

Strongly Agree

Agree

Neither Agree nor Disagree

Disagree

Strongly Disagree

3. I really wish I had a good way to keep an eye on my nurse manager.

Strongly Agree

Agree

Neither Agree nor Disagree

Disagree

Strongly Disagree 


\section{The Effect of Trust in Leader on Job Satisfaction and Intent to Leave}

4. I would be comfortable giving my nurse manager a task or problem which was critical to me, even if I could not monitor his/her actions.
Strongly Agree
Agree
Neither Agree nor Disagree
Disagree
Strongly Disagree

5. I would tell my nurse manager about mistakes I've made on the job, even if they could damage my reputation.
strongly Agree
Agree
Neither Agree nor Disagree
Disagree
Strongly Disagree

6. I would share my opinion about sensitive issues with my nurse manager even if my opinion were unpopular.
strongly Agree
Agree
Neither Agree nor Disagree
Disagree
Strongly Disagree

7. I am afraid of what my nurse manager might do to me at work.
Strongly Agree
Agree
Neither Agree nor Disagree
Disagree
Strongly Disagree 


\section{The Effect of Trust in Leader on Job Satisfaction and Intent to Leave}

8. If my nurse manager asked why a problem happened, I would speak freely even if I were partly to blame.

Strongly Agree

Agree

Neither Agree nor Disagree

Disagree

Strongly Disagree

9. If someone questioned my nurse manager's motives, I would give the nurse manager the benefit of the doubt.
Strongly Agree
Agree
Neither Agree nor Disagree
Disagree
Strongly Disagree

10. If my nurse manager asked me for something, I respond without thinking about whether it might be held against me.
Strongly Agree
Agree
Neither Agree nor Disagree
$\bigcirc$ Disagree
strongly Disagree 


\section{The Effect of Trust in Leader on Job Satisfaction and Intent to Leave}

\section{Section IV: Future Intentions}

Instructions: Please provide the answer that best describes the way you feel about each statement.

1. It is likely that I will actively look for a new job next year.
Strongly Agree
Agree
Neither Agree nor Disagree
Disagree
strongly Disagree

2. I often think about quitting.
Strongly Agree
Agree
Neither Agree nor Disagree
Disagree
strongly Disagree

3. I will probably look for a new job next year.
Strongly Agree
Agree
Neither Agree nor Disagree
Disagree
Strongly Disagree 


\section{CURRICULUM VITAE}

David Gibson Ph.D.

\section{DISSERTATION RESEARCH}

The Effect of Trust in Leader on Job Satisfaction and Intent to Leave Present Job in the Context of the Nursing Profession

\section{TEACHING EXPERIENCE}

Edgewood College, Madison, WI

2008-present

Instructor, Communication

- Facilitate learning process for courses such as, Introduction to Interpersonal Communication, Relational Communication, Public Speaking and Group Discussion and Team Leadership.

Marquette University, Milwaukee, WI

$\underline{2008-2010}$

Adjunct Instructor, Communication

- Facilitated learning process for courses such as, Leadership and Communication, Introduction to Communication, Gender and Communication and Small Group Communication.

Georgetown College, Georgetown, KY

$\underline{2000-2001}$

Instructor, Communication

- Facilitated learning process for courses such as, Group Dynamics, Business and Professional Communication, Training and Development, Public Speaking and Intercultural Communication.

- Achieved outstanding student satisfaction scores in Department of Communication. 
University of Tennessee, Knoxville, TN

$\underline{1999-2000}$

Graduate Teaching Assistant, Communication

- Facilitated learning process for the courses of Public Speaking and Business and Professional Speaking.

- Achieved outstanding student satisfaction scores in all courses taught.

Western Kentucky University, Bowling Green, KY 1997-1999

Graduate Teaching Assistant, Communication

- Facilitated the learning process for courses in Public Speaking and Business and Professional Communication.

- Achieved outstanding student satisfaction scores in all courses taught.

\section{CORPORATE ACCOMPLISHMENTS}

- Enhanced leadership acumen of V.P. and Director level executives as Executive Coach for companies; such as Royal Caribbean, ClubMed and Hellman Logistics.

- Reduced turnover from $23 \%$ to $12 \%$ and achieved beyond $90^{\text {th }}$ percentile in client satisfaction scoring through establishment and implementation of overall leadership and organizational development.

- Partnered with competing hospitals in the securing of $\$ 3.5$ million H1-B Technical Skills Grant, allowing for the hiring and training of over 100 needed nursing and allied health employees.

- Increased participation in leadership development programs by $400 \%$ by creating and delivering interactive, thought-provoking and fun training as well as changing name of programs to enhance perceived status.

\section{CORPORATE EXPERIENCE}

Right Management Consultants, Fort Lauderdale, FL

$\underline{2005-2008}$

Organizational Consultant

- Successfully provided executive coaching to a variety of leaders in several companies, including Royal Caribbean, ClubMed, Hellman Logistics, and Bayview Financial.

- Guided Director of Database Administration towards greater emotional intelligence enhanced political acumen, and more reliance on delegation of duties resulting in his promotion to VP.

- Coached Captain of cruise ship through issues revolved around guest interactions, decision making, and building relationships with team. Captain's ship went from \#9 
rated to \#2 rated ship in fleet in overall guest experience by the end of the coaching campaign.

- Coached VP, IT Operations through the development of strategic goals, the communication of those goals, and the techniques to monitor and achieve accountability of those goals.

- Achieved $99 \%$ landing rate in career transition arm of the organization by guiding displaced executives and professionals to better market skills and abilities to "wouldbe" employers.

- Conducted leadership development seminars in a variety of subjects including change management, interpersonal communication, and performance coaching for companies like Burger King and Cross Country Healthcare.

Jewish Hospital Healthcare Services, Louisville, KY

$\underline{2001-2004}$

\section{Manager, Training \& Organizational Development}

- Transformed culture of department from one of training to one of organizational development.

- Increased participation in leadership development programs by $400 \%$ by creating and delivering interactive, thought-provoking and fun training as well as changing name of programs to enhance perceived status.

- Efforts in organizational development practice helped account for decrease in turnover from $23 \%$ to $12 \%$.

- Assisted in leading and developing customer service program (based around RitzCarlton's Malcolm Baldridge Award winning program) that restored patient satisfaction scores beyond the $90^{\text {th }}$ percentile.

- Guided several departments to better define, declare, and demonstrate purpose and values as well as instill culture of accountability.

- Led efforts in the acquisition of two grants that amounted in \$3 million and \$75 thousand respectively to fund educational expenses of clinical staff among four participating hospitals and built a leadership development program that would be shared by 15 hospitals in Greater Louisville area.

\section{EDUCATION}

Ph.D. in Educational Leadership and Organizational Development - University of Louisville

Dissertation topic: The Effect of Trust in Leader on Job Satisfaction and Intent to Leave

M.A. in Organizational Communication - Western Kentucky University

B.A. in Political Science and Communication - University of Louisville 